\title{
INCLUSION OF STUDENTS WITH SPECIAL NEEDS IN PRIVATE SCHOOLS IN KUWAIT: CHALLENGES THAT FACE SCHOOL ADMINISTRATORS
}

\author{
A Dissertation \\ by \\ ALI M. A. M. A. A. ALANSARI \\ Submitted to the Office of Graduate and Professional Studies of \\ Texas A\&M University \\ in partial fulfillment of the requirements for the degree of \\ DOCTOR OF PHILOSOPHY
}

$\begin{array}{ll}\begin{array}{ll}\text { Chair of Committee, } \\ \text { Committee Members, }\end{array} & \begin{array}{l}\text { Beverly J. Irby } \\ \text { Gwendolyn Webb-Hasan } \\ \text { Shanna Hagan-Burke }\end{array} \\ & \begin{array}{l}\text { Lisa J. Bowman-Perrott } \\ \text { Mario Torres }\end{array}\end{array}$

August 2017

Major Subject: Educational Administration

Copyright 2017 Ali Alansari 


\begin{abstract}
The inclusion approach is one of the most effective ways of integrating students with special needs into society. According to Kuwaiti regulations, both public and private schools must increase quality services to assist students with special needs in inclusive classrooms. Although the inclusion approach is mandatory in Kuwait, schools have encountered barriers to its implementation. Therefore, there were three key goals to this research: (a) to identify challenges of the implementation of inclusion approaches that face private primary school administrators in Kuwait, (b) to identify how inclusion practices are implemented by administrators, teachers, and counselors in private Kuwaiti primary schools, and (c) to identify the differences in the implementation practices of inclusion between two private primary schools in Kuwait.
\end{abstract}

The findings revealed that the two schools faced six similar challenges, and three that differed. The obstacles the two schools had in common included: (1) parental issues, (2) academic barriers, (3) a lack of specialist teachers, (4) gaps in communication, (5) modification and accommodation matters, and (6) financial issues. The three that differed for the first school were: (1) low expectations, (2) the large number of students with LD, and (3) policy issues, while for the second school they were: (1) time management, (2) disciplinary issues, (3) systemic problems. Six key methods for implementing the inclusion approach were revealed. Four were common to both schools and two were different. The four in common were: (1) learning styles, (2) collaboration, (3) communication, and (4) preparation. The two seen solely in the first school were: (1) 
cooperative learning among students, and (2) discipline management, and in the second school they were (1) teaching LD students in small groups, and (2) anti-bullying sessions. Based on the findings of this research, future work should examine the challenges faced by school administrators attempting to implement the inclusion process, especially at the high school and university levels. 


\section{DEDICATION}

I would like to dedicate my dissertation to my dad and my mom whom I love dearly. I appreciate all your hard work and love; you've always believed in me and wished to be a better person and a better tutor. Words can never tell how grateful I am. Words cannot even begin to express how much you mean to me. Thank you for the patience while I pursue my dream.

Here I am finishing my PhD and feel unhappy for not being beside my mom struggling disease at home, wish I were there for you. My life would never be better when I listen to your voice praying and wishing the best for me. I am grateful to God for giving me such a great mom, and the unconditional love and support. I hope you will always be there to witness my accomplishments. I love you more than life itself and I love you to infinity and beyond.

Nobody has been more important to me in the pursuit of this project than the members of my family. I would like to thank my parents, wife, kids, brothers and sisters; whose love and guidance are with me in whatever I pursue. They are the ultimate role models. Most importantly, I wish to thank my loving and wonderful children, who provided an unending inspiration. To my supportive wife; your encouragement when the times got rough, are much appreciated and noted. It was a great relief to know that you were willing to provide management of our household while I completed my work. 


\section{ACKNOWLEDGEMENTS}

I would like to acknowledge several individuals who sacrificed their time and offered their wisdom toward my successful completion of this dissertation. All of these individuals were eager to offer whatever was needed to have this work accomplished.

This work would not have been possible without the support of my committee chair, Beverly J. Irby, who provided me with extensive personal and professional guidance and taught me a great deal about both scientific research and life in general. When I had a question, she responded immediately. Dr. Irby provided me significant suggestions on my exams and papers. Thank you, Dr. Irby, for believing in me and being such a wonderful person.

I would also like to extend my appreciation to my committee members, Gwendolyn Webb-Hasan, Shanna Hagan-Burke, and Lisa J. Bowman-Perrott, for consistently providing advice and input whenever needed. I would like to thank Dr. Webb-Hasan for providing significant information on equity and diversity. Also, she encouraged me to understand the importance of the family environment in the teaching process. Thank you so much, Dr. Webb-Hasan, for your patience while teaching us last summer. We learned a lot from you. Furthermore, thanks to Dr. Hagan-Burke, who helped me finish my systematic literature review accurately, and also helped me find the topic of my dissertation. Also, thanks to Dr. Bowman-Perrot, who provided several ideas to enhance my paper. One of the most important ideas focused on bilingual learners in Kuwait. This idea led me to focus on the bilingual private schools that implement the 
inclusion approach in Kuwait. Dr. Bowman-Perrot took from her family time to teach me in the summer class, which I will not forget.

Thanks also to Ms. Joyce Nelson, who assisted me from the beginning until the end of the academic journey. Ms. Nelson provided significant suggestions and advice to help me with my classes. I appreciate her help and support. To my colleagues, I will never find another great team like you. You never hesitated to help and encourage me to continue, especially Ms. Chelsi Pitts, who supported me during my academic journey. My special thanks to two private schools (counselors, principals, and teachers) in Kuwait who were helpful and gave me the chance to apply the study among members. Thank you for being patient and for the time given by teachers throughout the online meetings. All my gratitude to my friend Dr. Harold Manzano for all the help and advice to my children to overcome some obstacles. I cannot express enough thanks through the phase of face validity to Dr. Ahmad Alhilal and Dr. Ali Alkandary at Kuwait University for the continued support and encouragement. I also offer my sincere appreciation to $\mathrm{Mr}$. Abdul Malek Al-Ammar, Ms. Eman Al-Qabandi, and Ms. Bedour Almeshaileh for the feedback and effort exerted to support my research. Thanks also to Dr. Alaa Elwany at Texas A\&M University for the help and support. 


\section{CONTRIBUTORS AND FUNDING SOURCES}

\section{Contributors}

This work was supervised by a dissertation committee consisting of Professor Beverly J. Irby (advisor) and three committee members: Professor Gwendolyn WebbHasan of the Department of Education Administration and Professors Shanna HaganBurke and Lisa J. Bowman-Perrott of the Special Education Program.

All other work conducted for the dissertation was completed independently by the student.

\section{Funding Sources}

There are no outside funding contributions to acknowledge related to the research and compilation of this document.

vii 


\section{NOMENCLATURE}

$\begin{array}{ll}\text { DS } & \text { Down Syndrome } \\ \text { ELL } & \text { English Language Learners } \\ \text { IDEA } & \text { Individual with Disabilities Education Act } \\ \text { IEP } & \text { Individualized Education Plans } \\ \text { LD } & \text { Learning Disabilities } \\ \text { LRE } & \text { Least Restrictive Environment } \\ \text { PBS } & \text { Positive Behavior Support } \\ \text { RTI } & \text { Response to Intervention } \\ \text { SL } & \text { Slower Learner }\end{array}$

viii 


\section{TABLE OF CONTENTS}

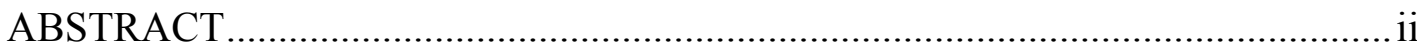

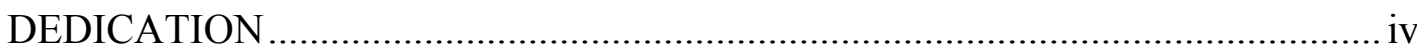

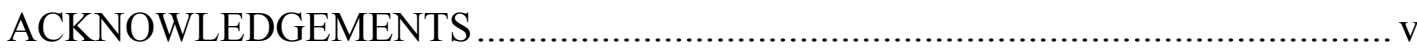

CONTRIBUTORS AND FUNDING SOURCES ............................................. vii

NOMENCLATURE ........................................................................... viii

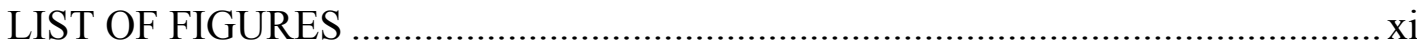

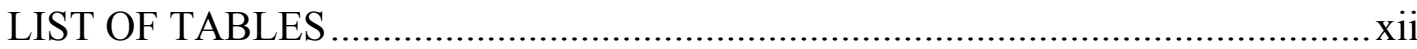

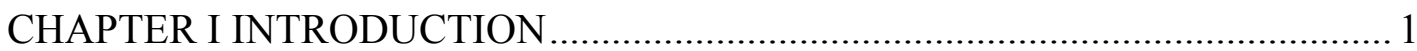

Problem Statement ................................................................................... 3

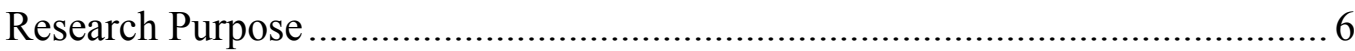

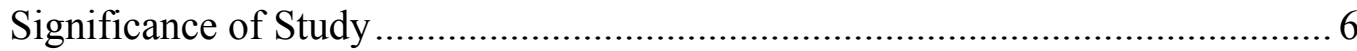

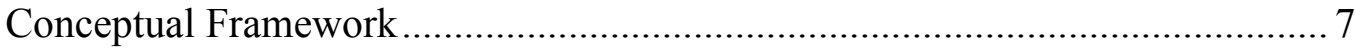

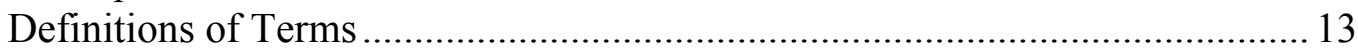

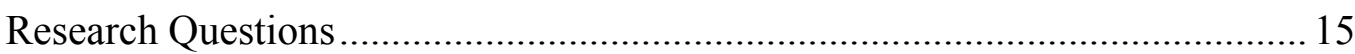

Limitations, Delimitations, and Assumptions........................................... 15

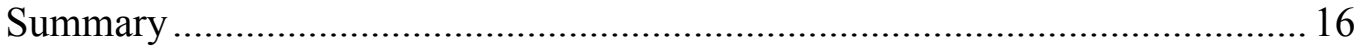

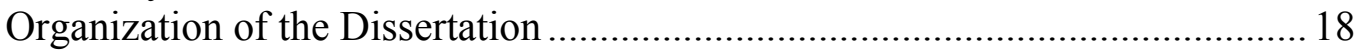

CHAPTER II SYSTEMATIC REVIEW OF THE LITERATURE ....................... 19

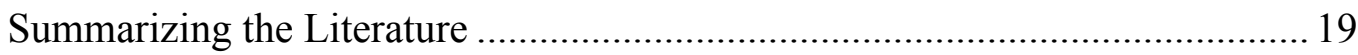

Research Purpose and Questions ............................................................. 24

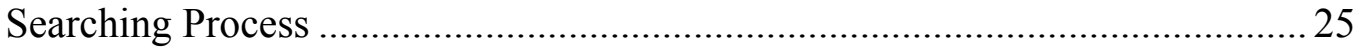

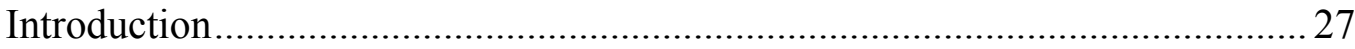

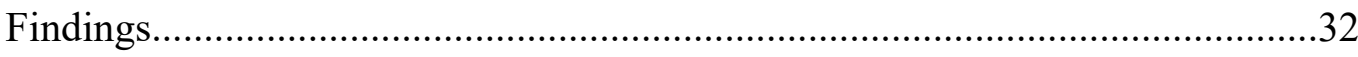

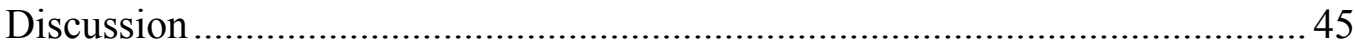

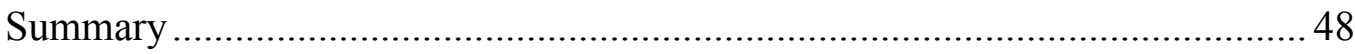

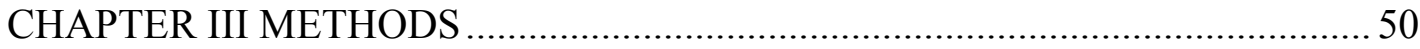

Purpose of the Study and Research Questions.............................................. 50

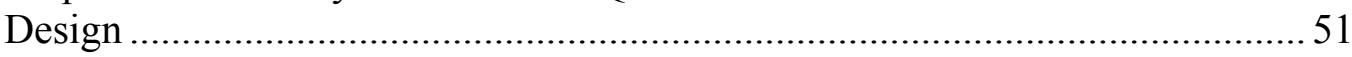

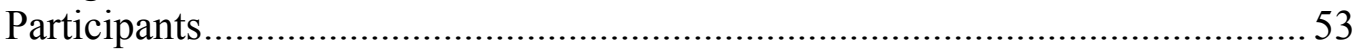




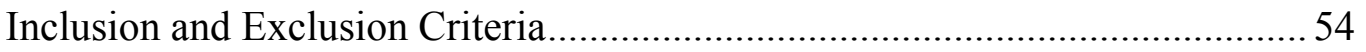

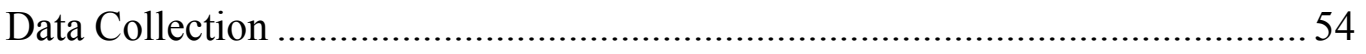

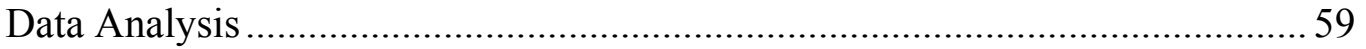

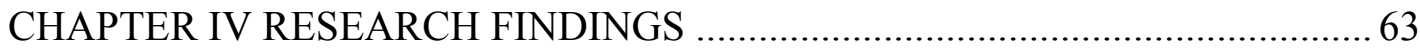

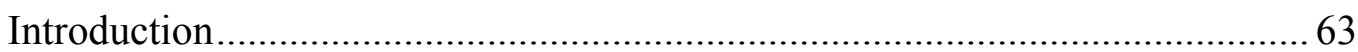

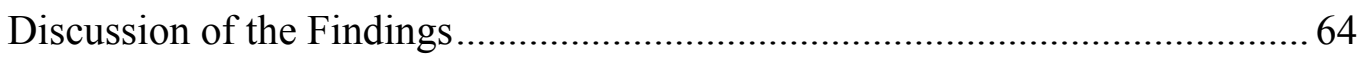

Summary of the Chapter ........................................................................... 110

CHAPTER V SUMMARY, IMPLICATIONS, AND RECOMMENDATIONS .. 111

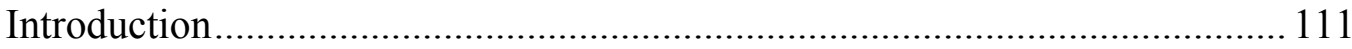

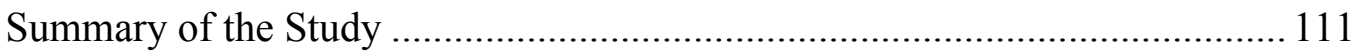

Summary of Findings.............................................................................. 114

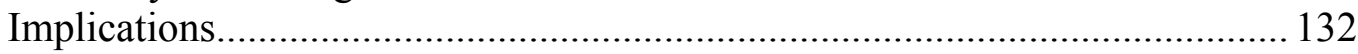

Recommendations for Future Research ................................................ 134

Recommendation for Practices ................................................................... 137

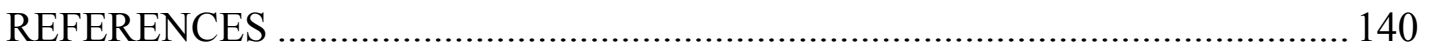

APPENDIX A SURVEY PROTOCOL ........................................................ 159

APPENDIX B THE INFORMATION SHEET ................................................ 163 


\section{LIST OF FIGURES}

Page

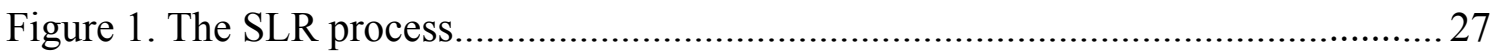

Figure 2. The percentage of the articles that were focused on challenges and practices......

Figure 3. The number of the articles that were based on quantitative, qualitative, and mixed methods.

Figure 4. Mind mapping.

Figure 5. Differences in the challenges faced by two private schools implementing inclusion.

Figure 6. Differences in inclusion implementation in both private schools. .105 


\section{LIST OF TABLES}

Page

Table 1. Studies in Kuwait Focus on the Inclusion Approach.........................................5

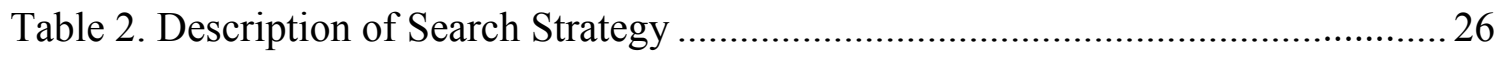

Table 3. Inclusion and Exclusion Criteria..................................................................... 26

Table 4. Challenges to Implementing Inclusion Common to the Administrators of Both Private Schools ............................................................................. 72

Table 5. Inclusion Practices Similar to Both Schools....................................................101 


\section{CHAPTER I}

\section{INTRODUCTION}

The inclusion approach is likely one of the most effective ways to immerse students with special needs into society (Stainback \& Stainback, 1984; Weber \& City, 2012; Wong, Poon, Kaur, \& Ng, 2015). However, this is only possible if schools are prepared to receive students with disabilities and prepare them for the future without any hesitation (Kauffman, Lloyd, Baker, \& Riedel, 1995). Moreover, the inclusion encourages teachers, leaders, and parents to look at students with disabilities from different perspectives. For example, teachers, leaders and parents should teach and treat all students equally, and recognize their significant abilities and untapped potential to achieve academic success (Stainback \& Stainback, 1984; Weber \& City, 2012). Indeed, the inclusion approach has been shown to be more effective on a global scale when compared with other special education approaches, such as providing special education services to students in separate self-contained classrooms (Tremblay, 2013). "The full inclusion stance calls for all students to receive their entire education alongside their general education peers, with their individualized education plans (IEPs) implemented in general education classrooms" (Hagan-Burke \& Jefferson, 2002, p. 113).

Stainback and Stainback (1984) were among the first to propose an approach that would allow students with special needs to be educated and treated as general education students. This approach supports teachers, administrators, and parents to engage students with special needs in general education with effective education and services (Kelly, 
Devitt, O'Keeffe, \& Donovan, 2014; Wong et al., 2015). The application of this approach, called inclusion, has a consistent track record of success in general education environment schools through helping and supporting students with special needs in United States (Fuchs \& Fuchs, 1994; Ringer \& Kerr, 1988; Weber \& City, 2012; Zigmond, Kloo, \& Volonino, 2009). Indeed, scholars asserted that students with special needs should participate in general education environments in schools alongside nondisabled students to better prepare themselves for their futures (Erwin, 1993; Stainback \& Stainback, 1984; Zigmond et al., 2009). However, opponents of inclusion asserted "regular education could not address the needs of many students with mild dis- abilities without the instruction, support, and accommodations provided through special education" (Hagan-Burke \& Jefferson, 2002, p. 113).

The inclusion approach has faced several challenges from 1984 to present. For example, Zigmond et al. (2009) noted the lack of curriculum, tools, educational environments and teachers with relevant specialties as serious challenges. Will (1986) mentioned, "Inclusion is to provide the best, most effective general education for all children. Unfortunately, the public-school system was not providing the best, most effective education possible for children with disabilities" (p. 411). Accordingly, it is critical to underline the challenges and make urgent strides for reform, so that educators, administrators, and parents are equipped, outfitted and prepared to give students with special needs their rights to be educated in general education (Zigmond et al., 2009).

It is understandable that the inclusion approach faces challenges in its implementation as experiences have been successful and others have impacted students' 
achievements negatively due to inadequate training for teachers' and unsuitable resources (Kauffman et al., 1995). On the international level, Ireland has faced significant challenges in the implementation of the inclusion approach due to poor training for teachers and administrators in the application of the inclusion which impacts students with disabilities ineffectively (O'Gorman \& Drudy, 2010).

Consequently, it is imperative to know more about inclusion to assist students with disabilities effectively (Kauffman et al., 1995). In addition, "the true essence of inclusion is based on the premise that all individuals with disabilities have a right to be included in naturally occurring settings and activities with their neighborhood peers, siblings, and friends" (Erwin, 1993, p. 1). However, this approach needs some good conditions that reflect the general schools' environment, resources, and readiness for implementation (Erwin, 1993; Kauffman et al., 1995; O'Gorman \& Drudy, 2010). The application of inclusive education practices presents an opportunity to treat and teach students with special needs without undue segregation. However, this goal may be less effective for students' academic achievement and wellbeing unless suitable responses to the aforementioned challenges to inclusion are identified and implemented (Kauffman et al., 1995).

\section{Problem Statement}

In 2010, Kuwaiti governors established a new regulation that considered inclusive education opportunities as one of the most indispensable rights of students with special needs to ensure students are treated fairly and equally with distributive justice in services and needs (Alfares, 2014; Almotairi, 2013). According to the Kuwaiti 
regulation, both general schools and private schools must increase the quality of special education services to help and support students with special needs successfully navigate their academic journeys (Almoosa, Storey, \& Keller, 2012; Weber \& City, 2012). Although, the inclusion education approaches are mandatory in Kuwaiti schools, Weber and City (2012) noted that schools have encountered serious challenges that pose significant barriers to its implementation in Kuwaiti schools. Furthermore, Kuwaiti schools are not prepared to receive and educate students with special needs (Almoosa et al., 2012; Weber \& City, 2012). Since 2010, only two groups of students with special needs had been incorporated into general schools (those with down syndrome and those regarded as slow learners); however, they were segregated in separate classrooms (Weber \& City, 2012). Although some Kuwaiti schools have adopted inclusion approaches for students with special needs, their progress in fully implementing the inclusion approach has been minimal (Almoosa et al., 2012). "Kuwait recently signed an agreement with United Nation Educational, Scientific and Cultural Organization (UNESCO), committing them to move towards more inclusive practices within their public-school system" (Almotairi, 2013, p. 261).

The agreement commanded Kuwait to promote students with special needs placement in inclusive schools. However, Kuwait has struggled to implement the inclusion approach because there is no clear vision for practicing the inclusion approach and there are insufficient resources and training available to prepare teachers and administrators for this mission (Al-Manabri, Al-Sharhan, Elbeheri, Jasem, \& Everatt, 2013). Nevertheless, there is a little research that could be used to assist Kuwaiti schools 
to overcome the challenges that have faced the inclusion approach. Kuwait is an old member state of Gulf Cooperation Council (GCC), which asserted that the inclusion approach is an obligation to all members of GCC United Arab Emirates, Oman, Qatar, Kuwait, Saudi Arabia and Bahrain), however, "Inclusive education in the countries of the remains at a developmental stage" (Crabtree \& Williams, 2013, p. 149), which needs more research on the inclusion approach to succeed. In fact, there have been only four studies that focused on the attitudes, perceptions, and opinions of the inclusion approach in the State of Kuwait, and there is no study that considered practices and challenges that face private schools of implementing the inclusion approach. I will provide a list of these studies that focused on the inclusion approach in Table 1.

Table 1

Studies in Kuwait Focus on the Inclusion Approach

\begin{tabular}{|c|c|c|}
\hline Authors & Sample & Focus \\
\hline $\begin{array}{l}\text { Al-Abdulghafoor } \\
\text { (1999) }\end{array}$ & $\begin{array}{l}\text { Mainstream education } \\
\text { administrators and } \\
\text { teachers in public } \\
\text { schools }\end{array}$ & $\begin{array}{l}\text { The opinions of integrating children with } \\
\text { SEN in mainstream primary schools. }\end{array}$ \\
\hline Aldaihani (2011) & $\begin{array}{l}\text { Teachers, students and } \\
\text { parents in public } \\
\text { schools }\end{array}$ & $\begin{array}{l}\text { Understanding the state of inclusive } \\
\text { education of students with mild intellectual } \\
\text { disabilities from the perspectives of } \\
\text { teachers, students, and parents }\end{array}$ \\
\hline $\begin{array}{l}\text { Al-Manabri et al. } \\
(2013)\end{array}$ & $\begin{array}{l}\text { Teachers for students } \\
\text { with learning } \\
\text { disabilities in public } \\
\text { schools }\end{array}$ & $\begin{array}{l}\text { Examining the impact of a project aimed at } \\
\text { improving Kuwaiti mainstream teachers' } \\
\text { attitudes, knowledge, and teaching } \\
\text { practices related to the inclusion approach }\end{array}$ \\
\hline Almotairi (2013) & $\begin{array}{l}\text { Teachers and head } \\
\text { teachers in mainstream } \\
\text { and special primary } \\
\text { schools in Kuwait } \\
\text { Teachers in public }\end{array}$ & $\begin{array}{l}\text { Examining attitudes of Kuwaiti primary } \\
\text { teachers and head teachers toward the } \\
\text { inclusion approach of children with } \\
\text { disabilities. }\end{array}$ \\
\hline
\end{tabular}


Unfortunately, there is little information on implementing the inclusion approach in private schools, which puts Kuwait in an embarrassing situation in the GCC. Weber and City (2012) asserted, "Some countries, such as Kuwait, have continued to develop and support their impressive infrastructure of segregated schools" (p. 88). Moreover, they argued that "the policy and legal framework for Kuwait's learning disabled education are adopted almost wholly from older U.S. and U.K. models of segregated education" (p. 90). For these reasons, I focused on the implementation of the inclusion approach in private schools, which may help my country to improve the implementation of inclusion in Kuwait and to have a better vision of inclusion in the future.

\section{Research Purpose}

The purpose of this study was threefold: (a) to identify challenges of the implementation of inclusion approaches that face private primary school administrators in Kuwait, (b) to identify how inclusion practices are implemented by administrators, teachers, and counselors in private Kuwaiti primary schools, and (c) to identify the differences in the implementation practices of inclusion between two private primary schools in Kuwait.

\section{Significance of Study}

There is a significant body of literature that has been published in the United States about the contributions of the inclusion approach to the quality of education of the students with special needs. Similarly, there are also studies that point out the challenges that schools face in the process of implementing the inclusion approach. However, little is known about the impact of the implementation of this theoretical framework in 
Kuwait. Therefore, I intended to investigate the conditions in which the application of this approach has been developed in Kuwait and particularly, provide insights into challenges that school face as well as successful practices in the establishment of the inclusion approach in this country. A better understanding of the conditions in which implementation has been developing will be helpful to administrators and teachers to establishing better strategies to include students with disabilities in their schools. I hope to give a valuable perspective on the challenges facing the implementation of the inclusion approach in Kuwaiti schools.

\section{Conceptual Framework}

According to the inclusion approach, which is defined as an approach that gives students with special needs their rights to be engaged and treated equally and fairly in the society (Wong et al., 2015). The principles that constitute this approach are similar to theorizing democratic and social justice education. For example, they are both required to provide suitable environments for all students. Students can exercise their rights to receive a quality education in general schools and participate in educational practices that emphasize mutual benefit (O'Gorman \& Drudy, 2010). However, inclusive schools in the States of Kuwait are not ready to receive students with special needs (Almoosa et al., 2012). In 2013, Almotairi asserted that there are several challenges in the implementation of the inclusion approach such as lack of knowledge, experience, and clear understanding of the inclusion approach; as well as an absence of quality training, and lack of resources. In addition to this, the combined benefits of the inclusion approach were not viewed as noteworthy to justify the risk of possibly harming the 
progress of children from regular classrooms. Therefore, it could be beneficial to follow theorizing democratic and social justice education to guide the surveyed and interviewed questions and analyze the results.

Administrators, teachers, and employees must implement the inclusion approach (Weber \& City, 2012), which I think could be initiated by creating an atmosphere of social justice in inclusive schools. Democracy plays an important role in social justice. It is not only a system of government that allows citizens to elect their representatives freely. "Democracy represents a way of organizing social life that is respectful, inclusive, and mutually beneficial one in which the principles to be developed clearly guide both beliefs and actions" (Shields, 2013, p. 1036). While a new regulation in Kuwait has required implementing the inclusion approach, which is one of the principles of democratic theory (Shields, 2013), this study will be guided by theorizing democratic theory and social justice education by looking at seven principles in the theorizing democratic and social justice education.

Nevertheless, I strongly believe that democratic and social justice education would be one of the best ways to enhance Kuwaiti schools because of the theorizing democratic and social justice education principles, which are (a) all persons in a given organization shall be treated respectfully; (b) the education institution will ensure equitable access for all; (c) the education institution will ensure equitable outcomes for all; (d) the practices of the organization should emphasize mutual benefit; (e) the norms and practices of the organization shall be equally inclusive of all members; (f) all members of a designated group (society, community, and school) shall have equal civil, 
political, and social rights as citizens; (g) competition for funds to ensure basic needs is undemocratic (Shields, 2013, p. 1037).

According to the inclusive approach, which provides students with special needs the right to be treated equitably in the school and to have every opportunity to be successful in their academic pursuits (Wong et al., 2015). The principles that constitute this approach are similar to theorizing democratic and social justice education, for example, both are required to provide suitable environments for all students, so students can exercise their rights to receive an equitable education in inclusive schools and participate in educational practices that emphasize mutual benefit (O'Gorman \& Drudy, 2010). However, inclusive schools in the States of Kuwait are not ready to receive students with special needs (Almoosa et al., 2012) because school have not yet met theorizing democratic and social justice education principles and many Kuwaiti schools have failed to ensure equitable access and outcomes for all (Alfares, 2014).

Meeting the educational needs of children and youth in the United States of America is required under the law (Yell, 2016) and this is true for Kuwait as well (Almotairi, 2013). From the civil rights movement and Brown v. Board of Education in 1954 until now, there are still students who have economic problem are struggled in American schools. Although, "the civil right that is protected under Constitution and enforced by legislation, have not always been provided to all citizens on equal educational basis" (Yell, 2016, p. 38).

Similarity, Kuwaiti' students with special needs are suffered from the inequitable treatment in school systems, which led Kuwaiti governors to establish a new regulation 
in 2010 that requires public and private schools to provide equitable opportunities to learn for students with disabilities (Alfares, 2014; Almotairi, 2013). Policy makers decided that creating an inclusive environment for everyone would be the best for students' achievements and interactions (Alfares, 2014), however, Weber and City (2012) noted that schools have faced serious challenges that hinder their goal. Critically, the principles of theorizing democratic and social justice education will be considered in in this study to more effectively comprehend the needs of students by following this theory.

\section{A Student Shall Be Treated Respectfully}

It is an essential point to be grasped; however, it is recommended for schools to utilize effective communication and to strive to maintain connections between family and schools' members (Freire, 2012; Nieto, 2015; Valencia, 2015). In American schools, a school leader should form a positive relationship between families and him/her by understanding families' activities, knowledge, conditions, language, religion, and background (Freire, 2012; Nieto, 2015; Valencia, 2015). In simplified terms, leaders need to be great listeners, and they need to put forth effort to visit with families at home (Freire, 2012). Creating a dynamic with the family members will allow for mutual trust between them and easier problem-solving. Most importantly, it will inspire school leaders to deliver opportunities for school' members and disadvantaged families to open a door for conversations about the problems and the best solution for them (Freire, 2012; Valencia, 2015). 
According to Kuwaiti school policy, leaders, and school officials must understand the culture and the nature of students with special needs to grasp their needs and enhance their academic levels in an inclusive setting (Weber \& City, 2012).

Typically, Arabs' children who have special needs or who are disadvantaged economically should be assessed and assisted in their schools (Crabtree \& Williams, 2013). Al-Shammari (2006) stated, "Understanding and building on a family's cultural interpretations of disability is essential in creating partnerships with parents of children receiving special education services" (p. 173).

\section{The Education Institution Will Ensure Equitable Access and Outcomes for All}

Unfortunately, American schools have faced challenges in closing the gap between students' achievement and this is evident in the failure to create an inclusive and productive environment for all to reach equity (Boykin \& Noguera, 2011). Determining the challenges that face American schools, as well as Kuwaiti schools and working together to create a clear path to be followed will create the opportunity to learn and close the gap between students' achievement (Almoosa et al., 2012). They asserted that research needed to be reflected in real schools' practices to be successful. Sadly, in American schools, the dropout rate, which is still high between students who have economic problem and students of color, is in need of serious action from practitioners, leaders, policy makers and schools' members to build capacity, plan purposefully and work persistently to reduce the dropout rate, and attain the "opportunity to learn" values and criteria. Gathering valuable data, raising knowledge concerning students' abilities and background, following ideas, and strategies will assist leaders in creating an 
inclusive environment for all (Boykin \& Noguera, 2011), which will be followed in this study. Certainly, the lack of effective practices is a problem that is spread throughout schools' actions.

Although teachers, principals, scholars, and policymakers solved many problems of the teaching practice, many issues should be considered and solved (Boykin \& Noguera, 2011). One of the main concerns is that the lack of teacher preparation in both USA schools (Bower-Phipps, Homa, Albaladejo, Johnson, \& Cruz, 2013) and Kuwaiti schools (AlMoussawi \& Omran, 2015). Indeed, the minister of higher education, Dr. Badr Alissa, pointed out that the majority of teachers' levels are feeble, and they need to attend a lot of training courses, and to read scientific material as well, as there was a national project of students' assessments that revealed the weakness of public school teachers and the relationship between the teacher preparation process and the educational achievement of students who have struggled in school. Moreover, it mentioned that teachers in Kuwait have a lack of professionalism in teaching, which requires reconsideration of the efficiency and quality of teacher preparation and programs, indicating that they cannot develop effective education practices without ensuring the quality of the preparation (AlMoussawi \& Omran, 2015). Unfortunately, many educators and leaders asserted that the weakness of the level of teachers threatens the future of Kuwait (AlMoussawi \& Omran, 2015).

In the United States, the rate of students of color and students with disabilities is elevated, which requires educators to understand the variety of students of color and their needs by creating an efficient teacher preparation program to close the gap (Bower- 
Phipps et al., 2013). Although students from varied backgrounds and unusual circumstances in the USA schools face challenges, teachers, leaders, and school workers cannot help them until they become cultured and qualified to serve them in an appropriate school setting (Bower-Phipps et al., 2013; Rodríguez, 2016). According to Boykin and Noguera (2011), it is necessary to "provide teachers with requisite skills to teach effectively, regardless of race and culture, a practice now widely recognized as essential" (p. 28).

\section{Definitions of Terms}

The Inclusion Approach: The Inclusion approach is an approach that allows students with disabilities the opportunity to have their needs met in general schools and to benefit from and build relationships with other students who may or may not be learning disabled. The inclusion approach encourages teachers to teach and educate both students with disabilities and non-disabled students in the same setting. All students with special needs shall be treated respectfully, equally, fairly in their schools (Stainback \& Stainback, 1984; Zigmond et al., 2009). According to Ministry of Education in the State of Kuwait (2008), there are just three categories are included in inclusive public schools in Kuwait which are Down Syndrome (DS), Slower Learner (SL), and Learning Disabilities (LD), however, they are excluded in separate classrooms, which does not reflect the inclusion approach intent. For this reason, students with learning disabilities will be considered in this study that are included in inclusive classrooms in private schools in Kuwait. 
Learning Disabilities (LD): “A child with a specific learning disability is one of average or above average intelligence who has specific difficulties, which can make learning very difficult. There may be deficits in any of the basic central nervous system functions, which have to do with the acquisition and use of listening, speaking, reading, writing, reasoning or mathematical abilities in attention, memory, language, auditory and visual perception, motor coordination and planning, spatial orientation, impulse control and sequencing. In short, if there is a discrepancy between the child's potential and actual achievement" (Makay, 2001, p. 2).

Accommodation: "Any technique that alters the academic setting or environment and enables students to show more accurately what they know" (Bryant, Dean, Elrod, \& Blackbourn, 1999, p. 1).

Modification: "Altering the work required in some way that makes it different from the work required of other students in the same class or activity" (Bryant et al. 1999, p. 1).

Down Syndrome (DS): "Down syndrome is a congenital disorder stemming from a chromosomal abnormality appearing in about one of every 800 births. This syndrome occurs when one chromosome has an extra "part," and an error occurs during cell division, or an extra chromosome exists, resulting in 47 chromosomes" (Spivey, 2006, p. 1).

Slower Learners (SL): “A slow learner is a child of below average intelligence, whose thinking skills have developed significantly more slowly than the norm for his/her age. This child will go through the same basic developmental stages as other children, 
but they will do so at a significantly slower rate. However, this development, while being slower, nevertheless it is relatively even" (Makay, 2001, p. 2).

Response to Intervention (RTI): The current model has become essential to identifying and assisting students with learning disabilities that struggle at school at an early stage (Ochoa, Brandon, Cadiero-Kaplan, \& Ramírez, 2014).

Least Restrictive Environment (LRE): LRE is key in protecting students with disabilities from segregation and discrimination under IDEA (Yell, 2016).

\section{Research Questions}

The following research questions guided this study:

1. What are the challenges of implementing inclusion approaches that face private primary school administrators in Kuwait?

2. In what ways are inclusion practices implemented by administrators, teachers, and counselors in private schools in Kuwait?

3. What are the differences in the implementation practices of inclusion between two private schools in Kuwait?

\section{Limitations, Delimitations, and Assumptions}

\section{Limitations}

One of the limitations of this study is that only administrators, teachers, and counselors who volunteer to be interviewed and surveyed will be included. Therefore, the study is limited by the number of administrators, teachers, and counselors who choose to participate in this study. Therefore, the results will be related to this particular population. Another limitation of this study is that Kuwaiti private schools have included 
students with learning disabilities. Therefore, this study will be focused on a main category of the special education field, which are learning disability.

\section{Delimitations}

A convenience sample of private schools in Kuwait was included. The second delimitation is that the study is restricted to administrators, teachers, and counselors in primary private inclusive schools who work in The State of Kuwait. The results of this study could be generalizable only to administrators, teachers, and counselors who (a) involve in inclusive primary private schools (b) in the States of Kuwait (c) have a student with learning disabilities.

\section{Assumptions}

Three assumptions of this study were: (a) I assume that the selected participants will be honest and forthcoming with their responses; (b) I will use appropriate tools to collect the data, and (c) The results will lead to further research on the inclusion approach in the State of Kuwait.

\section{Summary}

The Inclusion approach is likely one of the most effective ways to immerse students with special needs into society (Stainback \& Stainback, 1984; Weber \& City, 2012; Wong et al., 2015). However, this is only possible if schools are prepared to receive students with disabilities and prepare them for the future without any hesitation (Kauffman et al., 1995). According to the Kuwaiti regulation for 2010, both general schools and private schools must increase the quality of special education services to 
help and support students with special needs successfully navigate their academic journeys (Almoosa et al., 2012; Weber \& City, 2012).

Although, the inclusion education approaches are mandatory in Kuwaiti schools, Weber and City (2012) noted that schools have encountered serious challenges that pose significant barriers to its implementation in Kuwaiti schools. However, there is little information on implementing the inclusion approach in private schools, which puts Kuwait in an embarrassing situation in the GCC. Weber and City (2012) asserted, "Some countries, such as Kuwait, have continued to develop and support their impressive infrastructure of segregated schools" (p. 88). Also, little is known about the impact of the implementation of this theoretical framework in Kuwait. Therefore, I intended to investigate the conditions in which the application of this approach has been developed in Kuwait and particularly, provide insights into challenges that school face as well as successful practices in the establishment of the inclusion approach in this country.

A better understanding of the conditions in which implementation has been developing will be helpful to administrators and teachers to establishing better strategies to include students with disabilities in their schools. I hope to give a valuable perspective on the challenges facing the implementation of the inclusion approach in Kuwaiti schools. Therefore, this study has three research question to be answered in the end of this study, which are:

1. What are the challenges of implementing inclusion approaches that face private primary school administrators in Kuwait? 
2. In what ways are inclusion practices implemented by administrators, teachers, and counselors in private schools in Kuwait?

3. What are the differences in the implementation practices of inclusion between two private schools in Kuwait?

I followed theorizing democratic and social justice education to guide the surveyed and interviewed questions and analyze the results, which reflects the inclusion principles, which attempts to engage, treat, and teach the students with special needs fairly and respectfully in the society (Wong et al., 2015).

\section{Organization of the Dissertation}

This dissertation was comprised of five chapters. In Chapter I, I explained the purpose the problem, the significance of the study, the conceptual framework, and presented my research questions. In Chapter II, I presented my critique of the literature review on the inclusion of students with special needs in general schools: challenges and practices. In Chapter III, I included the details of my methodology, the participants, the instrumentation, the data collection, the data analysis, the reliability and validity. In Chapter IV, I comprised a discussion of the findings. In Chapter V, I included a summarization of the study, implications and recommendations for future research. 


\section{CHAPTER II}

\section{SYSTEMATIC REVIEW OF THE LITERATURE}

In this chapter, I summarized the literature on the inclusion of students with disabilities in regular education classrooms in the United States and internationally from the 1980s until now presenting the first part of this chapter. Next, I presented my critique of the literature review on the inclusion of students with special needs: challenges and practices. I adopted a systematic literature review methodology for this research because my goal was to gain a holistic and deep understanding of the literature on the topic of my interest as the second part of this chapter.

\section{Summarizing the Literature}

In this section, I presented major findings that summarize the literature on the inclusion of students with disabilities to determine challenges of implementing the inclusion approach, recommended practices and essential arguments on the inclusion approach for a deep understanding of the inclusion approach. In both the United States and international context, schools have seen challenges in the implementation of the inclusion in traditional settings, which impacts students' performance and well-being. Twenty-three of the literature reviews, which were presented from 1987 until 2016 are represented in this section.

\section{Social Skills and Academic Achievement}

Initially, many studies addressed the importance of finding the balance between the social and academic needs of students with disabilities. Sadly, many schools have 
focused on the achievement of students with disabilities and have ignored the social interactions, which is a fundamental part of the Individuals with Disabilities Education Act. The lack of social interaction has hindered the progress of students with disabilities. For this reason, many studies have encouraged schools to practice the social interaction in conjunction with academic activities in order to enhance students' social skills alongside their academic achievements (Bossaert, Colpin, Pijl, \& Petry, 2013; Coates \& Vickerman, 2008; Qi \& Ha, 2012; Reganick, 1995; Wang \& Reynolds, 1997).

Reganick (1995) declared that in the 1990s, many school districts across the United States could not reflect the tenets of least restrictive environment (LRE) accurately because it all of the resources were directed towards determining the students' weaknesses instead creating a positive atmosphere by focusing on students' strengths. Unfortunately, the development of social skills in these students was hindered by teachers, leaders, and policy makers when they isolated students with disabilities in a segregated setting (Reganick, 1995; Qi \& Ha, 2012; Wang \& Reynolds, 1997).

\section{Cooperation and Collaboration}

Although, complying with LRE mandate was a fundamental right for students with disabilities, specialist, and general teachers could not change students with disabilities' achievement due to the lack of cooperation and collaboration in inclusive schools. Consequently, diversified educational practices were recommended to design cooperative learning, technology, peer tutoring and multi-age classes in addition to having high expectations for students with disabilities (Reganick, 1995; Scott, Vitale, \& Masten, 1998). Neither access nor academic achievement are able to be obtained in a 
segregated special education; the inclusion approach could be the best solution to provide equal access for all students with disabilities and improve students' achievements, however, cooperative learning, an instruction strategy and a successful collaboration between administration, educators, and parents, are key factors to providing appropriate services to students with disabilities and enhance students' academic achievement (Alquraini \& Gut, 2012). The significance of collaboration among school members such as special teachers and general teachers, teachers and workers, and members of the school district with parents were recommended in American schools (Calculator \& Black, 2009; Qi \& Ha, 2012; Reyes, 2013; Salvador, 2013; Scott et al., 1998).

\section{Instructions, Class Management and Services for Students with Disabilities}

"Clearly, schools are not equipped to deal with the full range and impact of the problems presented by the students of the1990s" (Wang \& Reynolds, 1997, p. 3). Nevertheless, Wang and Reynolds (1997) focused on the financial issue that impacted the inclusion approach negatively and recommended to practice class management, class instruction, social activities to raise motivation, and partnership with parents to lead them and involve them in the teaching process (Alquraini \& Gut, 2012; Dallas, Ramisch, \& McGowan, 2015; Wang \& Reynolds, 1997).

\section{Importance of Quality Training and Teachers' Attitude}

Having a diverse positive climate, reducing the practice of labeling students with disabilities and assessing students frequently, are practical solutions that can be reached by training teachers sufficiently (Alkhateeb, Hadidi, \& Alkhateeb, 2016; Kurniawati, De 
Boer, Minnaert, \& Mangunsong, 2014; Scott et al., 1998). In 1998, Scott et al. asserted that there was a substantial positive correlation between professional training courses and teachers' attitude toward the inclusion approach, and they also found that there was a sturdy positive relationship between social and academic practices at schools. Moreover, they asserted that teachers' proficiency had directly impacted the implementation of the inclusion approach positively or negatively, however, both qualified teachers and regular teachers show increasingly positive attitudes towards the inclusion if they are afforded the proper training (Alkhateeb et al., 2016; Calculator \& Black, 2009).

A meta-analysis of a recent international study, which assumed that teachers have a positive attitude toward the inclusion, when they, unfortunately, did not (Unianu, 2012). Moreover, instructional adaptations in inclusive classrooms could be beneficial in defeating challenges by teachers who will be more able to accommodate a positive environment for students with disabilities and modify the curricula for them by following the instructional adaptations. Therefore, it is necessary to train teachers professionally to prepare them to teach and serve in an inclusive classroom, which impacts both their attitude and students' achievement positively (Kurniawati et al., 2014; Scott et al., 1998). Some studies examined the correlation between gender and teachers' training and how it could be effective, however, there was no relationship between gender and teachers' training, which will impact their attitude positively. Although an attitude which reflects positivity and encouragement by teachers is one of the most effective ways to immerse students with disabilities in an inclusive setting, some 
teachers who have a positive attitude toward the inclusion do not encourage the inclusion approach in its entire capacity (Alkhateeb et al., 2016; Orakc1, Aktan, Toraman, \& Çevik, 2016).

\section{Family Involvement}

Family involvement is essential if the goal is to increase students' motivation. Teachers should be trained to interact and build a positive relationship with parents and to involve families in teaching to create a healthy inclusive environment for all (Calculator \& Black, 2009). Therefore, communication and partnership are two keys to providing the adaptations and accommodations that individuals need to be active students in their classrooms (Salvador, 2013). Also, family involvement is a practical solution to implement in inclusive schools, which should be reflected by effective social and academic activities (Afolabi, 2014; Bossaert et al., 2013; Calculator \& Black, 2009). However, to be fair, there is a need to have solid evidence on the effectiveness of familial involvement on students' outcomes (Dallas et al., 2015). There have been studies that prove that parents' expectations are essential to enhancing students' achievements (Afolabi, 2014; Calculator \& Black, 2009). Nonetheless, teachers and administrators should identify specific goals to help the process of implementing the inclusion approach to students' families to collaborate, and choice interventional methods that fit with students' needs to improve academic levels (Rose, Shevlin, Winter, \& O'Raw, 2010). Although many scholars asserted the importance of parental attitude and encouragement, there is little is known about the examined the effects of parental 
attitudes on the social participation of children with special needs and their achievements (Alkhateeb et al., 2016).

General Problem Statement for the Systematic Literature Review for this study In the international context, some countries have faced challenges in the implementation of the inclusion approach in their general schools, which impacts students' achievement and well-being negatively. For instance, Kelly et al. (2014) mentioned that the principals in Ireland reported that over $40 \%$ of the students with special needs left the mainstream schools because the students did not receive suitable support to meet their academic, social, and emotional needs. Likewise, Kuwait has made little progress in successfully implementing the inclusion (Alfares, 2014; Weber \& City, 2012). Moreover, Wong et al. (2015) found that parents with disabled children are endeavoring to include their children in mainstream classrooms in Singapore. Although the inclusion approach has proved to be an effective means in increasing academic performance for students with disabilities, this approach has faced implementation challenges in general schools located in different places around the world. Therefore, this problem is international in scope and needs to be reformed.

\section{Research Purpose and Questions}

My purpose of this literature review is twofold (a) to identify, in the international context, challenges that general schools face in the implementation of the inclusion approach and (b) to identify practices of implementing inclusion in educational institutions. The following two questions guided this research. 
1. What are the challenges of implementing the inclusion approach in general schools?

2. What are the practices in the implementation of inclusion in general schools?

\section{Searching Process}

I conducted a thorough search via six databases in education: ERIC, Education Full Text (H.W. Wilson), Education Source, Google, Google Scholar, and PsycINFO. I chose these databases because they are related to the topic of my interest. Cochrane review was followed as a review for this study by defining the questions of the literature review and the criteria of including studies, descripting of the search strategy, identifying the process of the selection and collecting data, analyzing the findings by using tables and charts, and interpreting the result to reach the conclusion, recommendation, implementation and further research. To ensure the comprehensiveness of the literature search, a reference librarian was involved in the search process. The first process of research followed the keywords of the inclusion, special education, challenges and teachers, from 2005 until 2016. Table 2 includes my search strategy. 
Table 2

Description of Search Strategy

\begin{tabular}{cclc}
\hline Database & Date & \multicolumn{1}{c}{ Keywords and Combination } & $\begin{array}{c}\text { Retrieved } \\
\text { Articles }\end{array}$ \\
\hline ERIC, Education & February 27, & * (Title) Inclusion in the classroom or & 372 \\
Full Text (H.W. & 2016 & $\begin{array}{l}\text { inclusive classroom or inclusive program or } \\
\text { inclusion education or inclusive education* }\end{array}$ & \\
Wilson), Education & & $\begin{array}{l}\text { And Challenges or barriers or difficulties or } \\
\text { source, Google, }\end{array}$ & $\begin{array}{l}\text { obstacles* And Special education or special } \\
\text { needs or disabilities* And Teachers or }\end{array}$ \\
Google Scholar, & & educators*. & \\
PsycINFO & &
\end{tabular}

The next step was to establish the boundaries of the study to ensure articles relevant to the search questions were included. For this reason, I will provide a list of inclusion and exclusion criteria in Table 3.

\section{Table 3}

Inclusion and Exclusion Criteria

\begin{tabular}{|c|c|c|}
\hline Criterion & Inclusion & Exclusion \\
\hline Time & 2005 to 2016 & $\begin{array}{l}\text { Any articles published outside } \\
\text { this period }\end{array}$ \\
\hline Type of Article & Articles, Empirical study & $\begin{array}{l}\text { Review articles, Books and } \\
\text { book chapters. }\end{array}$ \\
\hline Language & English, Arabic & Non-English, Non-Arabic \\
\hline Sample & $\begin{array}{l}\text { Schools who serve students with } \\
\text { special needs from kindergarten } \\
\text { to high school }\end{array}$ & $\begin{array}{l}\text { Universities level or higher } \\
\text { education }\end{array}$ \\
\hline Topic & Related to the topic & Non- related to the topic \\
\hline Study Focuses on & General Classrooms & $\begin{array}{l}\text { Just Specific classroom such as } \\
\text { writing or mathematic }\end{array}$ \\
\hline
\end{tabular}

The article selection process, which follows the criteria for excluding articles, which are 331 articles, is described in Figure 1. 


\section{First Screening for the exclude criteria}

163 articles eliminated from 372 articles after primary screening of abstracts because they did not have findings for general schools or not related to the main topic

\section{Second screening for the exclude criteria}

94 articles were excluded because they focused on higher educaition or university level

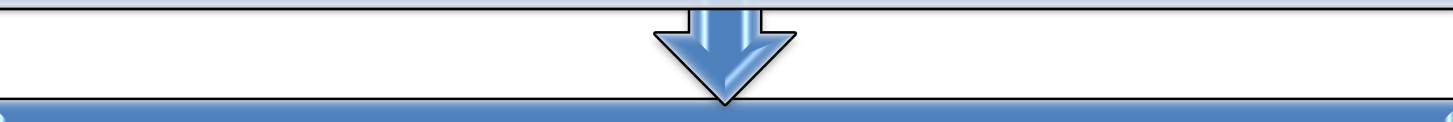

\section{Third screening for the exclude criteria}

74 were excluded because they focused on specific academic classes or specific disabilities

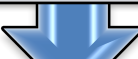

\section{Final included studies}

41 studies were included and analyzed in this literature

Figure 1. The SLR process.

\section{Introduction}

Historically, Stainback and Stainback (1984) have presented the original approach that reflects a solid reasoning for the amalgamation of special and general classrooms in order to allow students with special needs to be educated equally as regular students as the best approach. However, the public-school system was not prepared to provide "the best, most effective education possible for children with disabilities" (Will, 1986, p. 411). Will (1986) presented four obstacles created by special programs: (a) a fragmented approach to identifying students with disabilities that caused many to go un-served, (b) a dual system creating separate administrative bodies and 
isolated special programs with minimal communication between general and special educators, (c) stigmatization of students triggered by special education labels and segregation, and (d) perceptions promoted by the rules and eligibility requirements that school officials were uncooperative and unwilling to help. (Hagan-Burke \& Jefferson, 2002, p. 113)

Therefore, Will (1986) addressed the major areas of change needed in special education. The major areas in which she said change is possible are; raising expectations for all students to prepare them for a changing world; using strategies for instruction that rely on data; and increasing parental involvement. As Ringer and Kerr (1988) asserted, "There is now substantial evidence that most, if not all, children with disabilities, including children with very severe disabilities, can be educated appropriately without isolation from peers who do not have disabilities" (p. 6). In addition to these supportive ideas, there are some evidences that have appeared to disprove the effectiveness of special education programs by exposing the failure of special education programs to treat students with disabilities equally. For this reason, there is a need to encourage scholars to spotlight the inclusion approach for all students in their research (Ringer \& Kerr, 1988). Miller (1990) stated, "Leadership is an important variable in any school improvement effort. Whether leadership is located in the superintendent, principal, or teacher, someone or some small group has to champion the idea, provide necessary support, and work to initiate and maintain the change over time" (p. 18).

Additionally, collaboration between specialists and regular teachers is needed to improve the implementation of the inclusion approach by sharing knowledge, time, 
practices, and efforts (Miller, 1990). In 1991, Mostert asserted that the perception of disability, and the constraints brought by it, has changed with the inclusion movement. The Regular Education Initiative (REI) movement is grounded in beliefs based on denial. This denial is surrounded by the idea that students with special needs are no different from their peers and that, when placed in a general education setting, will be free from being labeled and will be able to perform well with their normally developing peers because there is no difference in potential between children.

In addition, "The true essence of the inclusion is based on the premise that all individuals with disabilities have a right to be included in naturally occurring settings and activities with their neighborhood peers, siblings, and friends" (Erwin, 1993, p. 1). Statistically, the National Association of State Boards of Education mentioned that approximately $43 \%$ of students with disabilities who attended special classes did not graduate or achieve the goal of special education (as cited in Kysilko, 1992). Furthermore, studies show that the program has more than a $50 \%$ failure rate in preparing students to obtain gainful employment after they dropped out from high school. For this specific reason, inclusion will be a more effective approach to be considered for students with disabilities to be prepared for the future (Kysilko, 1992).

In 1994, Fincher and Lewis declared that students' capacities would have been maximized in the inclusion approach if educators, teachers, and policymakers had understood the benefits of effectively implementing the inclusion approach in schools. In addition, having an inclusive environment would develop progressive social reactions for all students such as language improvement, courteousness in social settings, and 
higher self-esteem. Also, it would prevent many of vexing social problems, which many students with disabilities have faced. Fuchs and Fuchs (1994) declared, "Full inclusionists felt that eliminating special education programs will promote social competence of children with disabilities. The mentality of these individuals is that special education is the root of children with disabilities problems" (p. 308). Placing children with disabilities into regular education classrooms will not only encourage friendships, but also change the perception that typical children have of their peers with disabilities (Fuchs \& Fuchs, 1994).

In 2008, Gray and Gray explained:

The collision of IDEA and NCLB thrust schools into an inharmonious change process. NCLB presents a significant challenge to the implementation of IDEA by placing pressure on schools to simultaneously accomplish two difficult tasks. NCLB requires schools to provide nearly all students with uniform, rigorous, standards-based core curriculum instruction. In contrast to NCLB, IDEA calls for individualized and specially designed instruction of disabled students. Ironically, IDEA requires instruction of disabled students to be designed to meet their individual needs, yet NCLB requires all students to demonstrate competence on standardized assessments that that are not differentiated in either form or time constraints. (pp. 4-5)

On the contrary, opponents of the inclusion approach maintained that many students with special needs did not receive quality treatment in regular classes because regular teachers did not have enough time to use strategies that could enhance students' 
performance. Nevertheless, teachers were not prepared to treat students with special needs equally and fairly. Also, many specialists prefer to teach students with disabilities one by one (face to face) or teach the students in a small group by using a resource room because they firmly believe that students who have special cases will learn more separately (Hagan-Burke \& Jefferson, 2002; Idol, 1993, 1997). For example, students with emotional or behavioral disorders need a specific environment to be successful and gain the skills necessary for adult life. These specific environments cannot be created within all general education classrooms (Kauffman et al., 1995).

Many teachers who are working in inclusive programs expressed their feelings towards the inclusion by concerning the efficiency, organizing, managing, scheduling, and time demands as barriers to achieve the goal of the inclusion (Kauffman, McGee, \& Brigham, 2009). Indeed, it is not related to which is better but it is more related to teachers' preparation, curriculum, assessment, strategies, and modification. Teachers are not ready to face the challenges of the inclusion in their entirety, which has led students to fail (Kauffman et al., 2009). In general, the lack of intensive preparation for special teachers leads to attrition in general education, and especially in the inclusion (Brownell, Hirsch, \& Seo, 2004). To solve this problem, Brownell, Sindelar, Kiely, and Danielson (2010) came with a productive suggestion to avoid the attrition, which is using Response to Intervention (RTI) to prepare teachers and obtain some feedback from RTI. The feedback may help to attain enough information to help policymakers and educators have influence on decisions concerning the preparation of special education teachers and regular teachers to run the inclusion approach in general schools. Sadly, many teachers 
are judged negatively by leaders, governs, administrations, and many have lost their jobs because they did not receive their right to receive sufficient preparation and training. It is not fair to punish teachers without providing high-qualified preparation (Carnine, 1992).

The intensive preparation should be offered to equip and train all teachers together, which could encourage a more collaborative environment in inclusive schools (Brownell et al., 2010). Another extraordinary area that needs to be underlined is the perspective of social justice. "Teacher educators working from a social constructivist and social justice stance take a much different approach to the problem of disability" (Cochran-Smith \& Dudley-Marling, 2012, p. 240). Many academics emphasized, "Special educators felt displaced, and many did not have the requisite skills to conduct

effective consultation or collaboration" (Brownell et al., 2010, p. 364). Hagan-Burke and Jefferson (2002) mentioned, "Calls for special educational reform have been widespread in efforts to ensure that students with disabilities receive appropriate educational opportunities in the least restrictive environment" (p. 113).

\section{Findings}

In this section, I presented major findings that address the two research questions. Before that, I presented a brief overview of the publications included for this research.

\section{Overview of the Articles}

This systematic literature review included 41 articles for final analysis. Twenty countries were considered in the included articles; Australia, Bangladesh, China, Cyprus, Finland, Ghana, Greece, Kuwait, India, Ireland, Jordan, Pakistan, Palestine, Singapore, 
South Africa, Spain, Sweden, Thailand, Turkey, United states. In this overview, I will report research designs of the studies focused on challenges, and then the practices.

On one hand, out of 41 articles, 25 articles focused on challenges. Eleven articles were qualitative studies, ten quantitative studies, and four mixed methods. First, nine of the qualitative studies used interview and observation to answer their questions (Aldaihani, 2011; Angelides \& Hajisteriou, 2013; Deng \& Holdsworth, 2007; Lambe \& Bones, 2006; Malak, 2013; Mukhopadhyay, 2013; Ntuli \& Traore, 2013; Sucuoglu, Akalin, \& Sazak-Pinar, 2010; Sukbunpant, Arthur-Kelly, \& Dempsey, 2013). Just one of the qualitative study included both focus groups and interviews (Ajodhi-Andrews \& Frankel, 2010). One of the qualitative studies included only a focus group (Gustavsen \& De Silva, 2013).

Second, ten articles used quantitative studies, which used questionnaires or survey to collect their data (Abu-Heran, Abukhayran, Domingo, \& Perez-Garcia, 2014; Almotairi, 2013; Amr, 2011; Lambe, 2011; Mikami et al., 2013; O'Rourke \& West, 2015; Pasha, 2012). Third, four mixed method studies used interview and questionnaire or survey to collect their data (Helldin et al., 2011; O’Gorman \& Drudy, 2010; Rosemary \& Elsa, 2011; Sucuoglu et al., 2010).

On the other hand, out of 41 articles, 16 studies focused on practices for implementing the inclusion approach and 11 of those studies were quantitative (Chiner \& Cardona, 2013; Duchaine, Jolivette, \& Fredrick, 2011; Guo, Sawyer, Justice, \& Kaderavek, 2013; Melekoglu, 2014; Mikami et al., 2013; Ogelman \& Seçer, 2012; Peebles \& Mendaglio, 2014; Pinar \& Sucuoglu, 2013; Stanton-Chapman \& Brown, 
2015; Tremblay, 2013). Whereas, five studies were qualitative research design. Out of five, three studies contained interviews and observations for data collection, i.e., (Singal, 2008; Sucuoglu, Akalin, \& Pinar, 2014; Vlachou, Didaskalou, \& Kontofryou 2015).

One of them used a focus group (Dymond, Renzaglia, \& Chun, 2008). Furthermore, the last one used focus groups and interviews to gather the data (Ntuli \& Traore, 2013). The percentage of the articles that focused on challenges and practices is described in Figure 2.

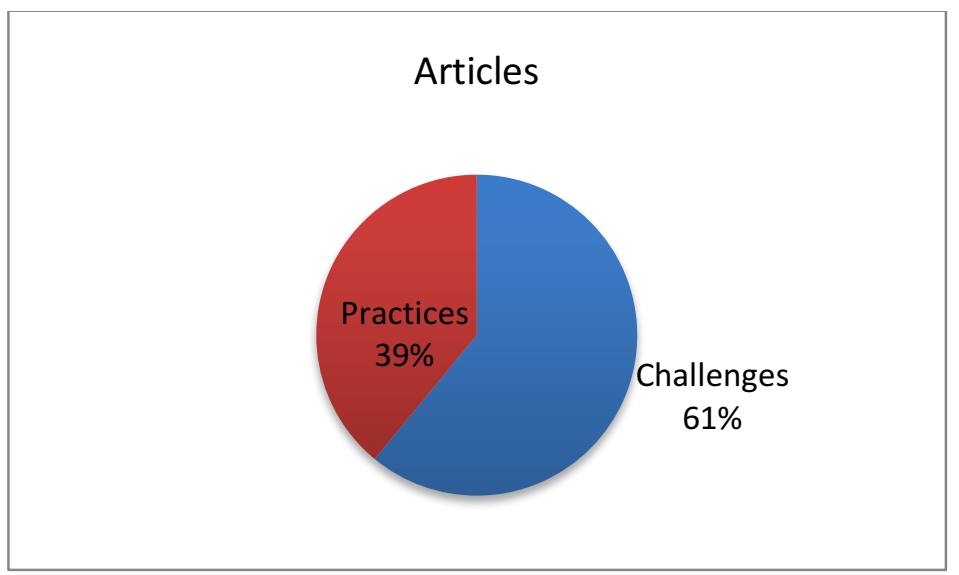

Figure 2. The percentage of the articles that were focused on challenges and practices.

Additionally, the number of the articles that were based on quantitative, qualitative, and mixed methods is described in Figure 3. 


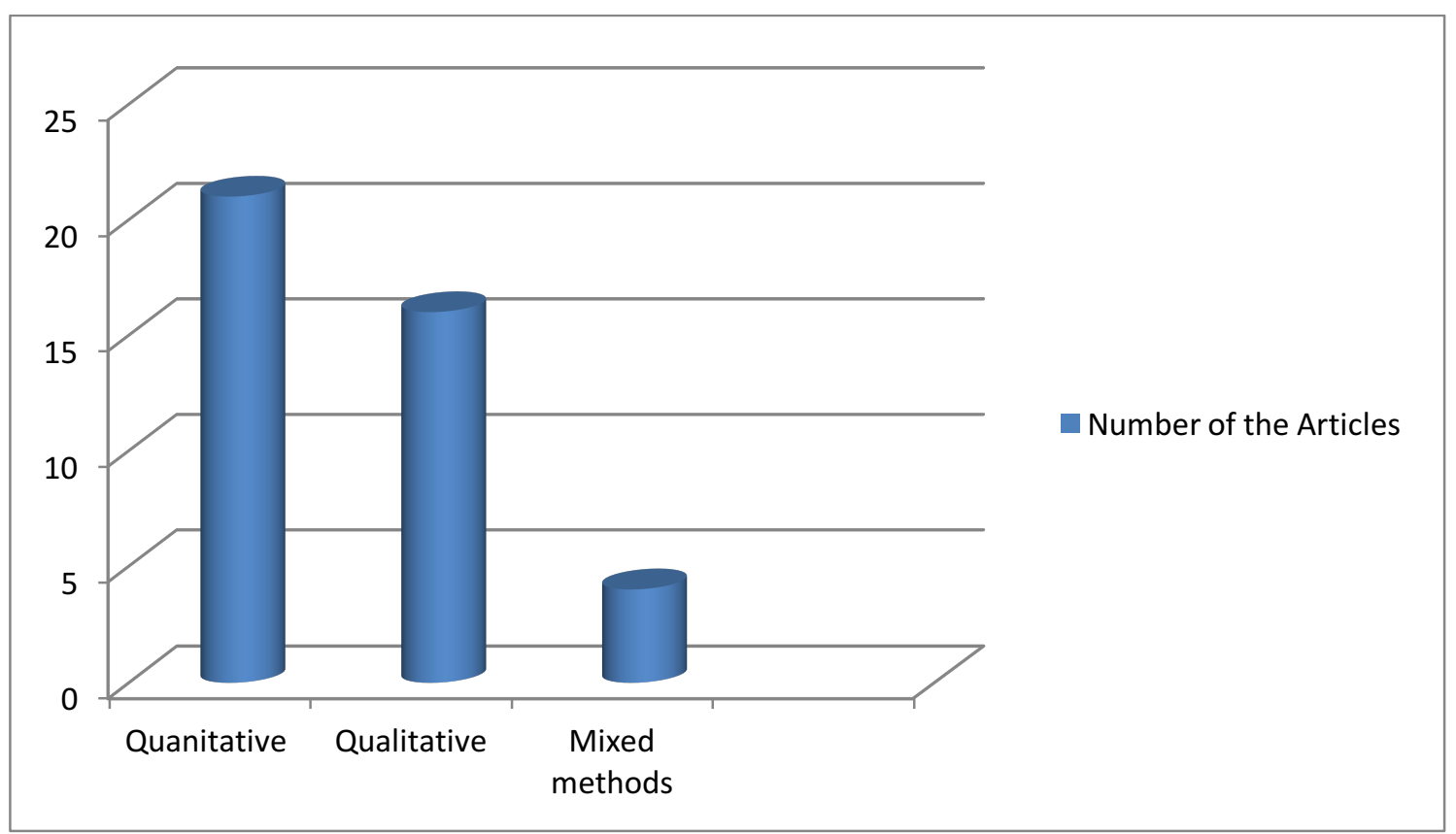

Figure 3. The number of the articles that were based on quantitative, qualitative, and mixed methods.

\section{The Challenges}

Out of the 41 empirical studies reviewed, 25 focused on the challenges facing general schools in implementing the inclusion approach. In this section, I will discuss the eight challenges that frequently were identified.

1. Lack of knowledge, experience, and clear understanding.

2. No collaboration between regular and special education teachers.

3. Absence of quality training.

4. Negative attitude and perception towards the inclusion approach.

5. Lack of resources, services and the environment.

6. Students are not ready to be in inclusive classrooms. 
7. Academic barriers.

8. Policy issues.

Lack of knowledge, experience, and clear understanding. I found that the most frequent obstacle in this review was lack of knowledge and misunderstanding of the concept of the inclusion approach, which was evident in many countries included in this literature review. Studies conducted in countries such as Guyana, Kuwait, Ireland, Singapore, South Africa, Pakistan, Palestine, Thailand, Turkey, mention that teachers lack the information and training necessary to implement the inclusion and that their inexperience directly affects the outcomes for special needs students (Abu-Heran et al., 2014; Agbenyega \& Klibthong, 2014; Ajodhia-Andrews \& Frankel, 2010; Almotairi, 2013; Lambe, 2011; Mukhopadhyay, 2013). Unclear job responsibilities and heavy workloads are also contributing factors, because teachers who work with students with special needs in general schools need to have a clear vision and goals to reach (Takala, Pirttimaa, \& Törmänen, 2009).

No collaboration between regular and special education teachers. The second most frequently mentioned challenges in this review is the lack of collaboration between regular and special education teachers that general schools in several countries such as Finland, Greece, Kuwait, Pakistan, South Africa, Sweden, Thailand, and the United states. This has become a substantial barrier between the inclusion approach and practices. Many students need help from special education teachers, but the disconnection between general education and specialist teachers puts students at a 
distinct disadvantage and ultimately places their right to a quality education at risk (Gustavsen \& De Silva, 2013; O'Gorman \& Drudy, 2010).

In order "to effectively include students with disabilities, general and special education teachers need to meet regularly and collaborate to develop curriculum, share information about each student's strengths and needs, and provide support to each other" (Dymond et al., 2008, p. 27). Collaboration is missed by teachers' practices for the inclusion approach in general schools, which became a robust challenge toward the inclusion approach (Almotairi, 2013; Dymond et al., 2008; Nel, Engelbrecht, Nel, \& Tlale, 2014; Pinar \& Socuolgu, 2013; Takala et al., 2009).

Absence of quality training. The third challenge general schools reported that hindered implementing inclusion was absence of quality training. Studies in Australia, Bangladesh, Ireland, Jordan, Kuwait, Palestine, Singapore, South Africa, Thailand, mentioned an absence of quality training programs to prepare teachers to be inclusive in schools (Almotairi, 2013; Malak, 2013; Mukhopadhyay, 2013; Sukbunpant et al., 2013; Thaver \& Lim, 2014). Pre-service teachers have the potential to be key contributors to the inclusion approach in general schools by equipping teachers to understand and serve students with special needs (Malak, 2013). However, many teachers have negative attitudes towards students with special needs and are hesitant to take strides to help them (Lambe \& Bones, 2006; Thaver \& Lim, 2014). Dymond et al. (2008) mentioned that many teachers have failed to help students with special needs in general schools because they did not have sufficient training, this reflected in their negative attitudes or perceptions towards the inclusion approach. In the same vein, teachers said that they are 
not ready to teach students with special needs (Agbenyega \& Klibthong, 2014; Amr, 2011; Kelly et al., 2014; Helldin et al., 2011).

Also, administrators have no services in place to help students with their classes, which impacts teachers' willingness to incorporate the inclusive approach in their classrooms (Vorapanya \& Dunlap, 2015). However, Abu-Heran et al. (2014) stated, "Attitudes toward students with disabilities are an important aspect of integrating them into regular classrooms or other social activities" (p. 467). Therefore, teachers in ordinary schools have the responsibility of accommodating the needs and interests of all learners, including children with disabilities. The attitude and willingness of primary school teachers to teach pupils with intellectual disabilities in regular schools is one of the factors that is critical to successful implementation of inclusive education (AbuHeran et al., 2014, p. 367).

Lack of resources, services and the environment. Scholars in China, Cyprus, Finland, Ghana, Ireland, Kuwait, and Turkey, mentioned that there were not enough services in inclusive schools to support the application of the inclusion approach in general schools. For example, inadequate support, health services and lack of clarity in the inclusion approach and their responsibilities toward students with special needs are a major hindrance (Abu-Heran et al., 2014). Additionally, there are limited of resources for students with special needs. Likewise, the general schools are not equipped to handle the diversity of special students (Adera \& Asimeng-Boahene, 2011; Almotairi, 2013; Angelides \& Hajisoteriou, 2013; Guo et al., 2013; Lambe \& Bones, 2006; Pasha, 2012). Some authors also mentioned that supports services are missing from general schools, 
which negatively affects the inclusion practices (Abu-Heran et al., 2014; Melekoglu, 2014; Pasha, 2012).

Students are not ready to be in inclusive classrooms. Two scholars consider that students are not ready for the inclusion approach in general schools because of their lack of self-confidence, and history of classroom disengagement and challenging behaviors (Ajodhi-Andrews \& Frankel, 2010; O'Gorman \& Drudy, 2010). Besides, some parents have a misunderstanding of the concept of the inclusion, which reflects in students' readiness to be engaged in inclusive classroom with their peers (O'Gorman \& Drudy, 2010). Meanwhile, students' abilities and skills could be hindered by parents having low expectations for their teachers (Dymond et al., 2008; O'Gorman \& Drudy, 2010). If there are low expectations towards students with special needs, the academic task has a significantly lower chance of success; it is a barrier in obtaining new knowledge and raising their confidence (Dymond et al., 2008). It is critical to understand that a teacher's negative attitude towards the inclusion approach drives students with special needs into having a lack of confidence, and they will not be ready for integration (Abu-Heran et al., 2014; Agbenyega \& Klibthong, 2014).

Academic barriers. Five articles mentioned that the curriculum in general schools did not fit students with special needs (Abu-Heran et al., 2014; Almotairi, 2013; Dymond et al., 2008; O'Gorman \& Drudy, 2010; Takala et al., 2009). One study from Palestine found that current teaching methods did not encourage student's learning, and this is an academic barrier that students with special needs face on the path to academic success (Abu-Heran et al., 2014). Moreover, time limitation for consultations is another 
significant hindrance to students with special needs and their parents. Unfortunately, in a regular school day there is simply no time to spare for one-on-one consultations (Takala et al., 2009). Moreover, class size is essential to take into consideration because it could impact negatively on students' performance (Ntuli \& Traor, 2013).

Policy issues. Five articles mentioned that there is a lack of commitment and a lack of the inclusion approach to support admission policy, which has become a formidable challenge towards the implementation of the inclusion (Ahmmed \& Mullick, 2014; Deng \& Holdsworth, 2007; Pasha, 2012; Vorapanya \& Dunlap, 2014). Class size is another policy issue; students' attention and perceptions are affected negatively when they are placed in large size class (Ahmmed \& Mullick, 2014; Deng \& Holdsworth, 2007; Pasha, 2012; Vorapanya \& Dunlap, 2014). Conversely, one study from Finland mentioned that small class sizes would have more relaxed and supportive atmospheres for students with special needs (Takala et al., 2009). In Thailand, many leaders in the educational community have expressed their disdain towards the lack of national funding schools have received, especially considering that the goal to properly teach all students equally and to do it well, is a massive undertaking. Furthermore, the policy allowed only few teachers take training courses. A problem arises when they share their knowledge and experiences with other teachers because of misconceptions and loss of important information emerge in the translation from teachers who took the training to teachers who did not take it (Vorapanya \& Dunlap, 2014). 


\section{Current Practices}

Sixteen out of the 41 empirical studies were focused on current practices adopted by general schools in the implementation of the inclusion approach in general schools. These four practice areas are:

1. Social skills and Collaboration

2. Teachers training

3. Task management

4. Setting suitable services, Resources, and Environment

Social skills and collaboration. Collaboration is one of the most important practices between general teachers and specialist teachers to be effective in general schools, when they consider the inclusion approach. Regular teachers and specialist teachers need to stand shoulder to shoulder to help students with special needs without hesitation for their academic success (Dymond et al., 2008). Moreover, teachers need to understand the case-by-case nature of special needs students in order to help students with their learning process, which requires enough training to reach this point of understanding (Evans \& Weiss, 2014; Monsen, Ewing, \& Kwoka, 2014; Nel et al., 2014; O’Gorman \& Drudy, 2010; Thaver \& Lim, 2014; Vorapanya \& Dunlap, 2014).

Understanding students with special needs could be reachable by having effective social skills teaching program. For example, researchers showed that a social-skill teaching program impacted positively on teachers' outcomes in Turkey (Pinar \& Socuolgu, 2013).

Moreover, in Ireland, some teachers have faced peer interaction difficulties, which became as barriers to practice an inclusive program and these barriers are related 
with social skills, peer interaction, and collaboration (O’Gorman \& Drudy, 2010).

Following Nel et al. (2014), "Collaboration refers to the interaction of different stockholders to help learners experiencing problems in learning activities" (p. 910). Nel et al. (2014) asserted that following collaboration as practices in general schools could be beneficial to earn social skills and impact students' achievements positively.

Another study found that there is no way for general teachers to help students with special needs without fully understanding them as an individual (Takala et al., 2009). Therefore, collaboration approach could be the best way for regular teachers to understand the students with special needs by working with specialist teachers as one group (Takala et al., 2009). Regular teachers need training from a specialist to help them understand the inclusion approach and students' characteristics with special needs (AbuHeran et al., 2014; Pinar \& Sucuoglu, 2013).

It is critical for teachers to develop a collaborative partnership when supporting learners who experience barriers to learning contents (Nel et al., 2014, p. 909). In order to form a group effort in general schools, both regular teachers and specialist teachers need to understand the full concept of collaboration, not only the description of collaboration methods and strategies in formal and informal school contexts (Nel et al., 2014).

Teacher training. Scholars found that general teachers need to be trained by experts to understand the concept of the inclusion approach (Abu-Heran et al., 2014; Agbenyega \& Klibthong, 2014; Ajodhia-Andrews \& Frankel, 2010; Duchaine et al., 2011; Lambe, 2011; Mukhopadhyay, 2013; O’Rourke \& West, 2015; Vorapanya \& 
Dunlap, 2014). Although, offering sufficient training for teachers who are participated in in inclusive classroom will have positive attitude and high level of self-efficacy for students with special needs (Peebles \& Mendaglio, 2014), the training opportunities available to pre-service teachers are few and far between in Australia (O'Rourke \& West, 2015).

Additionally, Pasha (2012) asserted that there is a lack of professional development for teachers and administrators, which is harmful for inclusive practices in Pakistan. Also, in 2011, Lambe declared that teachers identified lack of personal knowledge in Northern Ireland. The most significant areas in which teachers need training are social skills, academic skills, academic services, and using resources (O’Gorman \& Drudy, 2010; Vorapanya \& Dunlap, 2014). Teachers who take some training to increase their social skills, academic services, and utilize resources will definitely improve the condition of learning in their classes and help students with special needs to academically succeed (Chiner \& Cardona, 2013).

Moreover, raising positive attitude and beliefs towards the inclusion approach could be reached by practicing effective teachers training. For example, Melekoglu (2014) found that teachers have positive attitude and outcomes after an effective training in Turkey. Studies show that general teachers need to be trained by experts to understand the concept of the inclusion and increase positive attitudes and beliefs towards the academic performance of students with special needs (Abu-Heran et al., 2014; Agbenyega \& Klibthong, 2014; Ajodhia-Andrews \& Frankel, 2010; Duchaine et al., 2011; Lambe, 2011; Mukhopadhyay, 2013; O’Rourke \& West, 2015; Vorapanya \& 
Dunlap, 2014). Specifically, "The support of the teachers is absolutely necessary for any change to be possible, their voice and insight is fundamental to the success of any project”' (Abu-Heran et al., 2014, p. 461). Changing teachers' attitude and beliefs will drive the inclusion practices to success and lead students with special needs to develop their positive behaviors in environments in order to foster enjoyable learning experiences, which could be reachable by having effective training courses for teachers (Lambe, 2011; Melekoglu, 2014).

Task management. Four studies mentioned that there is a need for task management in general schools to implement the inclusion approach and have good practices (Abu-Heran et al., 2014; Mikami et al., 2013; Sucuoglu et al., 2010; Takala et al., 2009). It is essential to use the correct classroom management methods in order to have suitable environment, time, and resources for students with special needs (AbuHeran et al., 2014). Timing the work is another important task management skill that could help teachers to better focus students who struggle with their academic task (Takala et al., 2009).

Setting suitable services, resources, and environment. There is still a need to improve the quality of education in classrooms by having strong support services, resources, and suitable environments. Teachers who work in suitable environments and have access to appropriate materials are able to implement practices that foster the inclusion educational practices in their classrooms (Dymond et al., 2008; Melekoglu, 2014). For practicing the inclusion approach, there is a need to improve the academic and general materials (Abu-Heran et al., 2014). Also, creating a fit environment for 
students with special needs allows them to establish meaningful connections with their peers (Dymond et al., 2008).

\section{Discussion}

In this systematic literature review, I aimed to identify studies on challenges that general schools face in the implementation of the inclusion approach and to identify practices of implementing the inclusion in educational institutions. This systematic review identified 38 articles related to the literature topic. Based on the findings more research is needed on the practices in the implementation of the inclusion in general schools; I found that there are just four main practices that were considered in this literature for implementing the inclusion, whereas more than eight main challenges that faced inclusion approach. For example, Melekoglu (2014) indicated that in Turkey, 81\% of participating teachers in a study expressed that general schools are not ready to receive students with special needs, and they need to be educated in separate special education schools because there is a lack of ability to provide adequate education for students with special needs in general schools. Furthermore, there are no support services regarding inclusive schools.

In Ireland, O'Gorman and Drudy (2010) found that there is a need to develop more effective practices to face the lack of self-confidence, classroom disengagement, and peers' interaction difficulties in inclusive classrooms. Some possible practices to effectively implement the inclusion: having effective pre-service courses, in-service courses, adequate support, fit resources, special curriculum, a suitable environment and a project to develop teaching skills needs (Abu-Heran et al., 2014; Agbenyega \& 
Klibthong, 2014; Ajodhia-Andrews \& Frankel, 2010; Duchaine et al., 2011; Lambe, 2011; Melekoglu, 2014; Mukhopadhyay, 2013; O’Rourke \& West, 2015; Vorapanya \& Dunlap, 2014).

I found that one of the central challenges faced by the inclusion was a lack of knowledge and misunderstanding of the concept of the inclusion approach (Abu-Heran et al., 2014; Agbenyega \& Klibthong, 2014; Ajodhia-Andrews \& Frankel, 2010; Lambe, 2011; Mukhopadhyay, 2013). This could influence teachers' attitudes and perception negatively towards the task at hand (Abu-Heran et al., 2014; Agbenyega \& Klibthong, 2014; Ajodhia-Andrews \& Frankel, 2010; Duchaine et al., 2011; Lambe, 2011; Mukhopadhyay, 2013; O’Rourke \& West, 2015; Vorapanya \& Dunlap, 2014). However, there are a few empirical studies that were focused on examining an effective program to enhance the teachers' knowledge and skills in order to change teachers' attitudes and perceptions (Agbenyega \& Klibthong, 2014; Melekoglu, 2014; Pasha, 2012; Thaver \& Lim, 2014).

Future research may need to be focused on filling the gap between the implementation of the inclusion approach and education policy. In several countries, teachers have failed to practice the inclusion because they could not understand and reflect the inclusive policy (Ahmmed \& Mullick, 2014; Deng \& Holdsworth, 2007; Pasha, 2012). Also, some teachers did not receive enough support to educate the students with special needs adequately because of the lack of the inclusive policy (Vorapanya \& Dunlap, 2014). Therefore, studying this area could be valuable in implementing inclusion. Although the findings of this literature showed that improving the quality of 
education in inclusive schools and having enough support, suitable environment, and necessary services is mandatory to educate students with special needs with their peers equally (Abu-Heran et al., 2014; Dymond et al., 2008; Melekoglu, 2014). There is limited research that delves into how teachers, administrators, and researchers could place these keys in the inclusion.

Parents also have important roles in the implementation of the inclusion; however, many parents felt that they were unwelcome in their children' schools which impacted the inclusion negatively (Scorgie, 2015). In Singapore, parents attempted to include their children with disabilities in inclusive schools although they faced many challenges such as lack of resources, services and supports from their schools and the low expectation of schools' teachers toward their children (Wong et al., 2015). Furthermore, in Ireland over $40 \%$ of the students with special needs left the inclusive schools because parents were not satisfied by the schools' support and services (Kelly et al., 2014). It is clear that there the role parents play in the implementation of the inclusion is valuable.

Ultimately, in this systematic literature review, I found that limited research focused on gifted students who also have the right to be educated in an inclusive school with their peers (Kearney, 1996). Unfortunately, gifted students were neglected by researchers, teachers, policy-makers, and educators. Gifted students have fewer opportunities than other students to interact with their peers in general schools. For this reason, more research is needed to consider gifted students as specialists in the inclusion 
approach (Kearney, 1996). Additionally, limited research focused on students with or at risk emotional and behavioral disorder (EBD).

There was just one study focused on collaboration among teachers to increase positive behavior in inclusive classroom (Evans \& Weiss, 2014). Indeed, promoting prosocial behavior and decreasing problem behavior are needed for all students in inclusive classrooms in order to create a suitable environment for everyone (Bowman-Perrott, Burke, Zaini, Zhang, \& Vannest, 2015). Therefore, "There is a need to identify effective prevention-oriented approaches to behavior management, especially at the classroom level” (Bowman-Perrott et al., 2015, p. 1). Sadly, teachers are unfamiliar with approaches that could help to reduce students' bad behavior, which led them to struggle with students with or at risk of emotional and behavior disorder (Dunlap, Sailor, Horner \& Sugai, 2009).

\section{Summary}

The inclusion approach is one of the most effective ways to immerse students with special needs into society. This is only possible if schools are ready to receive the students and prepare them for the future. In the international context, some countries have faced challenges in the implementation of the inclusion in their general schools, which impacts students' achievement and well-being negatively. Therefore, the purpose of this systematic literature review is twofold: (1) to identify challenges that general schools face in the implementation of the inclusion approach; (2) to identify current practices of implementing the inclusion in general schools. A total of 41 empirical studies were included for final analysis. 
The findings revealed eight challenges, including (a) lack of knowledge, experience, and clear understanding; (b) no collaboration between regular and special education teachers; (c) absence of quality training; (d) negative attitude and perception towards the inclusion; (e) lack of resources, services, and the environment; (f) students are not ready to be introduced into inclusive classrooms; (g) academic barriers; (h) policy issues. In addition, four practices have been adopted by general schools to implement the inclusion. They are (a) social skills and collaboration; (b) teachers training; (c) task management; (d) setting suitable services, resources, environment. Based on the findings, more researchers should examine the practices in the implementation of the inclusion. 


\section{CHAPTER III}

\section{METHODS}

In this chapter, I explain my research methods, including: the research design, context of the study, participant selection, data collection, and data analysis. The purpose of this study and the research questions are also restated. Additionally, the research approach, participants, data sources, instrumentation, data collection, and data analysis are described. Finally, I conclude with a brief summary.

\section{Purpose of the Study and Research Questions}

There were three key goals to this study: (a) to identify challenges of the implementation of inclusion approaches that face private primary school administrators in Kuwait, (b) to identify how inclusion practices are implemented by administrators, teachers, and counselors in private Kuwaiti primary schools, and (c) to identify the differences in the implementation practices of inclusion between two private primary schools in Kuwait.

The following three questions guided this work.

1. What are the challenges to implementing the inclusion approach faced by private primary school administrators in Kuwait?

2. In what ways are inclusion practices implemented by administrators, teachers, and counselors in private primary schools in Kuwait?

3. What are the differences in implementation practices between the two private primary schools examined in this research? 


\section{Design}

In this study, I employed qualitative case studies to answer three research questions; my analysis emphasized the interpretations of principals, teachers, and counselors and their opinions related to the tenets of this study. Merriam (1988) believed that it was important to ask research participants "what they experience, how they interpret these experiences, and how they structure their social worlds" (p. 19). Therefore, I focused on principals, teachers, and counselors' reflections on inclusion practices, and how schools have evolved to create an appropriate inclusion environment for students with learning disabilities.

A cross-case analysis was adopted for this study, which means that two case studies were included in this research. Hays and Singh (2011) explained that "a case is a specific, unique, bounded system, and the case study allows the researchers to study individual(s), events, activities, or processes / elements of a bounded system” (p. 44). They went on to say that "the emphasis in the case study is on examining a phenomenon as it exists in its natural context, in order to identify the boundaries between the two by asking how and way" (Hays \& Singh, 2011, p. 44). I attempted to "gain entry into the conceptual world of my participants in order to understand how and what meaning they construct[ed]" (Merriam, 1988, p. 37).

\section{Procedures for the Survey}

Eight teachers (at least one math and one language teacher, preferably with a special education specialty), one principal, and one counselor were surveyed in order to obtain a diverse body of information. The qualitative design yielded data essential to 
answering the research questions. The qualitative survey was distributed via Qualtrics to individuals who agreed to participate; all surveys were completed within two days. The school principals who agreed to take part (and who signed the letter of agreement / site authorization) placed my recruitment materials in the mailboxes of the teachers and counselors. These individuals then contacted me if they were willing to participate. The survey was used to gather their opinions and perceptions of their schools' implementation of the inclusion approach. The survey took approximately 45 minutes; some participants chose to take it home and responded within two days.

In two interviews, a researcher asked follow-up questions for clarification via the GoToMeeting ${ }^{\mathrm{TM}}$ interview program. Both Qualtrics and GoToMeeting ${ }^{\mathrm{TM}}$ are owned by the College of Education and Human Development at the Center for Research and Development in Dual Language and Literacy Acquisition. Both programs were secure for the participants. Those who met the research criteria were provided with a Qualtrics link to submit their responses. A GoToMeeting ${ }^{\mathrm{TM}}$ interview was set up if any of the responses required clarification.

\section{Procedures for the Interviews}

First, I scheduled GoToMeeting ${ }^{\mathrm{TM}}$ interviews with prospective participants curious about the procedures of the survey and follow-up interviews. Next, verbal consents were collected from all interested participants. Then I sent email versions of the survey, which was created via Qualtrics. Individuals interested in participating in followup interviews wrote their name and email address at the end of their survey. Next, I continued with audio-recorded interviews. Follow-up interviews were conducted with 
four teachers and two principals via the GoToMeeting ${ }^{\mathrm{TM}}$ program (two teachers and one principal for each of the case study schools). One of each group of teachers was a special education specialist for students with learning disabilities, and one was a general education teacher who had students with learning disabilities in his or her class. I reminded each interviewee that the interview could be conducted in either Arabic or English, according to the participant's preference. All participants preferred English. Interview questions were read aloud. Interviewees were also provided with a copy of the interview questions so that they could follow along. They responded verbally, and I transcribed their responses immediately to ensure accuracy. Permission to audio record the interviews was given verbally by each participant.

The same interview procedure was followed for the principals. The interviews were conducted via GoToMeeting ${ }^{\mathrm{TM}}$, a copy of which is owned by the College of Education and Human Development at the Center for Research and Development in Dual Language and Literacy Acquisition. The researchers for this project have a personal GoToMeeting ${ }^{\mathrm{TM}}$ account with their own usernames and passwords. The interviews were recorded by the GoToMeeting ${ }^{\mathrm{TM}}$ account holder and transcribed. Then, the recording was deleted. No names were attached to the transcriptions. All information obtained in this study will be kept strictly confidential.

\section{Participants}

Per campus, eight teachers (at least one math and one language teacher, with one of those two being a special education teacher), one principal, and one counselor were surveyed to obtain diversity in the data. Interviews were conducted with two teachers at 
each of the two schools, for a total of four teachers. Follow-up interviews were conducted with the two principals, and the same procedure was followed as that which was employed for the teachers. The total sample size for this study was 20 . No public schools have endeavored to accommodate students with learning disabilities in inclusive classrooms. Therefore, I selected inclusive primary private schools that included students with learning disabilities.

\section{Inclusion and Exclusion Criteria}

The inclusion criteria for this study were as follows: (a) primary private schools in Kuwait that had implemented an inclusion approach for students with learning disabilities; (b) teachers speaking the English and/or Arabic languages; and (c) voluntary participation of teachers, counselors, and school administrators. The exclusion criteria for this study were: (a) public schools in Kuwait, (b) students, (c) parents, and (d) school workers who were not teachers, counselors, or school administrators.

\section{Data Collection}

\section{Purposeful Sampling Methods}

I used snowball sampling, asking questions of prospective participants that would help me reach the appropriate sample for my research. "Snowball sampling is a natural fit for a convenience sampling strategy, which may allow asking more questions to someone in the same field by using people's relationships with one another to identify the sample" (Hays \& Singh, 2011, p. 169). This process was employed by asking individuals who specialize in education and special education to suggest other prospective participants who might be knowledgeable about this topic. Also, two private 
schools offering the inclusion approach were determined and their participation was requested.

\section{Instrumentation}

I created open-ended interview questions to serve as a means of understanding the inclusion practices employed and challenges faced by school administrators in private Kuwaiti schools. The questions were used to "describe the diversity of certain cognitions or behaviors in a population" (Jansen, 2010, p. 1). Additional interviews were held after reviewing the answers to the qualitative surveys, if there was a need for clarification or to validate participants' responses. Twenty participants were engaged in this qualitative study. All of the interview and qualitative survey questions were related to the three research questions described above. A useful depth of understanding was gained by analyzing the participants' answers (Lunenburg \& Irby, 2008).

Interview and qualitative survey. The questions were qualitative in nature (see Appendix A) and open-ended. The interview questions were based on the original survey questions and designed to clarify and validate the earlier responses. Open-ended questions allow for more varied responses and inform future lines of questioning and areas of research. The interviews were conducted via video chat, using the secure GoToMeeting ${ }^{\mathrm{TM}}$ program. All interviews were conducted in English, according to the participants' preference. The qualitative design yielded essential data that helped to answer the research questions. Interview questions were read aloud to the interviewees, while the interviewees followed along on a separate hard copy. Interviewees responded verbally. I transcribed their responses immediately to ensure accuracy. The interviews 
were audio recorded after each participant offered their verbal permission to do so. The follow-up interviews with the principals were conducted in the same manner as those of the teachers.

Questions for the qualitative survey were distributed via Qualtrics to all who agreed to participate; all surveys were completed within two days. The school principals who agreed to participate (and who signed the letter of agreement / site authorization) placed the recruitment materials in the mailboxes of the teachers and counselors. A total of 22 individuals contacted me to participate. Those who met the criteria and indicated that they were willing to take part received a Qualtrics link so that they could submit their responses to the survey. Distribution was timed to coincide with their break times or other times that would be convenient, allowing them to answers accurately and thoroughly. However, some asked for more time and took the survey home. All surveys were completed within two days. Subsequently, participants who had indicated their willingness to participate in follow-up interviews were contacted.

Based on the purpose and topic of this study, a qualitative method was used to answer the three research questions. Data were divided into two categories: challenges to implementing inclusion and the actual processes of implementation used. I conducted individual interviews and asked open-ended questions. This step was kept as uniform as possible to allow "the same information (depth and breadth) to be covered with all participants" (Hays \& Singh, 2011, p. 239). The qualitative survey was used to diversify the findings and explore the significant variations among classroom practices and administrative policies. It did not reflect the number of people who had the same 
perspective or exhibited the same characteristics (Jansen, 2010). Finally, the answers provided were analyzed and interpreted, their relevance to the research topics was determined, and the value of the data was established (Jansen, 2010).

Demographics. Twenty qualitative surveys were distributed and four interviews were held to gather data from individuals working in two private primary schools in Kuwait. Additionally, the principals of both schools were also interviewed for follow-up purposes. The surveys were used to gather the respondents' opinions and perceptions of the implementation of inclusion in their schools. The surveys took about 45 minutes to an hour to complete; some were completed at school during break time, and some of the participants took the survey home and returned their answers within two days. Follow-up interviews were then conducted where a researcher asked questions about points that needed clarification; interviews were conducted via the GoToMeeting ${ }^{\mathrm{TM}}$ interview program. Both GoToMeeting ${ }^{\mathrm{TM}}$ and Qualtrics are owned by the College of Education and Human Development at the Center for Research and Development in Dual Language and Literacy Acquisition. Both programs were secure for the participants. The researchers for this project have a personal GoToMeeting ${ }^{\text {TM }}$ account with their own usernames and passwords.

There were two GoToMeeting ${ }^{\mathrm{TM}}$ sessions held. One was used to collect consent and establish a record of that consent, and the second was used to conduct the actual interviews. These interviews were recorded by the GoToMeeting ${ }^{\mathrm{TM}}$ account holder in the system, and were then transcribed. The recordings were then deleted and no names were attached to the transcriptions. All information obtained in this study will be kept 
strictly confidential. The interviews and qualitative surveys were conducted over a twoweek period in March of 2017. The interviews lasted an average of 45 to 60 minutes. The qualitative surveys were completed either at school or in the respondent's home environment; all were completed within two days.

Validity and reliability. Face validity was used to validate the survey of openended questions, the primary data-collection instrument used in this study. Three professors and three teachers who worked in the education field validated the questions used in the survey and those asked during the follow-up interviews. None of the study population was involved in the face validation process. Face validity examines the question content and how the questions reflect on the topic of the interest (Edmondson \& Irby, 2008). I edited and deleted certain points, words, and questions based on the suggestions received from the validation judges. The interview and survey questions were directly related to the purpose of this study, according to the six experts validating them. One judge was a professor in the Education Administration program at Texas A\&M University, two were professors in the College of Education in Kuwait University, and three were teachers in the field of Education. All agreed that the face of the instrument matched the purpose of the study, and the content of the instrument matched what the instrument was designed to measure.

For the survey and interview questions, I followed the conceptual framework of democratic and social justice education. This assured the validity of the questions by covering the most important elements of the inclusion approach; this also made sure that the instrument reflected the purpose of the study and related to the research questions 
more than did other tools. I assessed the transcription fidelity by comparing the transcriptions of the two interviews from the same school, and then compared them to the interviews from the second school. There were no incidents of significant variation between my immediate transcription and the records of the interviews. The interviews and qualitative survey were semi-structured. The estimated time required for the interview was approximately one hour.

\section{Conclusion}

All of the questions were open-ended, and the respondents and interviewees were given the opportunity to express their feelings; all were given identical surveys and posed identical survey questions. I gathered essential data from the teachers, principals, and counselors who responded concerning their opinions related to the implementation of the inclusion approach in their respective private primary schools in Kuwait.

\section{Data Analysis}

\section{Thematic Analysis}

The collected information was then coded and developed into themes, according to a process outlined in prior research. This prior research used coding to extract themes and organize those themes into categories. Particularly, I followed the process outlined in prior research examining the inclusion approach. The themes were developed from an outline analysis of the surveys and interviews collected in this study.

\section{Code}

A code is a label that collects various data together, based on a defining case or unit of analysis. This type of device has been referred to by a number of names, 
including domain, factor, theme, subtheme, and item. Codes can be descriptive or interpretive, and they can be labeled by the participant (emic codes) or the researcher (Hays \& Singh, 2011, p. 299).

\section{Identification of the Themes and Patterns}

Themes are higher-order codes, codes that have been collected together to describe a phenomenon (Hays \& Singh, 2011). This step is similar to a factor analysis in quantitative research, which involves identifying patterns, examining codes, and brainstorming ways in which the codes can be "chunk[ed] together" (Hays \& Singh, 2011, p. 300). In this study, I considered patterns or themes such as a school's strategies, activities, assessment procedures, environment, curricula, and source books or technology, all of which were related to the interview questions to answers to those questions.

\section{Comparative Pattern Analysis}

I compared patterns to determine if there were relationships among the themes and how they might have impacted school practices for implementing inclusion (Spall, 1998). Patterns in the challenges faced by the two schools' administrators were also compared and analyzed.

\section{Mind Mapping}

Mind mapping was engaged to gain a deeper understanding of the themes and analyze the practices of inclusion. Mind mapping was practiced by analyzing the literature review for this study, which was also used to interpret the final data. As mentioned above where I discussed identifying themes and patterns, the schools' 
strategies, activities, assessment processes, environment, curricula, and source books and technology were all useful for reflecting on the challenges to implementing the inclusion approach and the implementation practices employed.

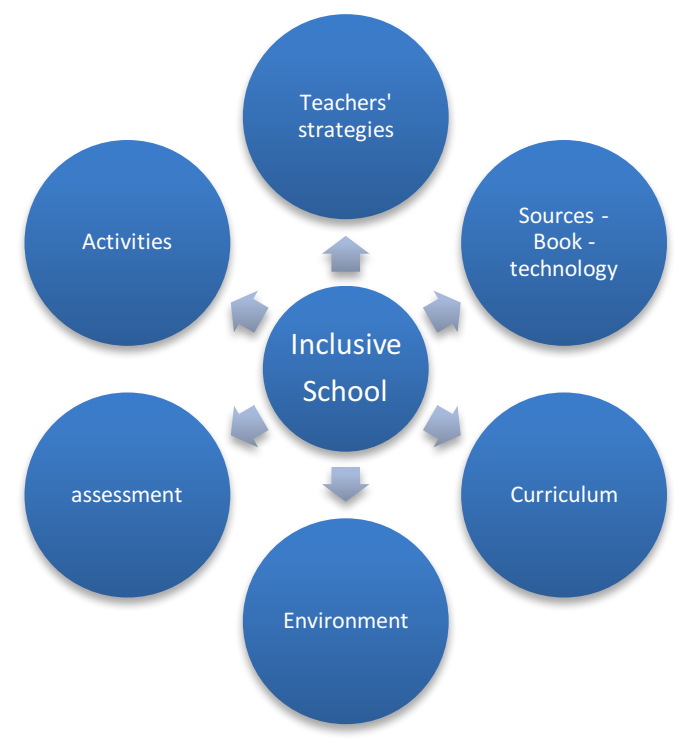

Figure 4. Mind mapping.

\section{Establishing Reliability and Trustworthiness}

I used several approaches to establish validity, as described below.

Memos. I recorded the interviews in order to retain all important information that could be valuable when analyzing the findings as they developed throughout the study. Memos "are typically associated with specific data collection methods, such as interviews, documents, and surveys" (Hays \& Singh, 2011, p. 205). In addition, audio recordings were beneficial to activating the memos. 
Member check. After reviewing the qualitative survey answers, follow-up interviews were conducted as needed to clarify certain answers. Member check validation was used as a means of following up on participants' responses.

Triangulation. A variety of sources were used to help ensure the reliability of the information. Contributing data were supported as credible by notes taken during the interviews and pictures obtained, when possible. Insights and descriptions of events or relationships were collected during this triangulation approach, which was essential to establishing trustworthiness (Erlandson, Harris, Skipper, \& Allen, 1993).

Reductions and limitations. I reduced the data to narrow the focus and help with collection, by writing down all of the information collected in the surveys and interviews during the first stage of analysis. I then determined the themes and gathered them in a table. All of these steps were important to accurately summarizing the memos in their entirety (Hays \& Singh, 2011). 


\section{CHAPTER IV}

\section{RESEARCH FINDINGS}

\section{Introduction}

The purpose of this study was threefold: (a) to identify challenges of the implementation of inclusion approaches that face private primary school administrators in Kuwait, (b) to identify how inclusion practices are implemented by administrators, teachers, and counselors in private Kuwaiti primary schools, and (c) to identify the differences in the implementation practices of inclusion between two private primary schools in Kuwait. Above, I investigated the conditions under which the application of this approach has developed, provided insights into the challenges faced, and highlighted successful practices. In this chapter, I discuss the findings that emerged from analyzing the perspectives of teachers, counselors, and principals at two particular private primary schools in Kuwait. I employed two qualitative case studies to answer three research questions, emphasizing the interpretations of these educators, their reflections on inclusion practices, and comparisons of how schools used to be and how much they have evolved on this topic. A cross-case analysis method was adopted to evaluate the 20 open-ended surveys received. Before engaging in the analysis, I received 22 verbal consents. After evaluating the 20 surveys, I contacted the two principals and two of the teachers for follow-up interviews. Ten surveys and two interviews for each school were evaluated. 
First, I considered the data to establish answers to my first research question: what obstacles do administrators and educators face when attempting to implement inclusion approaches in this type of private primary school? Next, the typical implementation practices were determined and evaluated for each school. Then, I compared the two case studies to identify variations in implementation, employing a cross-case analysis to answer the third research question. I used a phenomenological method to categorize important statements, and then gathered these statements into themes (Hayes, 2016). The data from the surveys and follow-up interviews were transcribed and the transcripts read several times as a means of isolating the most important themes in the participants' experiences. As per the process established in earlier research of this type, I "highlighted significant statements, sentences, or quotes" (Hayes, 2016, p. 72).

\section{Discussion of the Findings}

The responses were analyzed and coded into relevant themes. All significant themes were identified and isolated based on the three research questions. First, I read each response carefully, and noted the statements identifying challenges to and processes for implementing the inclusion approach at both schools. Next, I compared these data and drew conclusions to answer the three research questions. I found several themes. Below, I discuss the similarities and differences in the challenges faced by both schools (Case A and Case B), to answer the first research question: What are the challenges to implementing the inclusion approach that are faced by private primary school administrators in Kuwait? 


\section{Similar Challenges Faced by Both Schools' Administrators}

After collecting the data from the surveys and follow-up interviews for both schools, I selected the statements relevant to the challenges faced by school administrators. These included:

1. The principal of the first school, CA (2): "Parental and social issues."

2. CA (3): "Denial and rejection of ... disabilities from [the] parent."

3. CA (6): "Lack of parental involvement."

4. CA (2): "Some parents are shy to admit that their children have learning difficulties."

5. CA (2): "Some other parents are [in] denial [that] their [children are] special [needs students].”

6. CA (4): "Some parents think that schools [should do everything for their children. Basically, they expect so much from [a] school, but a great number of them do not do their part in uplifting their children's condition."

7. CA (8): "Some parents of those students aren't cooperative with the teachers, so the skills that they learn at school [are] not applied at home."

8. CA (2): "[There is] social rejection [of] the inclusion setting. It only attracts parents of LD children, which makes the approach more of an LD school rather than an inclusion school."

9. CA (1): "Negative attitude[s] toward inclusion."

10. CA (2): "Accurate diagnosis is [rarely] available." 11. CA (10): "Language barriers." 
12. CA (1): "The curriculum is way above their level because they are ESL students.”

13. CA (2): "There is social rejection of the inclusion setting; it only attracts parents of LD children, which makes the approach more of an LD school than an inclusion school."

14. CA (1): "The curriculum is way above their level because they are ESL students."

15. CA (5): "Labeling could negatively impact students with learning disabilities."

16. CA (3): "Overloads and extra work for teachers."

17. CA (7): "Teachers have to do a lot of work."

18. CA (2): "There is a lack of specialist teachers."

19. CA (3): "Some teachers don't have enough skill to handle the needs of all learners."

20. CA (3): "Absence of quality training from the governmental sector."

21. CA (9): "Gaps in communication among children in the school."

22. CA (9): "It is very difficult sometimes to get the mainstream students to accept students with learning disabilities."

23. CA (3): "A lot of modifications are needed for the curricula because most students are ESL students."

24. CA (3): "The curricula must be modified to meet the needs of each learner with special needs." 
25. CA (9): "I was expecting behavior problems, which are there."

26. CA (4): "I strongly believe that some students should not be in a bilingual school, learning a second language when they cannot even master their mother tongue."

27. CA (5): "Too often, these students face discrimination and low expectations."

28. CA (8): "There are a high number in mainstream classrooms in the school."

29. CA (8): "Some students are not identified as LD students; they attend mainstream classrooms as normal students because of parental rejection or the lack of assessment."

30. CA (7): "The financial load on school budgets because more teachers and resources are needed."

31. CA (2): "The high cost of school resources and staffing."

32. CA (2) "Some students are not identified as LD students; they attend mainstream classrooms as normal students because of parental rejection or the lack of an assessment."

33. CA (8): "More than one governmental sector is involved in the inclusion process, which makes the process more complex."

34. CA (2): "The school deals with more than one governmental sector to run the system."

35. CA (2): "No clear policy of inclusion for students with learning disabilities."

36. CA (3): "Weak inclusive education policy." 
37. CA (2): "Lack of a specialized governmental system to manage education settings and provide [the] peer services needed."

Next, I selected the significant statements regarding the challenges faced by school administrators in the second school, including:

1. CB (3): "Parents who are in denial about their kids' disabilities and do not offer the necessary support."

2. CB (1): "School members attempt to treat students as equal, but there is no true equal treatment; there have been cases of students moved out of classes, such as special needs or LSU students, because of their families. The school is easily persuaded by families of wealth and importance."

3. CB (7): "It also hurts the school when it comes to discipline; students have been rightfully suspended, but the suspensions are lifted when parents come in and complain.”

4. CB (7): "Parents in this culture do not readily accept that their child has a disability. Therefore, information is often left off of the IEPs that could be helpful in a classroom setting."

5. CB (9): "We mainly try to convince parents that their children may require specialized education.”

6. CB (7): "A true inclusive model would need more personnel to support those students in the mainstream."

7. CB (1): "The students are sent to the psychologist who uses an IQ test that is outdated and inappropriate for students who are second language learners." 
8. CB (2): "They give a few tests using the WJ gathering IQ only, and that's it."

9. CB (5): "Sometimes, the diagnosis for some students is incorrect."

10. CB (3): "We are teaching above the students' level, which only creates a larger gap in the students' learning process."

11. CB (3): "Our curriculum does not allow enough time for weak students to grasp concepts, especially in a class that has more students than there should be."

12. CB (3): "We started using Common Core this year, which has caused many problems and confusion for students."

13. CB (5): "What we are using is not suitable for our students. Therefore, lots of modifications need to be made."

14. CB (8): "Common Core is certainly not the right curriculum for inclusion students. They need intervention curricula."

15. CB (1): "The students are placed in the LSU building, which is a separate building from the mainstream classroom."

16. CB (5): "Sometimes there are problems with students being misdiagnosed. Therefore, they can be mistakenly placed in a setting that doesn't suit their specific needs."

17. CB (1): "The students don't have all the resources needed to maintain growth and support their differences."

18. CB (1): "The label is known among the student body." 
19. CB (1): "A lot of modifications are needed for the curricula because $95 \%$ of the students are non-native English speakers."

20. CB (5): "My school has good curricula but the books used this year are difficult for our students with learning disabilities. A lot of modifications have to be made ...."

21. CB (8): "Each lesson costs a lot of money and some students struggle to pay their tuition. There is no government support for some students so they get left behind."

22. CB (2): "We have a segregated special needs program, with students considered to be SLD, AU, ED, and/or ID. These children attend nothing with the general population. There's another group of kiddos who are supposedly on grade level but a little slower with learning. This is the Learning Support Program (better known as LSU). These kiddos only attend recess and PE together."

23. CB (5): "It is an inclusive environment to a certain extent, because there is a wide variety of students from all walks of life with their own special, specific needs. There is the vocational department, Special Needs Department, Resource Inclusion, LSU, AFL, and ESL, just to name a few. However, our students don't get together with the other students in the many departments available."

24. CB (7): "True inclusion is not practiced in the LSU program. The students receive all of their academics within the LSU classroom and are not included 
with the mainstream, accept during recess and programs such as Awards Day. However, the small group setting in an LSU class helps support positive behavior which, in turn, helps students' grades."

25. CB (9): "At my current school, I like the fact that we have a full-time learning support unit that consists of smaller class sizes, with a full-time homeroom teacher and assistant. This type of learning environment makes teaching and learning more successful, due to the fact that students get more individualized attention, the curriculum is modified according to each child's learning disability, and they're in a setting where all the students need help. It makes the child feel safe and comfortable. We also have a push-in program called Resource Inclusion where specialized teachers come into the mainstream classroom to help students who may not have severe learning disabilities, and therefore do not need the actual curriculum modified, but who may need someone to help them with concentrating, organizing their thoughts, and taking notes."

26. CB (9): "The inclusive program has made a major difference in students' grades, behavior, and overall self-esteem. We have students who were frustrated in the mainstream classes and placed in the LSU units, and their behavior has changed for the better. Students who feel they are active and viable participants in their classes do not have the same problems they had in the mainstream classes before receiving support." 
27. CB (2): "In my school, there are no challenges to implementing inclusion approaches because the inclusion students are in a separate classroom for the whole day.

Six of the above-listed challenges were common to both schools. I coded these into six different themes (see Table 4).

Table 4

Challenges to Implementing Inclusion Common to the Administrators of Both Private Schools

\section{Six Challenges Faced by Both Schools}

Parental issues

Academic barriers

Lack of specialist teachers

Gaps in communication

Modifications and accommodations

Financial issues

Six challenges to implementing the inclusion approach were faced by private school administrators in both schools. These were identified by coding their statements according to the various challenges. Each of these challenges is presented below.

Parental issues. Parental issues were one of the most persistent challenges.

Parents' denial or outright rejection of their children's disabilities, as well as a general lack of parental involvement, were clearly stated as a problem by all of the participants surveyed. Moreover, there was a lack of collaboration between the school and parents because of parents' rejection of their children's needs. It was also clear that no 
collaboration with parents was expected by the majority of participants in the current research. Certainly, collaboration among the school's administration, teachers, and parents is essential to managing students' needs and assisting them on their academic journey, especially when you consider the overarching goal of inclusion (Dymond et al., 2008). Unfortunately, according to the participants, this was not happening. Moreover, there was social rejection of the inclusion setting, which negatively impacted its implementation. For this reason, there would likely be significant benefits to changing social attitudes toward inclusion; this could be accomplished by educating the parents of students with learning disabilities. This goal is attainable if the school offers a socialskills teaching program, a method that has proven to positively impact teachers' outcomes in Turkey (Pinar \& Socuolgu, 2013). Many overseas schools (such as several in Ireland) have seen numerous barriers to the inclusion approach; as seen in this research, the main two are social skills and the interactions between teachers and parents (O’Gorman \& Drudy, 2010).

CB (1) asserted that there was no collaboration with parents, and parents of students with LD did not have sufficient knowledge; this has become an important challenge that needs to be solved. For example, the first participant in Case B, CB (1), stated that "the school is easily persuaded by families of wealth and importance, and they replace their children without accurate knowledge." CB (7) stated that "parents in this culture do not readily accept the fact that their child has a disability," which reflects the rejection of both parents and society. Nevertheless, CB (9) stated that "we ... mainly ... [try] to convince parents that their children may require specialized education.” 
According to Afolabi (2014), without creating a positive parental attitude with regards to special academic services, it is difficult to positively affect the implementation of inclusion. CA (2), who was the principal of the first school, mentioned that family involvement was ineffective because of the rejection of most people in that society. Inclusion can only be appropriately implemented by collaborating with school members and families (Afolabi, 2014; Bossaert et al., 2013; Calculator \& Black, 2009).

I engaged in a follow-up interview with the principal of the first school to clarify this parental issue. CA (2), Ms. Amina, believed that: most parents have suffered [from a] lack of knowledge ... And you go to the parent and you [say] to them, the child has dyslexia or ADHD. Whatever the case, they don't understand the actual case, so they take it as a disease or they take it as a deficit; we need to educate the parents. We are talking here about the knowledge of the case.

Next, I followed-up with Mr. Mac from the first school to better understand his perspective on parental issues. Speaking from his perspective as a teacher, he said that: some of the students don't do their homework. Why? Maybe because the parents don't [know] how to do the homework. Another thing we do for parents ... the parents come to be involved and participate in what the students are doing. For example, on Mother's Day, we ... do an activity ... Or sometimes we do international day, and every class has a song like (inaudible), or whatever we choose, we choose a country where the students 
have to buy the clothes and prepare to represent a certain country. Then the parents will come and see their kids doing it in the auditorium.

The issue of parents' rejection of students' special needs was emphasized by one teacher, who said: "I still remember last year. We had at least one kid who had a problem. We suspected this, so [we] needed to convince the parent ... sometimes the parents refuse to accept that the child has a problem ..."

Academic barriers. According to the participants, academic barriers were a substantial challenge that could hinder implementation of the inclusion approach. Lack of diagnosis and assessment were mentioned by several. According to the literature review, students from diverse backgrounds and special conditions are often understudied and misdiagnosed because of the inherent complexity of their cognitive abilities (Ortiz \& Fránquiz, 2015; Rodríguez, 2016). For this reason, we must investigate ways of shaping bilingual programs, especially with regards to the assessment and diagnosis of students with learning disabilities. Students require crossovers among many stages of measurement in order to be labeled as having a learning disability; however, this is only successful when there is accurate assessment and diagnosis (Bay \& Lopez-Reyna, 1997). CB (2) stated that "the label is known [among] the student body," which means that it could result in problems with adjusting to and becoming positively involved in the school community. Labeling is an important challenge mentioned in the literature review. For example, reducing the practice of labeling students with disabilities is vital to avoiding social rejection (Alkhateeb et al., 2016). Labeling problems are related to 
diagnosis and assessment, which should be accurate but also hidden from the student body (Alansari, 2009).

CA (2) asserted that "accurate diagnosis is partly available." Another participant mentioned that labeling a student as LD could negatively impact that student, which agrees with Bay and Lopez-Reyna's (1997) opinion on the need for multi-stage special needs assessments. For example, Response to Intervention (RTI), a current model, has become an important process for identifying, diagnosing, and assessing students with LD or other difficulties, and providing them with a program that offers practical solutions for mastering the associated challenges (Ochoa et al., 2014). Unfortunately, the assessment and diagnosis systems used in both schools evaluated in the current research depend solely on an IQ test; no other tools were used to identify students with LD. For example, CB (1), a participant at the second school, mentioned that "students are sent to the psychologist, who uses an IQ test that is outdated and inappropriate for students who are second language learners." CB (5) believed that "sometimes, the diagnosis of some students is incorrect."

Another point that should be considered is the curriculum. The majority of the participants mentioned that the various curricula were too advanced for students with learning disabilities. This is especially true since the LD students in both schools were also ESL students, which made their situations more complicated than was normal. This point was a concern of Mohr's (1995), who tried to solve this issue by arguing that teachers and school administrators should identify appropriate instructional accommodations for students with LD that are specific to their needs and abilities. For 
example, providing appropriate seating, time, and opportunities to practice new skills, while also keeping desks free from extraneous materials and allowing adequate space for movement were all recommended for inclusive settings (Mohr, 1995). Another suggestion was modifications that would "alter the work required in some way that makes it different from the work required of other students in the same class or activity" (Bryant et al., 1999, p. 1).

Besides accommodations, teachers in inclusive classrooms should modify tests, materials, assignments, and attendance to meet students' needs (Morningstar, Shogren, Lee, \& Born, 2015). Eventually, if a student is protected by IDEA, teachers and IEP team members must provide modified lesson plans for students with special needs, changing the materials, reducing the amount of information on tests, and adjusting assessment procedures such as by giving an oral rather than a written exam (Yell, 2016). Modifying the materials and overall curricula are essential to the proper implementation of the inclusion approach.

I also followed up with the principal of the first school to clarify their diagnosis and assessment issues. She explained that "accurate diagnosis of LD students is barely available, ... I meant that the child ... diagnose[d] as LD and refer[d] to us [is often] misdiagnosed from the governmental sector of the assessment. And when the child starts the school, and [is] misdiagnosed, we don't know what we do."

Professional testing is more complicated than IQ testing. Both Kuwaiti and American schools struggle to accurately assess students (Almoosa et al., 2012). However, American schools are doing better with assessment and identification because 
they employ the RTI model (Lembke, Hampton, \& Beyers, 2012). Meanwhile, Kuwaiti schools use discrepancies between IQ scores and students' actual achievement, which encourages schools to wait too long to assist students and ultimately leads to failed diagnoses (Alansari, 2009). Alansari (2009) emphasized that using the RTI model provides accurate diagnoses and appropriate instruction to students with disabilities in an inclusive setting. A third policy encourages providing educational services and effective teaching by qualified teachers. Yet both Kuwaiti and American schools have faced serious challenges in this area.

Lack of specialist teachers. Statements gathered from the survey indicated that many teachers don't have the skills necessary to handle the needs of all learners; this means that there is insufficient quality training from the governmental sectors administering both schools. Regular and special teachers must be trained to recognize the characteristics of students with learning disabilities and ways of teaching them effectively (Abu-Heran et al., 2014; Pinar \& Sucuoglu, 2013). This challenge was also referenced in the literature review; scholars asserted that general education teachers should be trained to handle the diversity seen in inclusive schools (Abu-Heran et al., 2014; Agbenyega \& Klibthong, 2014; Ajodhia-Andrews \& Frankel, 2010; Duchaine et al., 2011). The principal and one teacher at the first school observed an immediate need for specialist teachers to practice inclusion practices; however, the school could not handle the cost of such training without extra support.

A lack of specialist teachers certainly hinders implementation of the inclusion approach. Pasha (2012) indicated that there is a lack of professional development for 
teachers and administrators, which damages the effectiveness of inclusive practices in Pakistan; the same challenge was seen in both of the schools analyzed in the present research. Two other scholars supported this assertion, noting that the lack of specialist teachers could negatively impact the implementation of inclusion (O'Gorman \& Drudy, 2010; Vorapanya \& Dunlap, 2014). According to Rodriguez (2016), it is beneficial to regard bilingual teacher preparation as a fundamental means of assisting and supporting ELL students. Teachers' skills have a major impact on students' achievement (Wang \& Woolf, 2016). Consequently, this research highlights teacher preparation in the area of bilingual special education. The lack of proper teacher preparation is apparent not just in the persistence of this issue, but also in the number of English language learners that can be seen in the case study schools; this reflects the situation in the U.S., a country that has seen a dramatic increase in this area in recent years (Samson \& Collins, 2012; Wang \& Woolf, 2016).

Wang and Woolf (2016) also argued that there is a lack of specialist teachers, as have other scholars. For example, the public-school system is quite large, and studies have shown that the student population requiring specialist teachers has increased by $64 \%$ over the past 15 years. Students with special needs are growing significantly, alongside increases in the number of students registered in school (More, Spies, Morgan, \& Baker, 2015; Samson \& Collins, 2012; Wang \& Woolf, 2016). Normal teachers face many challenges when attempting to teach students with special needs in a general classroom. Unfortunately, there is no effective, academically collaborative bridge 
between normal and specialist teachers, which makes it even more difficult for normal educators in an inclusive environment (Brownell et al., 2010).

If the goal is to create an effective means of preparing teachers to handle students with special needs in regular classrooms, teachers must obtain teaching certifications from respected university programs and diverse experience with special needs students (Cochran-Smith \& Dudley-Marling, 2012). Unfortunately, the field of special education suffers from serious attrition because of the challenges faced by special education. There is a lack of intensive preparation for new teachers, as well as disadvantages to teaching students with special needs. Teachers must expend significant effort every day to enhance students' skills and normal teachers tend to be uncooperative (Brownell et al., 2004). These conditions were visible in both private schools evaluated in this research.

Preparing student teachers to a high level of quality is a lofty ambition; there is a significant gap between research and practice. Scholars must analyze and interpret the outcomes of special education teacher programs to fill this gap and improve upon the current situation (Brownell, 2002). In the end, it is imperative to underscore the challenges faced and make urgent strides toward reform so that teachers can be equipped, outfitted, and prepared to provide special needs students with the opportunity to be educated in a general education atmosphere (Zigmond et al., 2009). "Teachers must be prepared to utilize practices that are informed by prevailing scholarship and the professional standards that distinguish their respective specialty professions" (Wang \& Woolf, 2016, p. 37). It was also found that teachers in Kuwait suffer from a lack of professionalism in teaching, which demands that teacher preparation programs be 
reevaluated and reformed. Student teachers cannot develop effective education practices without quality preparation (AlMoussawi \& Omran, 2015).

This was reflected in both the general situation in Kuwaiti schools and the private schools evaluated in this study. Sadly, many educators and leaders described weaknesses in special education programs, a condition that threatens the future of Kuwait (AlMoussawi \& Omran, 2015). The Ministry of Education must provide educational and professional testing and certification to accurately assess students and serve those with disabilities (GCC, 2010). Even though the evaluation, identification, and intervention methods were found to be inaccurate, the positive impact was well-defined. Legislation was successfully passed in the same year that 300 specialists were trained to integrate disabled students into inclusive schools in Kuwait (Sabbagh, 2010). Yet this is not enough to service all of the inclusive schools in Kuwait, an assertion that is supported by the results of the survey distributed for this study.

Gaps in communication. The survey indicated that it could be very challenging to get mainstream students to accept students with learning disabilities. Also, CB (5) described lack of communication among students in different departments as an issue in the second school:

It is an inclusive environment to a certain extent because there is a wide variety of students from all walks of life with their own special, specific needs. There is the vocational department, Special Needs Department, Resource Inclusion, LSU, AFL, [and] ESL, just to name a few. However, our 
students don't get together with the other students in the many departments available.

This issue was also addressed by Salvador (2013), who emphasized that to have an effective inclusion atmosphere, schools must focus on two key elements:

communication and partnership. These ensure operational activities in the classroom. Unfortunately, these points were not addressed in the first inclusive private school analyzed in this research. Dallas et al. (2015) asserted that the involvement of the family is key to educating students, particularly those with learning disabilities, because it helps to create a suitable education community. Many scholars expressed a similar perspective, stating that the lack of communication among students hindered the progress of students with disabilities. They suggested schools encourage social interaction in conjunction with academic activities to enhance students' social skills and academic achievement (Bossaert et al., 2013; Coates \& Vickerman, 2008; Qi \& Ha, 2012; Reganick, 1995; Wang \& Reynolds, 1997).

This is an essential point; it is recommended that schools utilize effective communication techniques and strive to maintain connections between family and school administrators (Freire, 2012). School leaders should form positive relationships with families and strive to understand their activities, level of knowledge, living conditions, language, religion, and background (Freire, 2012). Simply stated, leaders must be great listeners; they must put forth the effort to visit with families at home (Freire, 2012). This will establish solid communication channels between students and 
teachers. Understanding students' backgrounds will help schools become valued members of the community (Freire, 2012; Weber \& City, 2012).

Modification and accommodation matters. Modifications are necessary to ESL students' success. In fact, the majority of students in both schools evaluated in this research were ESL. Both of the principals and many of the participants mentioned that the curricula should be modified for ESL students, in order to best meet their needs and provide specific support; however, ESL students should be exposed to the same concepts as general education students. This will allow all students to progress on the same level. This point was also made by CA (3), who declared that "curricula must be modified to meet the needs of each learner with special needs." Also, many of the participants asserted that the curricula are not suitable for students with LD; many modifications must be made. In fact, $95 \%$ of the students in these schools were ESL, which means that nearly all of the students were non-native English speakers. Another respondent believed that their school's curriculum was sound, but the books used were too difficult for students with LD.

Mohr (1995) made similar assertions, arguing that students with disabilities are diverse, and each has a particular learning style. This requires teachers in inclusive schools to alter their teaching approaches to match individual needs and modify books to fit each student. Certainly, learning style is one of the most significant points of accommodation for students with disabilities. Therefore, teachers should be willing to adapt and adjust their teaching approaches and tactics to assist students with disabilities in their classrooms. Providing appropriate seating, time, and practice opportunities, 
keeping desks free from extraneous materials, and providing adequate space for movement are all improvements recommended for inclusive settings. Sometimes it may be challenging for teachers to provide appropriate accommodations and modifications because of a lack of knowledge or experience, which is why the right teacher preparation is essential (Bryant et al., 1999).

Providing accommodations for individuals in American schools is required under Section 504 of the IDEA. Schools must accommodate students with special needs who face learning barriers (Yell, 2016). However, besides accommodations, inclusive classroom teachers must modify tests, materials, assignments, and attendance requirements according to their students' needs (Morningstar et al., 2015). Eventually, if a student is protected by the IDEA, teachers and the IEP team must provide modified lesson plans (Yell, 2016), change the student's required materials, reduce the amount of information included on tests, and modify the assessment procedure (for example, by giving an oral rather than a written exam; Morningstar et al., 2015).

Many studies in Kuwait and in an international context have recommended that modifying instructions and assignments is critical to students' success, along with concrete classroom demonstrations, careful monitoring of and adjustment to the pace, individual feedback, and the administration of multiple teaching modalities (AlHilawani, Koch, \& Braaten, 2008). Breaking tasks into small steps, shortening assignments, and lowering the difficulty level are all important techniques for use with slow learners (Al-Hilawani et al., 2008). In the United States, schools provide many of these accommodations and modifications to help students with special needs adjust to 
their classes. They have been successful in enhancing students' academic level in inclusive environments. In short, expanding scheduling, providing an appropriate setting and quality specialized materials, and reducing the number of materials and level of exam difficulty will all make a difference in students' level of achievement (NICHCY, 2016).

Financial issues. The financial demands of inclusion are a heavy burden on school budgets, since more teachers and other resources are needed than for regular education alone; schools cannot handle students with learning disabilities without adequate funds from the government. For example, one participant mentioned in the follow-up interview that "a non-Kuwaiti student is hard to reach [through] the inclusion service, because the cost is high and the government will not fund non-Kuwaiti students." To receive the services they need, they must pay a lot of money or the school musts help them with their tuition. One participant in the survey mentioned that the cost was very high for the services offered through the inclusion approach. The principal of the first school stated that the "high cost of school resources ... and ... staffing" were substantial and difficult to meet. This point is reflected in Ahmmed and Mullick (2014) who argued that there was a lack of commitment to support admissions policies, and this included financial assistance. The financial load on school budgets has become a serious challenge; as more teachers and resources are needed, school administrators struggle to cover the cost and build an inclusive environment. Also, each lesson costs a significant amount of money, and some students struggle to pay their tuition. This was the case in 
both schools evaluated for this research. Such conditions have led schools to provide inclusion services for some students out of their general budgets.

CB (4) stated that there was "no governmental financial support for some students, who [thus get] left behind." This issue was also addressed by Wang and Reynolds (1997), who asserted that financial issues negatively impacted the implementation of the inclusion approach, a situation that should be considered by scholars and policymakers (Alquraini \& Gut, 2012; Dallas et al., 2015; Wang \& Reynolds, 1997). Another financial problem was discussed by Wang and Reynolds (1997); if schools are not equipped for inclusion, students will have academic problems that will hinder their success. Many schools are not equipped to deal with all students, and especially students with disabilities. Wang and Reynolds argued that the impact of implementing the inclusion approach was slight in some inclusive schools because financial issues prevented them from reaching their full potential.

Three themes were coded for each school to reflect differences in the challenges they faced in implementing inclusion (see Figure 5). 


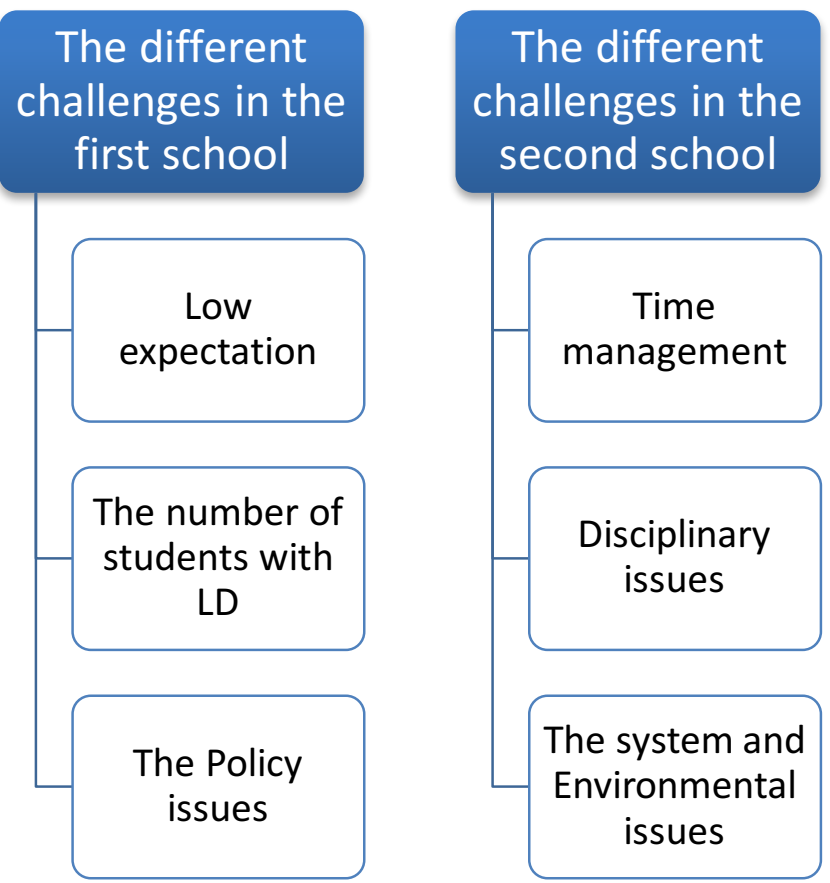

Figure 5. Differences in the challenges faced by two private schools implementing inclusion.

\section{Case A}

Low expectations. Three of the participants' comments supported the idea that low expectations for students with learning disabilities decreased the likelihood of a successful program. The most robust statement to this effect was: "I strongly believe that some students should not be in a bilingual school learning a second language when they cannot even master their mother tongue." Another assertion regarding low expectations was: "too often these students face discrimination and low expectations." According to Rubie-Davies (2007), students' performances will be either negatively or positively affected by teachers' practices. When teachers have low expectations, they use practices that do not challenge minority students; this robs them of the chance to grow and 
contributes greatly to adverse performances. Many students are failed by their parents' expectations or those of their teachers and principals.

Demanet and Van Houtte (2012) explained that when teachers' expectations are low, they expend less effort and time on students; this is reflected in gaps in student achievement. Students' isolation and limits on their participation and engagement eventually lead to fewer opportunities to learn. There is solid evidence of a robust relationship between aspirations and occupational outcomes. Many students of color have been affected negatively by teachers' treatment; their teachers' low expectations are reflected in their teaching practices (Boykin \& Noguera, 2011). Students are positively or negatively impacted by their teachers' behavior. Several studies have found that teachers' practices reflect their beliefs and expectations (Demanet \& Van Houtte, 2012; Simmons et al., 1999). Fostering high expectations for success is one of the most important components in motivating students to achieve their goals (Boykin \& Noguera, 2011). In shaping a new vision and creating an inclusive climate, schools will enhance student performance, creating opportunities to learn and effectively closing the achievement gap (Boykin \& Noguera, 2011; Brown \& Medway, 2007). In 2012, Morales affirmed that when a principal is able to reach out to educators and encourage them to increase their expectations for students, schools see an improvement in all of their students' outcomes. Sufficient educational leadership is a fundamental part of successful schools (Smith, 2013).

The number of students with LD in mainstream classrooms. The number of students in mainstream classrooms was high in this school, making the environment 
unsuitable for students with LD. Also, teachers faced difficulties in following the learning styles of their students and using essential technology and strategies. Some students with learning disabilities were not identified as LD, which made teaching difficult. The principal of the first school faced this issue when she tried to close the achievement gap between normal students and students with LD. She found she couldn't because of the high number of students in mainstream classrooms that had been misdiagnosed by the governmental sector. Even when a principal might attempt to change the number of the students in a mainstream classroom, school budgets often don't have the money to change the number of students in the classroom without governmental support.

Another factor is that parental denial has caused an increasing number of LD students to be placed in classrooms with their non-LD peers without their being identified as LD. This negatively impacts students' progress and risks a high number of students with LD being placed in the same classroom. This is a significant barrier to implementing the inclusion approach at many schools. The majority of participants from the first school believed that having small classes for students with learning disabilities would be the best way to focus on their differences and unique needs. In Finland, small classes were found to be a supportive atmosphere for students with special needs (Takala et al., 2009). It is believed that educating students in small groups and fostering collaboration is fundamental to providing accommodations that positively impact students' achievement (Bryant et al., 1999; Mohr, 1995). Many academic challenges occur because of class size. Large classes negatively affect students' attention and 
perceptions (Ahmmed \& Mullick, 2014; Deng \& Holdsworth, 2007). Small groups support students with learning disabilities. Ahmmed and Mullick claimed that small mainstream classrooms would significantly affect academic progress and behavior because they provide students with the assistance appropriate to their backgrounds and abilities.

The policy issue. Guidelines for the inclusion approach should be revised to facilitate a more accurate implementation of inclusive practices. More than one governmental sector is involved in the inclusion process, which makes its implementation complex; this position was expressed by the principal of the first school. This principal also believed that there is no clear policy for inclusion of students with LD; school administrators follow the normal policy for all students. Moreover, there was a lack of specialized governmental assistance in managing this unique educational setting; this position is reflected in the works of several scholars (Ahmmed \& Mullick, 2014; Deng \& Holdsworth, 2007; Pasha, 2012; Vorapanya \& Dunlap, 2014) who emphasized a lack of commitment and support for admissions policies. These have become formidable challenges to implementing inclusion (Ahmmed \& Mullick, 2014; Deng \& Holdsworth, 2007; Pasha, 2012; Vorapanya \& Dunlap, 2014).

Policymakers must coordinate their efforts to serve students with disabilities in inclusive schools (Zigmond et al., 2009), but the essential requirements for implementing inclusion are not currently properly identified by policymakers (Kauffman et al., 1995). There must clear policies and regulation to guide inclusive schools seeking to implement inclusion. Regulation \# 8, which passed in 2010 in Kuwait, forces schools 
to make a space for students to participate together in academic life, without discrimination. This point was discussed by Guernsey, Nicoli, and Ninio (2007), who argued for all students to have the opportunity to access general tertiary education on an equal basis.

\section{Case B}

Time management. CB (3) and CB (5) both asserted that the curriculum was too advanced for LD students. It did not allow weak students enough time to grasp complicated concepts, especially in overcrowded mainstream classrooms. Many scholars have confirmed this belief, and recommended that school administrators offer task management courses to teachers to help them better manage their time and organize their classrooms (Abu-Heran et al., 2014; Mikami et al., 2013; Sucuoglu et al., 2010; Takala et al., 2009). Abu-Heran (2014) argued that it was essential to use proper classroom management methods to establish a suitable environment and offer enough time and resources to students with special needs. Timing the work is essential to making progress in both teaching and learning. Time management skills help teachers to manage their students' time, especially those struggling with academic tasks (Takala et al., 2009). Even when a child has a significant disability, time and energy should be focused on promoting their abilities (Grant \& Ray, 2016). Schools should manage students' tasks in ways appropriate to their background, knowledge level, and abilities, (Grant \& Ray, 2016; Mikami et al., 2013). As the participants in this study explained, limitations on time have hindered students' progress. 
Disciplinary issues. CB 1 and CB 5 indicated that there was no strong policy for discipline in the school, and as a result the school suffered. In fact, some students had rightfully been suspended, but the suspensions were lifted when parents complained. This issue was a serious challenge to implementing inclusion. Yell (2016) believed that without creating a positive climate and protecting students from violent behavior, schools cannot be secure and thus will violate Regulation 504 of the IDEA. Ensuring fairness and equity for students with special needs should be the mission of school administrators. Making significant academic and behavioral progress is required by law; IEPs must be filed for each special needs student, for their protection (Yell, 2016).

The system. The school system has become a point of conflict for the principal and teachers at the second school. Some of the participants agreed with the system allowing LD students to participate in mainstream classrooms. Conversely, the principal and some of the other participants believed that a full-time LSU program should be implemented according to the students' needs; ideally, students with LD would be taught separately in small groups. This would mean that the LSU program would not be inclusive. CB (7) stated that although the LSU program engages students with LD in some social activities, it does not represent true inclusion. The LD students received all of their academic training in LSU classrooms and were not included in the mainstream accept during recess and programs such as Awards Day. CB (7) also believed that the small group setting would help support positive behavior, and in turn would improve students' grades. Significantly, the principal of the second school, CB (9), stated: 
At my current school, I like the fact that we have a full-time learning support unit that consists of smaller class sizes, up to 10 students, maximum, with a full-time homeroom teacher and assistant. This type of learning environment makes teaching and learning more successful because students get more individualized attention; the curriculum is modified according to each child's learning disability and being in a setting where all the students need help, it makes the child feel safe and comfortable. We also have a push-in a program called Resource Inclusion where specialized teachers come into the mainstream classroom to help students who may not have severe learning disabilities and therefore do not need the actual curriculum modified, but who may need someone to help them with concentrating, organizing their thoughts, and taking notes.

The principal went on to say that:

the inclusive program has made a major difference in student grades, behavior, and overall self-esteem. We have students who were frustrated in the mainstream classes and had been placed in the LSU units, and their behaviors have changed for the better. Students who feel they are an active and viable participant in their classes do not have the same problems they had in the mainstream classes before receiving support.

The principal mentioned that implementing the full inclusion approach for some students was particularly difficult, and students could become frustrated in mainstream classrooms. For this reason, those students were placed in the LSU program to enhance 
their academic success; teachers were able to adapt to their learning styles, backgrounds, and abilities. Conversely, one teacher believed that some students placed in the LSU program could succeed in an inclusion setting. Consequently, there is no unified team that can connect the two programs; this negatively impacts the inclusion approach by segregating students with LD in the LSU program. This point was discussed by much of the research in the literature review. Many scholars have agreed that the inclusion approach should be implemented for all students, especially those who have LD. Others have argued for special classes for students with LD to better address their different needs.

For example, Fuchs and Fuchs (1994) argued that the inclusion approach inspires teachers, leaders, and parents to work together to treat all students equally and focus on their unique abilities. Inclusion has been more efficient than other special education approaches, such as providing special education services in segregated classrooms (Fuchs \& Fuchs, 1994; Tremblay, 2013). Supporters of inclusion believe that it is the best way to involve students with disabilities in a school setting, so long as effective teaching and services are available (Fuchs \& Fuchs, 1994; Kelly et al., 2014; Wong et al., 2015). A number of scholars asserted that students with special needs are best served when they participate in general schools alongside non-disabled students; such experiences better prepare students for the future (Erwin, 1993). It has been argued that it is unreasonable to isolate students with disabilities to provide for their needs (Coates \& Vickerman, 2008; Rose et al., 2010; Wang \& Reynolds, 1997). 
Opponents of inclusion, however, think that "regular education could not address the needs of many students with mild disabilities without the instruction, support, and accommodations provided through special education” (Hagan-Burke \& Jefferson, 2002, p. 113). The absence of suitable curricula, tools, learning environments, and qualified teachers are serious obstacles to implementing inclusion (Zigmond et al., 2009). Will (1986) argued that the best and most effective education for all children is not provided in a general educational setting that does not reflect the tenets of inclusion. Negative cases were presented from many schools across the United States where insufficient training for teachers, inappropriate resources, and unsuitable materials were being used (Kauffman et al., 1995).

As mentioned above, Kuwait is a member of the GCC, which requires full inclusion for students with disabilities (Crabtree \& Williams, 2013). However, member countries have found it difficult to properly implement inclusion; as a result, inclusion has become a controversial topic (Ministry of Education in the State of Kuwait, 2008). Kuwaiti schools tend to resist integrating students with disabilities because they are unprepared. This is also evident in UAE schools, which have been described as the least accepting of integrating students with intellectual disabilities into general education classrooms. Sadly, “until recently, children with Down's Syndrome were known as Mongols in UAE" (Weber \& City, 2012, p. 93). Conversely, Almotairi (2013) has argued that Kuwaiti educators have a positive attitude towards inclusion, and they are encouraged to teach students with disabilities in inclusive settings. Kuwaiti governors have supported full inclusion in school settings, establishing a new regulation that 
describes inclusive education opportunities as one of the most indispensable rights of students with special needs (Alfares, 2014). Yet while including students with special needs in inclusive classrooms is now required in Kuwait, Weber and City (2012) stated that there is no evidence that inclusion has increased students' achievements; this is also reflected in Kauffman et al. (1995).

While the debate regarding, its utility continues, the fact remains that Kuwaiti schools are not prepared to receive and educate students with special needs (Almoosa et al., 2012; Weber \& City, 2012). Kuwait has failed to implement inclusion (Weber \& City, 2012) because of the uncertain vision, inadequate resources, and lack of professional training available to educators (Al-Manabri et al., 2013; Ministry of Education in the State of Kuwait, 2008). Kuwait has had troubles similar to those seen in the United States, which is a reflection of the obstacles of inclusion on a global scale.

To clarify school administrators' opinions on the systemic issues hindering the implementation of exclusion, I followed up with one of the principals of the two schools analyzed in this research. She said:

Let's say they have hyperactivity. Let's say they are overstimulated by having 25 other kids in the classroom or 24 other kids, so because of that, we want to make sure all of our students are successful; so we place them in a smaller classroom setting. However, they are still following the same curriculum. They're still following, they are under the mainstream, they are under my supervision, because here we have a different unit. It's called special needs, and they are not included in our model. So, if we have a child who has an IQ 
of 70 or below, we refer them to the special needs. Our kids in the LSU program, they are basically the same. Of course, the teachers that we hire are trained in how to use different strategies for different modalities of learning. Some of them are marked in aesthetics, some of them are auditory, [and] some of them are more visual, but they have the same schedule.

The challenges that face schools when they implement the inclusion approach are easiest to overcome when there are other, alternative paths to treating students with LD that are appropriate to their needs.

\section{Differences in Inclusion Practices}

Above, I have addressed similarities in the inclusion practices of the administrators, teachers, and counselors in the schools analyzed for this research. Next, I will present differences in their implementation practices, in order to answer the second and third research questions: In what ways are inclusion practices implemented by administrators, teachers, and counselors in private schools in Kuwait? What are the differences in the implementation practices of inclusion between the two private schools analyzed here?

After collecting the data from the surveys and follow-up interviews for both schools, I selected the statements relevant to the inclusion practices. The significant statements in Case A were as follows:

1. CA (9): "In some cases, using collaborative learning helps both kinds of students a lot.” 
2. CA (9): "A cooperative approach, along with a creative teaching style; however, the creative teaching style ... isn't always happening depending on the teacher."

3. CA (9): "The classes are supposed to be taught with multi[ple] methodologies and style[s]."

4. CA (8): "Differentiation in teaching methods."

5. CA (7): "Differentiation [in] curricula, worksheets, exams, [and] instructions, so that each student can achieve the needed goal according to his/her potential and abilities."

6. CA (9): "Building relationships and collaboration between teachers and a benevolent counseling department, physiotherapy, speech therapy, and occupational therapy."

7. CA (2): "Practicing [a] highly effective discipline management system."

8. CA (2): "Engaging students with learning disabilities in several activities such as Sports Day.”

9. CA (1): "The school offers 10 Professional Days in the beginning of [the] school year."

10. CA (8): "Immediate short assessment and long assessment for all students with learning disabilities."

11. CA (8): "Highly effective discipline management system in the school."

12. CA (8): "Small group of LD students in a class for the intervention." 
Next are the statements relevant to inclusion practices implemented by administrators, teachers, and counselors in Case B:

1. CB (1): "In the beginning of the year, there was a professional development [program] on how to implement the new curriculum and textbook. The professional development was also [on] teaching students and making sure they are successful in a concept before moving on."

2. CB (1): "Immediate short assessment and long assessment for all students with learning disabilities."

3. Ms. Hiba: "The school always educates us on the latest technology that can be used and most recent methods and techniques in teaching students with learning disabilities. Students learn in different ways and at a different pace. Therefore, PD is provided to improve on our skills and techniques of delivering information and general knowledge to students."

4. CB (9): "Knowing that the majority of our students are non-native English Language Learners ... we make it a priority to make the curriculum accessible to all of the students. In addition to this, we make special modifications and a slower pacing for our inclusion students."

5. CB (9): "The resources and ... technology [are] available for all students equitably, [especially] for those with learning disabilities."

6. CB (5): "Small group of LD students in a class for the intervention."

7. CB (5): "Creating [an] IEP for each child."

8. CB (1): "Multi[ple] learning styles are used." 
9. CB (5): "Different techniques and strategies are used to accommodate each student's needs, depending on their learning style. Some students are visual, auditory, kinesthetic, logical, social, solitary, artistic, verbal ... etc.”

10. CB (8): "Implementing differentiation in classrooms."

11. CB (9): "Teachers are trained to differentiate their teaching methods. Individualized Education Plans are set for any child receiving modifications or accommodations in their learning, and efforts are made to cater to the different modalities of learning [such as] visual, kinesthetic, audio, etc."

12. CB (3): "Students are able to interact with others, be it mainstream or special needs, at break times, as well as [on] field trips. All students from the same grade level share the same break times in the same space, which allows them to be included and communicate with students of different abilities."

13. CB (6): “Anti-bullying sessions are given, implanting group work and peer teaching, [as well as] monthly awards for achievements and behavior [and] end of the year awards and medals enhancing sport activities."

14. CB (8): "Commendation and modification for helping and supporting students with learning disabilities to reach ... equity in the school."

Four practices were identified as similar to both private schools in Kuwait. I coded them as four different themes (see Table 5). 
Table 5

Inclusion Practices Similar to Both Schools

\begin{tabular}{ll}
\hline & Four Inclusion Practices \\
\hline Learning style & \\
Collaboration & \\
Communication & \\
Preparation & \\
\hline
\end{tabular}

These four practices are explained below.

Learning style. According to participants from both schools, each special need student must have an IEP plan; multiple teaching styles were used for students with learning disabilities in an effort to enhance their academic achievement. Teachers agreed that students' needs could differ greatly and required appropriate curricula, exams, worksheets, and further instruction. These multiple learning styles could be achieved when teachers received proper training. When such training was received, teachers exhibited increasingly positive attitudes towards inclusion (Alkhateeb et al., 2016; Calculator \& Black, 2009).

The majority of participants from both private schools asserted that school practices included considering the learning style of each child and differentiating teaching techniques for students with learning disabilities. Teachers were provided with a learning styles checklist to help them understand students' differences, and help them select the best technical teaching mechanisms. Also, courses were offered at the beginning of the school year that helped develop teachers' skills in a variety of LD teaching methodologies. Matching techniques to individual needs is essential for 
students with LD, especially in inclusive classrooms. Understanding each student's learning style helps teachers assist students with LD, according to their individual needs (Mohr, 1995). Reid, Lienemann, and Hagaman (2013) also argued that although offering strategies and resources to students with LD can be difficult, it is key to students' success. Teachers from both schools agreed on the importance of a suitable learning environment, as well as addressing students' beliefs, finding ways to motivate their academic pursuits, and appropriate teaching methods.

Collaboration. The majority of the participants from both schools emphasized that collaboration was a vital element of inclusive education. Both principals encouraged teachers and staff to work together as a team, and share information and experiences with love and respect. Most of the participants believed that collaboration among teachers and physio, speech, and occupational therapists was essential. The principals both strove to encourage teamwork to reach the schools' academic goals (O'Gorman \& Drudy, 2010). Disconnection between general education and specialist teachers can often lead to detrimental outcomes (Gustavsen \& De Silva, 2013; O'Gorman \& Drudy, 2010). The principal in the second school (Case B) stated: "my primary goal is to encourage teamwork among all staff members, with the focus of the child's best interest in mind;" this reflected O'Gorman and Drudy's argument (2010). One teacher stated that "teachers are encouraged to meet and discuss the needs of students." Specialist teachers collaborate with mainstream educators to reach those who need help.

Communication. Many of the participants explained that school colleagues engage students with learning disabilities during activities such as Sports Day, National 
Day, and Mother's Day. Such interaction is one of the most important ways of forming new relationships with other students and learning to communicate with peers (Boykin \& Noguera, 2011). For this reason, both schools focused on social activities as a way of building proper lines of communication. Research has revealed strong evidence that greater engagement leads to improved rates of success (Nieto, 2015). It is essential, however, for schools to also implement efficient communication channels among students, teachers, and parents (Valencia, 2015). CB (3) stated: "students could interact with other mainstream [students] at break times, as well as [on] field trips." Finally, both schools adjusted the schedules of students with learning disabilities to overlap with normal students' break times; events were held in the same space, which allowed them to be included and gave them opportunities to communicate with students of different abilities.

Preparation. Professional development was offered to the teachers, counselors, and staff at both schools. At the beginning of the school year, both schools offered ten professional days to prepare educators to implement different strategies and properly assist their students. Both school principals sought out technology and other resources to assist with students' learning. CA (8) indicated: "the resources and the technology are available for all students equitably, particularly for those with learning disabilities." Furthermore, immediate short and long assessments were available for all students with learning disabilities, which is another essential tool (Abu-Heran et al., 2014). Finally, $\mathrm{CB}$ (1) and CA (8) both explained that professional development classes on how to implement new curricula and textbooks were offered by the school administration at the 
beginning of the year. Such professional development was essential to helping teachers teach students and make sure they understood a concept before moving on.

In both schools, teachers were offered professional development classes in different types of instruction, access to educational technology and software, and workshops on new curricula. The current year's professional development focused on resources for encouraging student participation and helping young learners develop the skills needed for success in a classroom setting. The principal of the second school explained: "the curriculum is accessible to everyone in our school; knowing that the majority of our students are non-native English Language Learners ... we make it a priority to make the curriculum accessible to all of the students." Both schools' administrators made special modifications to their respective curricula and exams for students with LD. As mentioned above, technology was also available to all students, and particularly those with learning disabilities. Improving the quality of education in inclusive schools and offering enough support, a suitable environment, and access to all necessary services (such as technology) is mandatory for properly educating students with special needs (Abu-Heran et al., 2014; Dymond et al., 2008; Melekoglu, 2014); this was reflected in both schools' preparation for the new school year.

Next, I compare the two case studies to identify differences in their implementation of the inclusion approach (see Figure 6). 


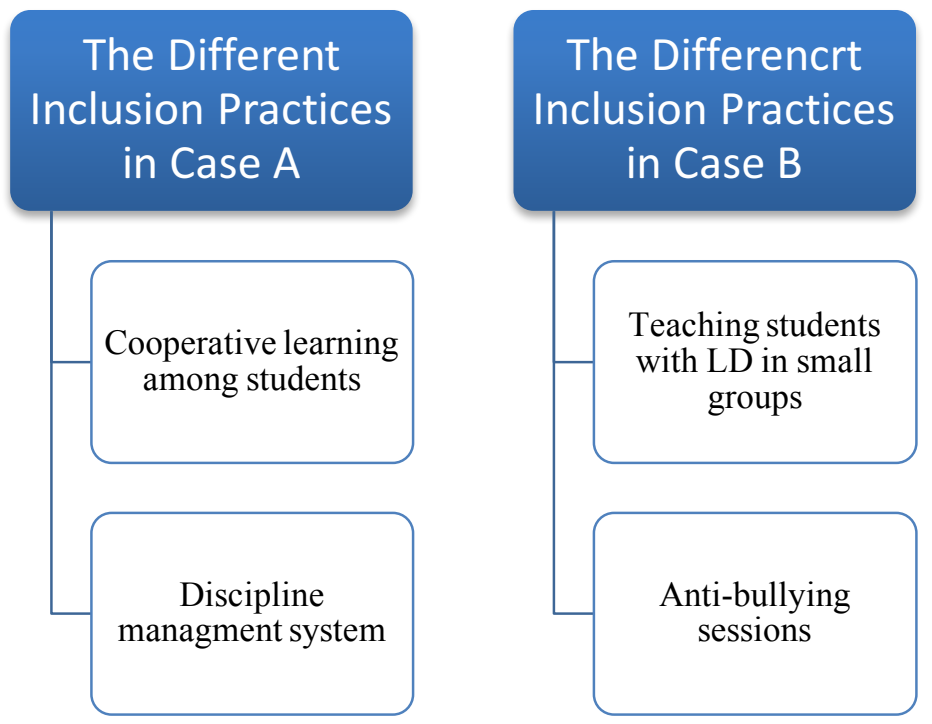

Figure 6. Differences in inclusion implementation in both private schools.

\section{Case A}

Cooperative learning among students. Cooperative learning is an essential practice that supports students in their academic pursuits (Qi \& Ha, 2012). Cooperative learning was practiced in the first school (Case A). Most of the participants believed that using collaborative learning helped students with learning disabilities as well as normal students; this belief was reflected in remarks made by CA (2), CA (4), and CA (8). CA (9) affirmed that a cooperative approach was a creative teaching style used by the school; however, whether a particular student was exposed to it depended on the teacher. It has been argued that using a cooperative learning strategy is essential for students with special needs (Calculator \& Black, 2009; Qi \& Ha, 2012; Reyes, 2013). The practice leads to a more inclusive environment and diversified educational practices; the result is a cooperative learning environment that is especially useful for students with disabilities (Scott et al., 1998). Although cooperative learning and successful collaboration among 
the administration, educators, and parents are key to providing appropriate services to students with disabilities and enhancing students' academic achievement (Alquraini \& Gut, 2012), the principal of the first school and CA (1) found it difficult for the school to connect and collaborate with parents to improve students' knowledge, experience, and skills. Unfortunately, the majority of participants believed that parents of students with LD were unwilling or unable to collaborate with the school.

Discipline management system. Discipline management was practiced by the first private school in this study. The principal declared that the goal of discipline management is "to protect both normal students and students with LD by following [a] clear discipline system and guidelines, which have to be active in the school." According to most of the participants from the first school, a strict "discipline management system was followed in their school to change and develop students' behaviors." CA (2) stated that following a "highly effective discipline management system is essential in our school." It could positively impact their interactions and students' engagement. Yell (2016) argued that discipline protected both regular students and students with learning disabilities; according to the Texas disciplinary system, schools must offer a positive climate and environment and develop clear, appropriate, and consistent expectations. A school must identify disruptive student behavior and ensure an equal opportunity to make significant academic progress. According to the majority of participants from the first school, these goals ensured an inclusive environment for all. Without creating a positive climate and protecting students from violent behaviors, schools cannot be considered secure and that would violate the IDEA and Regulation 504 (Yell, 2016). 
Ensuring fairness and equity for students with special needs was the mission of the school administrators and staff (Yell, 2016). CA (9) explained: "I was expecting behavior problems, which are there; however, the school has followed a good discipline management [program] to change students' behavior."

\section{Case B}

Teaching LD students in small groups. Many of the participants claimed that they taught students with learning disabilities in small groups. One stated that efforts to educate students with learning disabilities and solve their behavioral problems were most effective in small groups, such as when they are gathered in resource rooms for mandatory lessons. For example, CB (7) said that:

true inclusion is not practiced in the LSU program. The students receive all of their academics within the LSU classroom and are not included with the mainstream, accept during recess and programs such as Awards Day; however, the small group setting in an LSU class helps support positive behavior which, in turn, helps student grades.

CB (9), who is the principal of the second school, explained:

At my current school, I like the fact that we have a full-time learning support unit which consists of smaller class sizes, with a full-time homeroom teacher and assistant. This type of learning environment makes teaching and learning more successful, due to the fact that students get more individualized attention, the curriculum is modified according to each child's learning disability, and being in a setting where all the 
students need help ... makes the child feel safe and comfortable. We also have a push-in program called Resource Inclusion where specialized teachers come into the mainstream classroom to help students who may not have severe learning disabilities and therefore do not need the actual curriculum modified, but who may need someone to help them with concentrating, organizing their thoughts, and taking notes.

Support for this point can also be found in the literature review (Ahmmed \& Mullick, 2014; Takala et al., 2009) and in in the statements of the second school's teachers (Case B). For example, many challenges were described relating to class size; students' attention level and perception are negatively affected by larger class sizes (Ahmmed \& Mullick, 2014; Deng \& Holdsworth, 2007). Teaching LD students in small groups will best support them academically and in terms of social interaction.

Takala et al. (2009) asserted that the most effective way to teach LD students is one by one. However, this wasn't addressed by the schools' principals, teachers, or counselors. Whether or not a student should be taught one-on-one depends on their level of need; in some cases, it may be possible for them to achieve their academic goals in groups (Takala et al., 2009). Indeed, many specialists prefer to treat students with disabilities alone or in a small group such as in a resource room because they believe that special students learn better separately (Idol, 1993). This perspective was reflected in the second private school's practices; sometimes, they taught their students in small groups. Conversely, Ahmmed and Mullick (2014) argued that by offering smaller mainstream classrooms, schools could encourage academic progress while also resolving 
behavioral problems. Their recommendation of small mainstream classes was not followed by the second private school evaluated in this study.

Anti-bullying sessions. Anti-bullying sessions were offered by the second private school. CB (6) mentioned that anti-bullying sessions were supported by school administrators and teachers because they offered the opportunity to implant group work and distribute monthly peer teaching awards, end of the year behavior awards, and medals for sports activities. CB (7) stated that "Awards Day was provided to support positive behavior, which in turn helps student grades."

The school administrator didn't have a specific program or model for reducing bullying in school; however, fundamental activities were offered to reduce violence in the school environment. The participants from the second private school believed there was ample collaboration among teachers to increase positive behavior in inclusive classrooms, which Evans and Weiss (2014) believed was essential to success. The majority of the school's teachers and the principal stated that promoting pro-social behavior and decreasing behavioral problems were important for creating an inclusive environment and developing students' communication skills; this opinion is echoed by Bowman-Perrott et al. (2015). The principal, teachers, and counselors were not unfamiliar with ways of reducing students' bad behavior; they offered awards at the end of the year. Similarly, Dunlap et al. (2009) argued that teachers should be familiar with academic approaches that support students' rights and reduce negative behavior. 


\section{Summary of the Chapter}

In this chapter, I discussed the findings that emerged from my analysis of the survey responses provided by teachers, counselors, and principals at two private primary schools in Kuwait. Participants were queried on the procedures for and challenges to implementing inclusion with respect to special needs students. I employed two qualitative case studies to answer three research questions. My analysis emphasized the descriptions of the participants' experiences and their opinions related to the tenets of this study.

A cross-case analysis was adopted to compare two private schools' experiences with implementing an inclusion approach. Twenty open-ended surveys were received, and a total of nine key challenges to implementation were identified. Six were common

to both and three differed between the two. Also, six key mechanisms for implementing inclusion were located for each school. Four were common to both schools, and two were different. Finally, I discussed the practices and challenges specific to each school and compared their conclusions to the literature review. 


\section{CHAPTER V}

\section{SUMMARY, IMPLICATIONS, AND RECOMMENDATIONS}

\section{Introduction}

In this chapter, I present a summary of this study, discuss the implications of the inclusion approach in private primary schools in Kuwait and provide recommendations based on further research.

\section{Summary of the Study}

In Chapter I, I introduced the problems participants of this study found with the implementation of inclusion approach in their districts in Kuwait. According to Kuwaiti regulations in 2010 , both general schools and private schools must increase the quality of special education services to help and support students with special needs in their endeavor to successfully navigate their academic journeys (Almoosa et al., 2012; Weber \& City, 2012), and to successfully immerse students with special needs into society (Stainback \& Stainback, 1984; Weber \& City, 2012; Wong et al., 2015). Then, I established the purpose of this study by identifying the challenges of the implementation of inclusion approaches that private primary school administrators in Kuwait have encountered, (b) identifying how inclusion practices are implemented by administrators, teachers, and counselors in private Kuwaiti primary schools, and (c) identifying the differences in the implementation practices of inclusion between two private primary schools in Kuwait. Unfortunately, little is known about the challenges of implementing the inclusion approach in Kuwaiti schools because it is a practice limited to private 
schools, and more studies need to be done to better understand the problems. Accordingly, I intended to investigate the conditions in which the application of this approach has been developed in Kuwait in particular, to provide insights into challenges that schools face as well as study successful practices in the establishment of the inclusion approach in this country. Next, I established three research questions to be answered by this study, which were:

1. What are the challenges of implementing inclusion approaches that face private primary school administrators in Kuwait?

2. In what ways are inclusion practices implemented by administrators, teachers, and counselors in private schools in Kuwait?

3. What are the differences in the implementation practices of inclusion between two private schools in Kuwait?

I followed the democratic and social justice theory standard for education as a guide and surveyed and interviewed teachers who practice inclusion approach in Kuwait and analyzed the results, which reflect the inclusion principles and attempt to engage with and teach students with special needs fairly and respectfully in society (Wong et al., 2015).

In Chapter II, I presented my critique of the literature review on the inclusion of students with special needs: challenges and practices. I adopted a systematic literature review methodology for this research because my goal was to gain a holistic and deep understanding of the literature on the topic of my interest as the second part of this chapter. I found eight challenges, including (a) lack of knowledge, experience, and clear 
understanding; (b) no collaboration between regular and special education teachers; (c) absence of quality training; (d) a negative attitude and perception towards the inclusion; (e) a lack of resources, services, and the environment; (f) students are not ready to be introduced into inclusive classrooms; (g) academic barriers; (h) policy issues. In addition, four practices have been adopted by general schools to implement the inclusion. They are (a) social skills and collaboration; (b) teachers training; (c) task management; (d) setting suitable services, resources, environment. Based on the findings, more researchers should examine the practices of implementing inclusion.

In Chapter III, I explained my research methods including: the research design, context of the study, participant selection, data collection, and data analysis. The purpose of the study and research questions were restated. Also, the research approach, participants, data sources, instrumentation, data collection, and data analysis were provided. Finally, I concluded this chapter with a brief summary. According to the instrumentational section, I created a qualitative survey and follow-up interview to collect the data. All of the questions were open-ended, and the interviewers were given space to express their feelings based on the same survey questions. I obtained the necessary feedback from teachers, principals, and counselors concerning the inclusion approach in two private primary schools in Kuwait. Per campus, eight teachers, one principal, and one counselor were surveyed to provide a pool of diverse information. Interviews were conducted with two teachers at each of the two schools virtually (a total of four teachers). Also, I conducted follow-up interviews with the two principals in the 
same manner as the teachers. The total sample size for this study was 20 . Finally, I discussed the findings of this study in Chapter IV.

\section{Summary of Findings}

I discussed the findings that emerged from the analyzation of the perspectives of teachers, counselors, and principals in two private primary schools in Kuwait on the challenges of the implementation inclusion. I employed two qualitative case studies to answer the three research questions by emphasizing the interpretations of principals, teachers, and counselors' experiences and opinions that were related to the tenets of this study. Subsequently, I presented the similar challenges that face both school administrators. Next, I presented the differences between the challenges in both schools, starting with the first school as Case A and then with the second school as Case B to answer the first question of the research, which was: What are the challenges of implementing inclusion approaches that face private primary school administrators in Kuwait?

Nine challenges to the implementation of inclusion were identified by administrators in each school. I identified six similar challenges to the implementation of inclusion in both schools, and three which were different. The six similar challenges were:

1. Parental issues.

2. Academic barriers.

3. Lack of specialist teachers

4. Gaps in the communication. 


\section{Modification and accommodation matter.}

6. The financial issues.

\section{Parental Issues}

According to the majority of the participants' responses, parental and social issues were the most important challenges that should be identified. In fact, parents' initial and sometimes prolonged denial and rejection of the disabilities was a clear issue that was stated by all the participants in the survey. Moreover, there was a lack of collaboration between the school and the parents because the parents could not accept and come to terms with student's cases. In 2008, Dymond et al. asserted that collaboration among school members, teachers and parents is essential to managing and assisting students on their academic journey, especially when inclusion is considered. Unfortunately, according to the participants, there was a lack of collaboration between parents and both schools, and no clear path to resolving this issue, which came at a cost to the students. Moreover, there was a problem in the area of social rejection to the inclusion setting, which impacted the implementation of inclusion negatively. The parental rejection section of the survey was reflected by Afolabi (2014) who declared that without creating a positive parental attitude towards special academic services, it would be difficult to affect the implementation of inclusion positively. Also, a participant in the second school mentioned that family involvement was not effective because of the burden of rejection forced on students and their families by society. Certainly, inclusion approach could be implemented accurately by working and 
collaborating with school members and families (Afolabi, 2014; Bossaert et al., 2013; Calculator \& Black, 2009).

\section{Academic Barriers}

According to participants in both schools, academic barriers were declared as a massive challenge that could hinder the implementation of the inclusion approach. A lack of diagnosis and assessment was stated by several participants, which was replicated in 2015 by Ortiz and Fránquiz. The misdiagnoses of learning disabled students make the goals of teachers who do have positive a positive attitude towards the implementation of inclusion both inaccessible and unrealistic (Ortiz, \& Fránquiz, 2015; Rodríguez, 2016). Consequently, students require many crossover stages of measurement to be labeled as students with learning disabilities; however, this process can be successful if there is a purposeful program for the assessment and diagnosis of students with LD (Bay \& Lopez-Reyna, 1997). Unfortunately, there are no accurate standards by which to assess and diagnose students with LD in either one of the private schools and there are some cases which were labeled as students with LD who were not students with LD. The label issue is related to the diagnosis and the assessment of learning disabilities, which should be accurate and secure (Alansari, 2009). However, there is no precise assessment in place in either of the schools. Indeed, the assessment and the diagnosis in the both schools depend heavily on the IQ test and nothing else was utilized to diagnose students with LD.

Another point that should be considered under the academic issue is the curricula. The majority of the participants mentioned that the curriculum is academically 
out of reach for students with learning disabilities. Especially considering that the students with learning disabilities in both of the schools are ESL students, which makes the conditions doubly challenging. This point was a concern to Mohr (1995) who tried to solve this issue by asserting that teachers and school members should identify appropriate instructional accommodations for students with LD depending on their needs and abilities. For example, providing appropriate seating, time and practice, while keeping desks free from materials, and providing adequate space for movement are all improvements recommended to inclusive settings (Mohr, 1995). Another suggestion is a modification which "alters the work required in some way that makes it different from the work required of other students in the same class or activity" (Bryant et al., 1999, p. $1)$.

\section{Lack of Specialist Teachers}

The shortage of specialist teachers was replicated in the both schools' responses, which reflected the need for expert training for regular and special teachers to help them better understand the characteristics of students with learning disabilities and to teach them more effectively (Abu-Heran et al., 2014; Pinar \& Sucuoglu, 2013). This challenge was supported by the literature review in this study by asserting that general teachers should be trained accurately to handle the diversity present in inclusive schools (AbuHeran et al., 2014; Agbenyega \& Klibthong, 2014; Ajodhia-Andrews \& Frankel, 2010; Duchaine et al., 2011). The principal and a teacher in the first school observed that the immediate need for specialist teachers to practice accurate inclusion is vital; however, the schools cannot handle the cost without extra support. A lack of specialist teachers 
will certainly harm the implementation of the inclusion approach, but schools simply cannot afford them. Another scholar who agreed with Pasha (2012) who indicated that there is a lack of professional development for teachers and administrators, which was damaging for inclusive practices in Pakistan, and which reflected the same challenge in both cases and schools. Furthermore, two scholars supported this assertion and noted that the lack of specialist teachers could impact the implementation of inclusion negatively (O'Gorman \& Drudy, 2010; Vorapanya \& Dunlap, 2014).

According to Rodriguez (2016), it is beneficial to regard bilingual teacher preparation as a fundamental component in assisting and supporting ESL students, this is one of the most significant issues scrutinized in order to enhance the implementation in schools. Also, teachers' skills have a major impact on students' achievement (Wang \& Woolf, 2016). Consequently, it is essential to highlight bilingual special education teacher preparation in this study. The shortage of teacher preparation has become apparent not just because of the sustained issues, but also because of the number of English language learners in U.S., which have increased dramatically in recent years (Samson \& Collins, 2012; Wang \& Woolf, 2016).

\section{Gaps in Communication}

Many participants mentioned that the greatest challenge is sometimes finding ways to encourage mainstream students to accept students with learning disabilities. It is evident that the lack of communication between the students split between the different departments became an issue in the second school. Moreover, some of the students with LD were rejected in the first school by regular students when they attempted to 
participate in their activities, which was asserted in 2013 by Salvador. Moreover, Salvador (2013) emphasized that to have an effective inclusive environment in schools, schools should focus on two key components, which are communication and partnership to assure the operational activities in their classrooms. Unfortunately, these points were missed in both of the inclusive private schools in Kuwait.

\section{Modification and Accommodation Matter}

The majority of the students in both schools were ESL students, which proves that modification and accommodation matter in both private schools. All participants asserted that curricula must be modified to meet the needs of each learner with special needs. In fact, $95 \%$ of the students were ESL students in both schools; the books were too difficult to be used for students with LD, which reflected the same idea of Mohr (1995) who declared that students with disabilities are diverse and they need a variety of modifications to both their learning materials and lesson plans in order to be successful. Therefore, teachers should be willing to adapt and adjust teaching approaches and tactics to assist students with disabilities in their classrooms. Providing appropriate seating as well as adequate time and practice, while keeping desks free from materials, and providing enough space for movement are all improvements recommended to inclusive settings under the accommodation section (Bryant et al., 1999). Conclusively, providing commendations for individuals in American schools is required under the IDEA and Section 504. Schools must accommodate students with special needs who face learning barriers in their schools to practice their rights alongside other students (Yell, 2016). 


\section{The Financial Issues}

The financial component of properly implementing inclusion was very burdensome on both schools' budgets, as more teachers and other resources are needed; both school find it increasingly difficult to accommodate all students with learning disabilities without adequate funds from the government. The first schools' principal and a teacher of the second school asserted that the services provided by the inclusion approach are so expensive that students cannot utilize them without financial support from the government. Schools have done their best to offer financial assistance in some cases in order to provide the services of the inclusion approach, however, both schools continue to struggle with the high cost of implementing the inclusion approach." This point reflected Ahmmed and Mullick's (2014) point about the lack of commitment to support admission policy including the financial support. The financial load on school budget has become a serious challenge as more teachers and resources are needed, schools' administrations struggle to cover the cost required to build an inclusive environment. Wang and Reynolds (1997) asserted that the financial issue impacted the implementation of the inclusion approach negatively, which should be considered by scholars and policymakers (Alquraini \& Gut, 2012; Dallas et al., 2015; Wang \& Reynolds, 1997). Another financial problem which reflected the same financial challenge was mentioned by Wang and Reynolds (1997) if the school is not equipped to provide inclusion, the school will have an academic problem, which will hinder its success. 
Next, three themes were coded in each school to the differences in the challenges of implementing inclusion between two private schools. I present the different challenges of implementing the inclusion approach in the first school as Case A.

Following, I present the different challenges of implementing the inclusion approach in the first school as Case B.

\section{Case A}

Low expectations. A trend of low expectations for students with learning disabilities was stated by three of the participants of the first school, which decreased the likelihood of a successful model of the inclusion approach. This issue was declared in 2007 by Rubie-Davies, that students' performance is impacted negatively by teachers' practices when teachers foster low expectations for them. Furthermore, Demanet and Van Houtte (2012) explained that when teachers' expectations of some students are low, they spend less effort and time working with these students, reflecting a gap in students' achievement. Student isolation limits their participation and engagement and eventually leads to hindered learning opportunities. There is solid evidence of a robust relationship between aspiration and occupational outcomes. Meanwhile, teacher expectation is a critical factor in maintaining the achievement gap as well as reflecting teacher practices in classrooms. Fostering high expectations for success is one of the most important components in the process of motivating students to move toward their goals (Boykin \& Noguera, 2011). By shaping a new vision and creating an inclusive climate, schools will have the ability to enhance student performance, thus creating opportunities to learn and 
effectually closing the achievement gap (Boykin \& Noguera, 2011; Brown \& Medway, 2007).

The number of students with LD in the mainstream classroom. Two of the participants stated that the number of the students in a mainstream classroom is too large to be a suitable environment for students with LD. Another issue is that some students with learning disabilities were not identified as LD students and they are included in the mainstream classrooms a held to the standards of a normal curriculum despite their disabilities, which presents a challenge for both teachers and students in their classrooms. The principal of the first school attempted to change the number of students allowed in a mainstream classroom, however, the school budget was not able to provide the money needed to change the number of students in a classroom without the support of the Kuwaiti government. In 2009, Takala et al. discussed this point and recommended that providing small class sizes for students with LD could be the best way to focus on the differentiations between the students and assist them in the inclusive classrooms.

The concept of the small class size was supported in Finland schools which placed a great deal of importance on providing supportive atmospheres for students with special needs (Takala et al., 2009). Studies show that treating students in small groups and fostering collaboration is fundamental to providing accommodations which positively impact students' achievements (Bryant et al., 1999; Mohr, 1995). Many academic challenges occurred because of the class size disrupted the student's attention, and studies show that perceptions are affected negatively when they are placed in large classes (Ahmmed \& Mullick, 2014; Deng \& Holdsworth, 2007). 
The policy issue. The principal stated that the inclusion policy issue involves more than one governmental sector, which makes the process and the implementation of the inclusion approach complex. Moreover, the principal and a teacher mentioned that there is no clear policy concerning the inclusion approach for students with LD; members of school districts follow the standard policy for all students, which offers equality but not the equity. One of the participants mentioned that there is a lack of a specialized governmental system that manages education setting. This point was cited by several scholars such as inclusion (Ahmmed \& Mullick, 2014; Deng \& Holdsworth, 2007; Pasha, 2012; Vorapanya \& Dunlap, 2014). They emphasized that there is a lack of commitment and a lack of the inclusion to support admission policy, which has become a formidable challenge towards the implementation of the inclusion (Ahmmed \& Mullick, 2014; Deng \& Holdsworth, 2007; Pasha, 2012; Vorapanya \& Dunlap, 2014).

\section{Case B}

Time management. CB 3 and $\mathrm{CB} 5$ asserted that the curriculum is above the levels of students with LD and it does not allow enough time for weak students to grasp concepts, especially in a mainstream classroom that has more students than there should be. Many scholars confirmed this issue, and they recommended that school administrations offer task management courses to their teachers to manage their time and organize their classrooms effectively (Abu-Heran et al., 2014; Mikami et al., 2013; Sucuoglu et al., 2010; Takala et al., 2009). In 2014, Abu-Heran asserted that it is essential to use the correct classroom management methods to cultivate a suitable environment as well as adequate time, and resources for students with special needs in 
inclusive schools. Time management skills are essential for students who have struggled with their academic tasks, and it is important that teachers are able to practice time management skills as well (Takala et al., 2009). According to students' backgrounds, knowledge, and abilities, the school should manage their tasks including time management (Grant \& Ray, 2016; Mikami et al., 2013).

Disciplinary issues. Two participants indicated that there is no strong policy for discipline in the second school, which his detrimental to students and the school when it becomes necessary. They asserted that some students have been rightfully suspended, but the suspensions were lifted when parents expressed complaints. This issue has become a serious challenge toward implementing the inclusion approach. Yell (2016) emphasized that without creating positive climates, and protecting students from violent behaviors, the school will not be secure and it will violate the regulation of IDEA, and 504. Ensuring fairness and equity for students with special needs is the mission of school administrators and members. To ensure this, strives toward significant academic and behavior progress are required of schools by law, which makes schools follow IEP for each student carefully to protect their students (Yell, 2016).

The system issue. The issue is that no unified team can make a connection between the inclusion approach and LSU program, which impacts the inclusion approach negatively by segregating students with LD in the LSU program unnecessarily. Some of the participants have agreed to a full-time learning support program (LSU) program according to the students' needs, which teaches students with LD separately in a small group. A participant asserted that although the LSU program engages students 
with LD in some social activities, it is not true inclusion. Many scholars have agreed that the most efficient course of action is for inclusion approach to be implemented for all students, especially those who have LD. Some of them have even argued to have special classes for students with LD to handle their needs and differentiations.

For example, Fuchs and Fuchs (1994) mentioned that inclusion approach inspires teachers, leaders, and parents to work together to treat all students equally and distinguish their abilities. Undeniably, supporters of the inclusion approach believe that inclusion is the most effective means for teachers to involve students with disabilities in a school setting with effective teaching methods and services that would provide them with the knowledge necessary to be productive members of society (Fuchs \& Fuchs, 1994; Kelly et al., 2014; Wong et al., 2015). Arguably, opponents of inclusion declared "regular education could not address the needs of many students with mild disabilities without the instruction, support, and accommodations provided through special education" (Hagan-Burke \& Jefferson, 2002, p. 113). Likewise, the absence of suitable curriculum, tools, learning environments and qualified teachers are serious challenges to implementing inclusion (Zigmond et al., 2009).

Next, I present the similar four practices of implementing the inclusion approach in both school and the differences of the inclusion practices in the both school, which were two practices in each school to answer the third questions to answer the second and third research questions, which were: In what ways are inclusion practices implemented by administrators, teachers, and counselors in private schools in Kuwait? What are the 
differences in the implementation practices of inclusion between two private schools in Kuwait?

I found several themes that depicted the participants' perspectives towards the inclusion approach in their schools, which reflected the practices of implementing the inclusion approach in their school. Subsequently, I presented the four similar inclusion practices implemented by administrators, teachers, and counselors in both private schools in Kuwait. Next, I present the differences in the implementation practices of inclusion between the two private schools in Kuwait. I present the inclusion practices of the first school as Case A. Following, I present the inclusion practices of the second school as Case B to answer the second and the third research questions.

Similar Inclusion Practices Implemented by Administrators, Teachers, and the Counselor in Both Private Schools in Kuwait

According to the inclusion practices that were implemented by principals, teachers, and counselors, four of the practices were identified as similar in both private schools in Kuwait, which I coded into four different themes. Those themes are

1. Learning Style

2. Collaboration

3. Communication

4. Preparation

Learning style. All the participants in both schools stated that each student has had an IEP plan, and multi teaching methods were used for students with learning disabilities to enhance their academic levels. The majority of the teachers agreed that 
there was a differentiation between students' abilities, which required accurate curricula, exams, worksheets and further instructions. The multi-learning styles could be reached when teachers are afforded proper training to teach students according to their differentiations and learning styles. Consequently, teachers showed increasingly positive attitudes towards inclusion; when they were trained accurately (Alkhateeb et al., 2016; Calculator \& Black, 2009). Also, many teachers declared that it is important that the school focuses on the learning style for each child and the differentiation between students with learning disabilities. Courses were offered in the beginning in the year by schools to develop teachers' skills to use multiple methodologies for students with LD. Different techniques and strategies are used to accommodate each student's needs, depending on their learning style. In 1995, Mohr asserted that matching individual needs for each student is essential for students with LD when they are included in inclusive classrooms.

Collaboration. The majority of the participants in both schools emphasized that collaboration is a vital component of school practices. Principals have encouraged working as a team. Teachers and school members were encouraged to share their information and experiences with love and respect. Most of the participants asserted that collaboration between teachers, in the areas of physiotherapy, speech therapy, and occupational therapy is the most important task in their schools. O'Gorman and Drudy (2010) encouraged collaboration among school members and they asserted that the main goal of the school principal to encourage team work and implement inclusion in order to reach the school's academic goals. Conversely, it has been noted that the disconnection 
between general education and specialist teachers puts students in an unfortunate disadvantage (Gustavsen \& De Silva, 2013; O'Gorman \& Drudy, 2010).

Communication. Many of the participants asserted that schools' colleagues have engaged students with LD in several activates such as Sports Day, National day, and Mother Day, which reflected the idea of Boykin and Noguera (2011), that peer engagement an parental involvement is crucial to the success of the inclusion approach. Therefore, both schools have focused on social activities to build proper communication in their schools. In 2015, Nieto asserted that research reveals strong evidence that greater engagement leads to greater success. It is an essential concept to be grasped; however, it is recommended for schools to utilize efficient communication among students, teachers, and parents to develop students' academic skills (Valencia, 2015). Both schools have adjusted the schedules of students with learning disabilities so that their break times coincide with those of their non-learning disabled peers, in the same space, which allows them to be included and to communicate with regular students.

Preparation. All of the participants in both schools mentioned that professional development was offered to them at the beginning of the school year to prepare them to implement different strategies to assist their students precisely. Both school principals prepare their school in technology and strive to accommodate teachers with adequate resources that could assist students' learning. Furthermore, immediate short assessment and long assessment is available for all students with learning disabilities in both schools, which inclusive schools offer to enhance the classroom' atmospheres (AbuHeran et al., 2014). In the both schools, teachers were provided with the opportunity for 
professional development in differentiated instruction, access to educational technology and software in addition to workshops on the new curriculum.

Both schools' administrations have made special modifications to the curriculum and the exams for students with LD. All of these points were included in the schools' preparation. The technology was available for all students equitably, particularly for those with learning disabilities. Improving the quality of education in inclusive schools and having enough support, suitable environment, and access to necessary services such as technology was made mandatory to educate students with special needs with their peers properly (Abu-Heran et al., 2014; Dymond et al., 2008; Melekoglu, 2014), which reflected the both schools' preparation in terms to enhance students' academic levels.

Next, I identified the differences in the implementation practices of inclusion approach between the two private schools. I began with the first school, which was Case A, following the second school, which was Case B

\section{Case A}

The differences in the implementation practices of inclusion in the first school were two practices, which were:

1. Cooperative learning

2. Discipline management.

Cooperative learning. The majority of the participants in the first school mentioned that the teachers in their classrooms have practiced cooperative learning, which is an essential practice that helps and supports students in their academic endeavors (Qi \& Ha, 2012). It is recommended that using a cooperative learning strategy 
between students is essential to assess students with special needs in their classrooms (Calculator \& Black, 2009; Qi \& Ha, 2012; Reyes, 2013). For a better inclusive environment and diversified educational practices, the first school has created cooperative learning and collaboration to help students with LD in their academic journeys, which was asserted in 1998 by Scott et al.

Discipline management system. A discipline management system was practiced by the first private school in this study. The principal declared that the goal of the discipline management system is to protect both normal students and students with LD by following clear discipline system and guidelines, which have to be active in the school. The majority of the participants of the first school, mentioned that a highlydisciplined management system was followed in their schools to change and develop students' behaviors. In 2016, Yell mentioned that discipline is to protect both regular students and students with learning disabilities and according to the Texas discipline, schools must offer a positive climate and environment, develop clear, appropriate, and consistent expectations. Next, a school must locate disruptive student behaviors and ensure equity with making significant progress. Without creating positive climates, and protecting students from violent behavior, the school will not be a secure place, and it will violate the regulation of IDEA, and 504 (Yell, 2016). Also, ensuring fairness and equity for students with special needs is the mission of school' administrators and members (Yell, 2016). 


\section{Case B}

The differences in the implementation practices of inclusion in the second school was two practices, which were:

1. Teaching students with LD in small groups

2. Anti-bullying sessions.

Teaching students with LD in small groups. The majority of the participants in the second school declared that they taught students with LD in small groups, which impacted the students' performance positively. One of the participants stated that enhancing students with learning disabilities' educational levels and solving their behavior problems could be reachable by teaching the students in small groups such as teaching them in resource rooms. In 2014, Ahmmed and Mullick asserted that the role of the class size is essential to developing students' skills. It is recommended that practicing teaching methods with students with LD in small groups support the students in inclusive classrooms academically and interactively (Ahmmed \& Mullick, 2014; Takala et al., 2009). Although teaching students with LD is an essential part of the students' academic progress, teaching them one by one is more effective than teaching them in small groups (Takala et al., 2009). Ahmmed and Mullick asserted that by offering small size mainstream classrooms in schools, significant progress could be reached and behavior problems could be solved. It is evident that they recommended the small classroom size but were unable to fully implement the concept in the mainstream classes, which is evident in the second private school in this study. 
Anti-bullying sessions. Anti-bullying sessions were offered by the second school in this study. A teacher asserted that anti-bullying sessions were supported by the school administrator by implanting group work, peer teaching monthly awards for achievements, behavior end of the year awards, and medals enhancing sports activities. It seems that the school administrator has no specific program or model to be practiced to reduce the bullying in school' environment; however, she has offered fundamental activities to reduce this issue in the school environment. The majority of the participants stated that there was collaboration among teachers to increase positive behavior in the inclusive classroom, which was supported by (Evans \& Weiss, 2014). The majority of the schoolteachers and the principal firmly agree with Bowman-Perrott et al. (2015) that promoting pro-social behavior, and decreasing problem behavior are important for all students in classrooms to create an inclusive environment and develop students' communication. The principal, the teachers, and the counselor were not entirely familiar with approaches that could help to reduce students' bad behavior; however, they did their best by offering awards at the end of the year. This point was reflected by Dunlap et al. (2009) who asserted that teachers should be familiar with the academic approach to support the right of students' behaviors and reduced the negative behaviors.

\section{Implications}

According to the both schools, there was classroom disengagement, and difficulty in the area of peer interaction in the inclusive environments;

1. There is a need to develop more effective practices to face the lack of selfconfidence, classroom disengagement, and peers' interaction difficulties in 
inclusive classrooms. In my opinion, practices should be observed by school administrators, scholars and policymakers to effectively implement inclusion, which are having effective pre-service courses, in-service courses, adequate support, fit resources, special curriculum, a suitable environment and a project to develop teaching skills needs.

2. I found that one of the central challenge that faced school' administrators was the rejection of diagnoses by the parents, and a lack of parental involvement in the programs which should be considered by scholars and educators in both schools in Kuwait. Also, the administrators should find a way to involve the parents in the school activities.

3. Unfortunately, some teachers did not receive adequate support to educate the bilingual students with special needs in the both schools, therefore, assisting future teachers in creating culturally responsive classroom environments is important to cultivating learning. Also, future teachers should be ready to provide clear education intentions and values to students' families and create a collaborative environment between them. To accomplish these goals, future teachers need to understand how important their expectations for bilingual students with special needs are, as well as the significance of culturally responsive classrooms, and how the practice of these values will impact their performances and attitudes. Collaborative efforts will be fundamental for future teachers in order to complete their job efficiently. 
4. Offering quality information, quality expectations, and high cognitive efforts are essential to enhance students' performance in the inclusion settings in the both schools.

5. Future teachers need to be supported academically, socially, and emotionally to practice the inclusion approach and activities in their schools.

\section{Recommendations for Future Research}

After reviewing the findings, I recommended future research in the area of inclusion approach and better enforcement of the Kuwaiti law \# 8 that supports the inclusion approach in Kuwaiti schools., which is:

1. Future research should focus on filling the gap between the implementation of the inclusion approach and educational policy, which reflected the first school challenge in this study. Also, it was evident that teachers in both schools did not receive enough support to educate the students with special needs adequately. Consequently, studying this area could be valuable in implementing inclusion.

2. According to the findings, the majority of the participants in the second school (Case B) asserted that LSU, which is the segregated setting, is more appropriate than an inclusive setting for some students with LD because the difficulty of including students with LD in inclusive classrooms in their schools was a major hindrance to teachers who strived to provide adequate education for LD students in mainstream classroom setting, it is inferred that in these conditions, students need to be educated in separate special 
educational setting. This area need to be examined in the future research and experimental studies.

3. The lack of specialist teachers should be examined and solved by educators, administrators, scholars, and policymakers by providing future research on this area. Unfortunately, there are a few empirical studies that were focused on examining an effective program to enhance the teachers' knowledge and skills in order to implement the inclusion approach in their schools.

4. Future research may need to focus on filling the gap between the administrative policy and implementation of the inclusion approach, education policy and teachers' preparation program that offered by universities in order to meet the needs for inclusion and education policy.

5. More research is needed for assessment reform and instructional intervention in order to diagnose students who have problematic language issues or students who special education issues.

6. Although the findings of this study showed that improving the quality of education in the inclusive schools and having enough support, suitable environment, and necessary services is mandatory to educate students with special needs with their peers equitably, there is limited research that delves into how teachers, administrators, and researchers could accomplish these feats.

7. In my opinion, parents have important roles in the implementation of inclusion; having specific research on involving parents in the teaching 
process is valuable to the implementation of the inclusion approach in Kuwaiti schools.

8. According to the both schools' participants, no one mentioned the gifted students with LD in their schools. Gifted students have fewer opportunities than other students to interact with their peers in both schools. For this reason, more research is needed to consider gifted students as unique in the inclusion approach. Additionally, neither schools' participants mentioned students with LD and at risk emotional and behavior disorder. Unfortunately, limited research in Kuwait focused on students with at risk emotional and behavioral disorder (EBD), which should be considered.

9. Increasing awareness among teachers, administrators, parents and school members could prevent the challenges of implementing inclusion, however, it may help to study how increased awareness could benefit the implementation and practice of the inclusion approach.

10. Findings also provide direction for future research on the inclusion approach that encourages researchers to investigate and examine the inclusion at the university level, as well as the kindergarten level because there was a limitation of this study by focusing on the primary private schools in Kuwait.

11. Although I found a policy issue as a challenge that faced school administrators in the first private school in Kuwait and just a few articles were found in the literature that consider the policy of the inclusion approach, which need to be examined by researchers. I believe that following a clear 
policy, plan, and practice to implement inclusion approach is key to helping and supporting students with special needs in private and general schools. Therefore, having accurate research on the policy and practice could be helpful for implementing the inclusion approach.

\section{Recommendation for Practices}

1. Professional teaching preparation is a central recommendation to develop the concept and implementation of the inclusion approach. According to the majority of the participants in both schools, there was a dire lack of specialist teachers who possess the skills to teach students with LD accurately, which may impact negatively on teachers' attitudes toward the inclusion approach. Moreover, in the second school, the majority of the teachers prefer to treat students with disabilities in small groups because they believe that students who have special cases will learn more separately, however, more preparation is needed in order to teach students with LD according to their needs in small groups. This recommendation is more related to teachers' preparation, curriculum, assessment, strategies, and modification.

2. The intensive preparation should prepare and train all teachers together to encourage them to be as a collaborative team in inclusive schools in the both schools in Kuwait.

3. Using RTI Model for students' academic performances in both schools is an important recommendation to find an accurate assessment and intervention. 
4. Subsequently, I concur with Hammond, Campbell, and Ruble (2013) who stated that RTI is needed for helping and supporting students with disabilities in their outcomes and behaviors, and this is evident in both private schools in Kuwait. It has three fundamental points, which are universal screening that should be done three times a year, including a brief assessment of objective skills. Next, the three tiers of intervention should be used several strategies should be adopted to help students with their disabilities and the progress monitoring.

5. Using Positive Behavior Support (PBS) for students' behaviors and attitudes is a vital recommendation to be practiced in the both private schools in Kuwait. Both schools have offered activates to change students' behaviors, however, they didn't follow an accurate program to change students' behaviors and support positive behaviors. It is of great importance to develop disabled students' behaviors and help them reach a better social life.

6. According to the study findings, both schools need a special program or model to follow in order to have a solid system to change students' behavior positively. I believe that PBS is an affective model in private schools in Kuwait. There are various features of PBS as an intervention, which can change human behaviors and promote desired behaviors with fidelity. It seems that PBS will be one of the most effective models to be used in Kuwaiti schools. 
7. Policymakers should consider students' needs, without looking at their nationality. Financial support was not provided for non-Kuwaiti students in Kuwaiti schools, which impacts the implementation of the inclusion approach negatively.

8. Teachers should reflect their knowledge and multicultural theories into practice to create an inclusive and diverse environment.

9. Having high expectations for all students in both schools is fundamental to change students' performances. I believe that in both schools, if teachers cultivate a relationship with every learner by capturing students' hearts and inspiring them in their quest to conquer academic achievement, the parties will succeed. Teacher expectation is a critical factor in maintaining the achievement gap, reflecting teacher practices in classrooms. Fostering high expectations for success is one of the most important components in the process of motivating students to move toward their goals.

10. By shaping a new vision and creating an inclusive climate, schools will have the ability to enhance student performance, thus creating opportunities to learn and effectually closing the achievement gap. 


\section{REFERENCES}

Abu-Heran, N., Abukhayran, A., Domingo, J., \& Pérez-García, M. P. (2014).

Perceptions and expectations of Palestinian teachers towards inclusive education in Bethlehem district. Electronic Journal of Research in Educational Psychology, 12(2), 461-482.

Adera, B. A., \& Asimeng-Boahene, L. (2011). The perils and promises of inclusive education in Ghana. Journal of the International Association of Special Education, 12(1), 28-32.

Afolabi, O. E. (2014). Parents' involvement and psycho-educational development of learners with special educational needs (SENs): An empirical review. Romanian Journal of School Psychology, 14, 7-31.

Agbenyega, J. S., \& Klibthong, S. (2014). Assessing Thai early childhood teachers' knowledge of inclusive education. International Journal of Inclusive Education, 18(12), 1247-1261.

Ahmmed, M., \& Mullick, J. (2014). Implementing inclusive education in primary schools in Bangladesh: Recommended strategies. Educational Research for Policy \& Practice, 13(2), 167-180.

Ajodhia-Andrews, A., \& Frankel, E. (2010). Inclusive education in Guyana: A call for change. International Journal of Special Education, 25(1), 126-144. 
Al-Abdulghafoor, M. (1999). A survey study to know the teachers' and administrators' opinions and attitudes in public education towards the integration of exceptional children in ordinary primary schools. The Journal of Educational Research Centre-Qatar University, 1(15), 161-193.

Al-Hilawani, Y. A., Koch, K. R., \& Braaten, S. R. (2008). Enhancing services for students with mild disabilities in the Middle East Gulf Region: A Kuwait initiative. TEACHING Exceptional Children Plus, 4(5), n5.

Al-Manabri, M., Al-Sharhan, A., Elbeheri, G., Jasem, I. M., \& Everatt, J. (2013). Supporting teachers in inclusive practices: Collaboration between special and mainstream schools in Kuwait. Preventing School Failure: Alternative Education for Children and Youth, 57(3), 130-134.

Al-Shammari, Z. (2006). Special education teachers' attitudes toward autistic students in the autism school in the state of Kuwait: A case study. Journal of Instructional Psychology, 33(3), 170.

Alansari, A (2009). The effectiveness of a response to intervention model on developing word recognition skills for students with reading disabilities in the primary stage in State of Kuwait. Retrieved from http://gulfkids.com/pdf/Disability_KG_5.pdf

Aldaihani, M. (2011). A comparative study of inclusive education in Kuwait and England (Doctoral dissertation). Birmingham, UK: University of Birmingham.

Alfares, S. (2014, February 12). Altaleea open an education file in Kuwait (4), Alfares: interesting «education» disability seasonal and the use of experts and advisors global. Altaleea. Retrieved from http://altaleea.com/?p=4746 
Alkhateeb, J. M., Hadidi, M. S., \& Alkhateeb, A. J. (2016). Inclusion of children with developmental disabilities in Arab countries: A review of the research literature from 1990 to 2014. Research in Developmental Disabilities, 49, 60-75.

Almoosa, A. S., Storey, V., \& Keller, C. (2012). Meeting the needs of all: Why schools in Kuwait are failing to meet their moral obligation and what can be learned from the US education system. Journal of Alternative Perspectives in the Social Sciences, 3(4), 997-1018.

Almotairi, M. (2013). Investigating Kuwaiti teachers' and head teachers' attitudes towards inclusion (Doctoral dissertation). Birmingham, UK: University of Birmingham.

AlMoussawi, M., \& Omran, H. (2015, April 29). The weakness of the level of teachers threatens the future of Kuwait. Retrieved from http://ajialq8.com/?p=19201

Alquraini, T., \& Gut, D. (2012). Critical components of successful inclusion of students with severe disabilities: Literature review. International Journal of Special Education, 27(1), 42-59.

Amr, M. (2011). Teacher education for inclusive education in the Arab world: The case of Jordan. Prospects, 41(3), 399-413.

Angelides, P., \& Hajisoteriou, C. (2013). Implementation strategies of inclusive education in Cypriot classrooms. Journal of the International Association of Special Education, 14(1), 22-33.

Bay, M., \& Lopez-Reyna, N. (1997). Preparing future bilingual special educators: The lessons we've learned. Teacher Education and Special Education, 20(1), 1-10. 
Bossaert, G., Colpin, H., Pijl, S. J., \& Petry, K. (2013). Truly included? A literature study focusing on the social dimension of inclusion in education. International Journal of Inclusive Education, 17(1), 60-79.

Bower-Phipps, L., Homa, T. D., Albaladejo, C., Johnson, A. M., \& Cruz, M. C. (2013). Connecting with the "other" side of us: A cooperative inquiry by self-identified minorities in a teacher preparation program. Teacher Education Quarterly, 40(2), $29-51$.

Bowman-Perrott, L., Burke, M. D., Zaini, S., Zhang, N., \& Vannest, K. (2015).

Promoting positive behavior using the good behavior game: A meta-analysis of single-case research. Journal of Positive Behavior Interventions. doi:1098300715592355

Boykin, A. W., \& Noguera, P. (2011). Creating the opportunity to learn: Moving from research to practice to close the achievement gap. Alexandria, VA: ASCD.

Brown, K. E., \& Medway, F. J. (2007). School climate and teacher beliefs in a school effectively serving poor South Carolina (USA) African-American students: A case study. Teaching and Teacher Education, 23(4), 529-540.

Brownell, M. T. (2002). Special education teacher supply and teacher quality: The problems, the solutions. Focus on Exceptional Children, 35(2), 1-16.

Brownell, M. T., Hirsch, E., \& Seo, S. (2004). Meeting the demand for highly qualified special education teachers during severe shortages: What should policymakers consider? The Journal of Special Education, 38(1), 56-61. 
Brownell, M. T., Sindelar, P. T., Kiely, M. T., \& Danielson, L. C. (2010). Special education teacher quality and preparation: Exposing foundations, constructing a new model. Exceptional Children, 76(3), 357-377.

Bryant, R., Dean, M., Elrod, G. F., \& Blackbourn, J. M. (1999). Rural general education teachers' opinions of adaptations for inclusive classrooms: A renewed call for dual licensure. Rural Special Education Quarterly, 18(1), 5-11.

Calculator, S. N., \& Black, T. (2009). Validation of an inventory of best practices in the provision of augmentative and alternative communication services to students with severe disabilities in general education classrooms. American Journal of Speech-Language Pathology, 18(4), 329-342.

Carnine, D. (1992). Expanding the notion of teachers. Journal of Applied Behavior Analysis, 25(1), 13-19.

Chiner, E., \& Cardona, M. C. (2013). Inclusive education in Spain: How do skills, resources, and supports affect regular education teachers' perceptions of inclusion? International Journal of Inclusive Education, 17(5), 526-541.

Coates, J., \& Vickerman, P. (2008). Let the children have their say: Children with special educational needs and their experiences of physical education-A review. Support for Learning, 23(4), 168-175.

Cochran-Smith, M., \& Dudley-Marling, C. (2012). Diversity in teacher education and special education the issues that divide. Journal of Teacher Education, 63(4), 237-244. 
Crabtree, S. A., \& Williams, R. (2013). Ethical implications for research into inclusive education in Arab societies: Reflections on the politicization of the personalized research experience. International Social Work, 56(2), 148-161.

Dallas, B. K., Ramisch, J. L., \& McGowan, B. (2015). Students with autism spectrum disorder and the role of family in postsecondary settings: A systematic review of the literature. Journal of Postsecondary Education and Disability, 28(2), 135147.

Demanet, J., \& Van Houtte, M. (2012). Teachers' attitudes and students' opposition: School misconduct as a reaction to teachers' diminished effort and affect. Teaching and Teacher Education, 28(6), 860-869.

Deng, M., \& Holdsworth, J. C. (2007). From unconscious to conscious inclusion: Meeting special education needs in West China. Disability \& Society, 22(5), 507522.

Duchaine, E. L., Jolivette, K., \& Fredrick, L. D. (2011). The effect of teacher coaching with performance feedback on behavior-specific praise in inclusion classrooms. Education and Treatment of Children, 34(2), 209-227.

Dunlap, G., Sailor, W., Horner, R. H., \& Sugai, G. (2009). Overview and history of positive behavior support. In Handbook of positive behavior support (pp. 3-16). New York, NY: Springer.

Dymond, S. K., Renzaglia, A., \& Chun, E. J. (2008). Inclusive high school service learning programs: Methods for and barriers to including students with disabilities. Education and Training in Developmental Disabilities, 43(1), 20-36. 
Erlandson, D. A., Harris, E. L., Skipper, B. L., \& Allen, S. D. (1993). Doing naturalistic inquiry. Newbury Park, CA: Sage.

Erwin, E. J. (1993). The philosophy and status of inclusion. Envision: A Publication of The Lighthouse National Center for Vision and Child Development, 1, 3-4.

Evans, C., \& Weiss, S. L. (2014). Teachers working together: How to communicate, collaborate, and facilitate positive behavior in inclusive classrooms. Journal of the International Association of Special Education, 15(2), 142-146.

Fincher, R. M., \& Lewis, L. A. (1994). Learning, experience, and self-assessment of competence of third-year medical students in performing bedside procedures. Academic Medicine, 69(4), 291-295.

Freire, P. (2012). Pedagogy of the oppressed. New York, NY: Continuum.

Fuchs, D., \& Fuchs, S. (1994). Inclusive schools movement and the radicalization of special education. Exceptional Children, 60(4), 294-309.

GCC. (2010). Law No. 8 of 2010 concerning the rights of persons with disabilities in Kuwait. Retrieved from http://www.gcclegal.org/LawAsPDF .aspx? country $=1 \&$ LawID $=3763$

Grant, K. B., \& Ray, J. A. (2016). Home, school, and community collaboration: Culturally responsive family engagement (3rd ed.). Los Angeles, CA: Sage. 
Gray, J., \& Gray, J. (2008). The implementation of differentiated instruction for learning disabled students included in general education elementary classrooms (Doctoral dissertation). Available at http://gateway.proquest.com/openurl?url_ver=Z39.882004\&res_dat=xri:pqdiss\&rft_val_fmt=info:ofi/fmt:kev:mtx:dissertation\&rft_dat =xri:pqdiss:3351121

Guernsey, K., Nicoli, M., \& Ninio, A. (2007). Convention on the Rights of Persons with Disabilities: Its implementation and relevance for the World Bank. Retrieved from http://siteresources.worldbank.org/SOCIALPROTECTION/Resources/SPDiscussion-papers/Disability-DP/0712.pdf

Guo, Y., Sawyer, B. E., Justice, L. M., \& Kaderavek, J. N. (2013). Quality of the literacy environment in inclusive early childhood special education classrooms. Journal of Early Intervention, 35(1), 40-60.

Gustavsen, B., \& De Silva, H. M. (2013). Inclusion of rational models in an electromagnetic transients program: Y-parameters, Z-parameters, S-parameters, transfer functions. Power Delivery, IEEE Transactions on, 28(2), 1164-1174.

Hagan-Burke, S., \& Jefferson, G. L. (2002). Using data to promote academic benefit for included students with mild disabilities. Preventing School Failure: Alternative Education for Children and Youth, 46(3), 112-118.

Hammond, R. K., Campbell, J. M., \& Ruble, L. A. (2013). Considering identification and service provision for students with autism spectrum disorders within the context of response to intervention. Exceptionality, 21, 35-50. 
Hayes, S. D. (2016). Ucea professors' perceptions of principal preparation program challenges in developing candidates for the instructional leadership role (Doctoral dissertation). Texas A\&M University, College Station, TX.

Hays, D. G., \& Singh, A. (2011). Qualitative inquiry in clinical and educational settings. New York, NY: Guilford.

Helldin, R., Backman, O., Dwyer, H., Skarlind, A., Hugo, A. J., Nel, N., \& Muller, H. (2011). Opportunities for a democratic pedagogy: A comparative study of South African and Swedish teachers' attitudes to inclusive education. Journal of Research in Special Educational Needs, 11(2), 107-119.

Idol, L. (1993). Special educator's consultation handbook (2nd ed.). Austin, TX: PROED.

Idol, L. (1997). Creating collaborative and inclusive schools. Austin, TX: PRO-ED.

Jansen, H. (2010). The logic of qualitative survey research and its position in the field of social research methods. In Forum Qualitative Sozialforschung/Forum: Qualitative Social Research, 11(2).

Kauffman, J. M., Lloyd, J. W., Baker, J., \& Riedel, T. M. (1995). Inclusion of all students with emotional or behavioral disorders? Let's think again. Phi Delta Kappan, 76(7), 542-546.

Kauffman, J. M., McGee, K., \& Brigham, M. (2009). Enabling or disabling? Observations on changes in special education. Kaleidoscope: Contemporary and Classic Readings in Education, 328. 
Kearney, K. (1996). Highly gifted children in full inclusion classroom. Highly Gifted Children, 12(4), 1-5.

Kelly, A., Devitt, C., O'Keeffe, D., \& Donovan, A. M. (2014). Challenges in implementing inclusive education in Ireland: Principal's views of the reasons students aged $12+$ are seeking enrollment to special schools. Journal of Policy and Practice in Intellectual Disabilities, 11(1), 68-81.

Kurniawati, F., De Boer, A. A., Minnaert, A. E. M. G., \& Mangunsong, F. (2014). Characteristics of primary teacher training programmers on inclusion: A literature focus. Educational Research, 56(3), 310-326.

Kysilko, D. (1992). Winners all: A call for inclusive schools. The Report of the NASBE Study Group on Special Education. Alexandria, VA: NASBE.

Lambe, J. (2011). Pre-service education and attitudes towards inclusion: The role of the teacher educator within a permeated teaching model. International Journal of Inclusive Education, 15(9), 975-999.

Lambe, J., \& Bones, R. (2006). Student teachers' perceptions about inclusive classroom teaching in Northern Ireland prior to teaching practice experience. European Journal of Special Needs Education, 21(2), 167-186.

Lembke, E. S., Hampton, D., \& Beyers, S. J. (2012). Response to intervention in mathematics: Critical elements. Psychology in the Schools, 49(3), 257-272.

Lunenburg, F. C., \& Irby, B. J. (2008). Writing a successful thesis or dissertation: Tips and strategies for students in the social and behavioral sciences. Thousand Oaks, CA: Corwin Press. 
Mackay, K. (Spring 2001). What's the difference-slow learner or learning disabled? Retrieved from http://www.speld-sa.org.au/about-us/history .$h t m l$ task $=$ view\&id $=80$

Malak, S. (2013). Inclusive education reform in Bangladesh: Pre-service teachers' responses to include students with special educational needs in regular classrooms. International Journal of Instruction, 6(1), 195-214.

Melekoglu, M. A. (2014). Characteristics of inclusive classrooms in Turkey. Journal of the International Association of Special Education, 15(2), 24-30.

Merriam, S. B. (1988). Case study research in education: A qualitative approach. San Francisco, CA: Jossey-Bass.

Mikami, A. Y., Griggs, M. S., Lerner, M. D., Emeh, C. C., Reuland, M. M., Jack, A., \& Anthony, M. R. (2013). A randomized trial of a classroom intervention to increase peers' social inclusion of children with attention-deficit/hyperactivity disorder. Journal of Consulting and Clinical Psychology, 81(1), 100.

Miller, L. (1990). The regular education initiative and school reform lessons from the mainstream. Remedial and Special Education, 11(3), 17-22.

Ministry of Education in the State of Kuwait. (2008). The national report: Development of education in Kuwait. Retrieved from http://www.ibe.unesco.org /National_Reports/ICE_2008/kuwait_N R08.pdf

Mohr, L. L. (1995). Teaching diverse learners in inclusive settings: Steps for adapting instruction. Paper presented at the Council for Expectation Children Annual Convention, Indianapolis, Indiana. 
Monsen, J. J., Ewing, D. L., \& Kwoka, M. (2014). Teachers' attitudes towards inclusion, perceived adequacy of support and classroom learning environment. Learning Environments Research, 17(1), 113-126.

More, C. M., Spies, T. G., Morgan, J. J., \& Baker, J. N. (2015). Incorporating English language learner instruction within special education teacher preparation. Intervention in School and Clinic, 51(4), 229-237. doi:10.1177 $/ 1053451215589183$

Morningstar, M. E., Shogren, K. A., Lee, H., \& Born, K. (2015). Preliminary lessons about supporting participation and learning in inclusive classrooms. Research and Practice for Persons with Severe Disabilities, 40(3), 192-210.

Mostert, M. P. (1991). The regular education initiative: Strategy for denial of handicap and the perception of difference. Disability, Handicap \& Society, 6(2), 91-101.

Mukhopadhyay, S. (2013). Inclusive education for learners with special educational needs in Botswana: Voices of special educators. Journal of the International Association of Special Education, 14(1), 41-49.

Nel, M., Engelbrecht, P., Nel, N., \& Tlale, D. (2014). South African teachers' views of collaboration within an inclusive education system. International Journal of Inclusive Education, 18(9), 903-917.

NICHCY. (2016). Supports, modifications, and accommodations for students. Retrieved from http:/www.parentcenterhub.org/repository/accommodations/

Nieto, S. (2015). The light in their eyes: Creating multicultural learning communities. New York, NY: Teachers College Press. 
Ntuli, E., \& Traore, M. (2013). A study of Ghanaian early childhood teachers' perceptions about inclusive education. Journal of the International Association of Special Education, 14(1), 50-57.

Ochoa, A. M., Brandon, R., Cadiero-Kaplan, K., \& Ramírez, P. C. (2014). Bridging bilingual and special education: Opportunities for transformative change in teacher preparation programs. Association of Mexican American Educators Journal, 8(1).

Ogelman, H. G., \& Seçer, Z. (2012). The effect inclusive education practice during preschool has on the peer relations and social skills of 5-6-year olds with typical development. International Journal of Special Education, 27(3), 169-175.

O'Gorman, E., \& Drudy, S. (2010). Addressing the professional development needs of teachers working in the area of special education/inclusion in mainstream schools in Ireland. Journal of Research in Special Educational Needs, 10(1), 157-167.

Orakcı, Ş., Aktan, O., Toraman, Ç., \& Çevik, H. (2016). The influence of gender and special education training on attitudes towards inclusion. International Journal of Instruction, 9(2).

O'Rourke, J., \& West, J. (2015). Education assistant support in inclusive western Australian classrooms: Trialing a screening tool in an Australian context. International Journal of Disability, Development \& Education, 62(5), 531-546.

Ortiz, A. A., \& Fránquiz, M. E. (2015). Coeditors' introduction: Culturally responsive practices in the preparation of teachers who serve emergent bilinguals. Bilingual Research Journal, 38(1), 1-5. 
Pasha, S. (2012). Readiness of urban primary schools for inclusive education in Pakistan. Journal of Research \& Reflections in Education, 6(2), 113-128.

Peebles, J., \& Mendaglio, S. (2014). Preparing teachers for inclusive classrooms: Introducing the individual direct experience approach. Inclusive Education: Socially Just Perspectives and Practices, 245.

Pinar, E. S., \& Sucuoglu, B. (2013). The outcomes of a social skills teaching program for inclusive classroom teachers. Educational Science: Theory \& Practices, 13, $2247-2261$.

Qi, J., \& Ha, A. S. (2012). Inclusion in physical education: A review of literature. International Journal of Disability, Development and Education, 59(3), 257-281.

Reganick, K. (1995). Social and academic issues of inclusive education. Retrieved from http://files.eric.ed.gov/fulltext/ED392176.pdf

Reid, R., Lienemann, T. O., \& Hagaman, J. L. (2013). Strategy instruction for students with learning disabilities. New York, NY: Guilford.

Reyes, C. M. H. (2013). The sociocultural factors that influenced the success of nontraditional, Latina, pre-service teachers in a required online instructional media and technology course (Doctoral dissertation). Kansas State University.

Ringer, L., \& Kerr, S. (1988). Integration-the legal imperative. Minnesota UAP Impact, 1(2), 2. 
Rodríguez, D. (2016). Bilingual special education: Investigating and implementing evidence-based practices in schools. Journal of Multilingual Education Research, 6(1), 2.

Rose, R., Shevlin, M., Winter, E., \& O’Raw, P. (2010). Special and inclusive education in the Republic of Ireland: Reviewing the literature from 2000 to 2009. European Journal of Special Needs Education, 25(4), 359-373.

Rosemary, K. C., \& Elsa, F. (2011). Trekking back to mainstream for inclusive education. Problems of Education in the 21st Century, 33, 29-40.

Rubie-Davies, C. M. (2007). Classroom interactions: Exploring the practices of high and low expectation teachers. British Journal of Educational Psychology, 77(2), 289306.

Sabbagh, H. (2010, November 17). Qualifying 300 specialists for integrating disabled students successfully. Retrieved from http://www.alayam.com/alayam /first/430984/News.html

Salvador, K. (2013). Inclusion of people with special needs in choral settings: A review of applicable research and professional literature. Update: Applications of Research in Music Education, 31(2), 37-44.

Samson, J. F., \& Collins, B. A. (2012). Preparing all teachers to meet the needs of English language learners: Applying research to policy and practice for teacher effectiveness. Washington, DC: Center for American Progress. 
Scorgie, K. (2015). Ambiguous belonging and the challenge of inclusion: Parent perspectives on school membership. Emotional and Behavioural Difficulties, 20(1), 35-50.

Scott, B. J., Vitale, M. R., \& Masten, W. G. (1998). Implementing instructional adaptations for students with disabilities in inclusive classrooms: A literature review. Remedial and Special Education, 19(2), 106-119.

Shields, C. (2013). Theorizing democratic and social justice education. In B. J. Irby, G. Brown, R. Lara-Alecio, \& S. Jackson (Eds.), The handbook of educational theories (pp. 1035-1046). Charlotte, NC: Information Age.

Simmons, P. E., Emory, A., Carter, T., Coker, T., Finnegan, B., Crockett, D., \& Labuda, K. (1999). Beginning teachers: Beliefs and classroom actions. Journal of Research in Science Teaching, 36(8), 930-954.

Singal, N. (2008). Working towards inclusion: Reflections from the classroom. Teaching and Teacher Education, 24(6), 1516-1529.

Smith, D. H. (2013). Deaf adults: Retrospective narratives of school experiences and teacher expectations. Disability and Society, 28(5), 674-686.

Spall, S. (1998). Peer debriefing in qualitative research: Emerging operational models. Qualitative Inquiry, 4(2), 280-292.

Spivey, B. L. (2006). Down syndrome. Retrieved from http://www.superduperinc.com /handouts/pdf/116_Down_Syndrome.pdf

Stainback, W. C., \& Stainback, S. B. (1984). A rationale for the merger of special and regular education. Exceptional Children, 51(1), 102-111. 
Stanton-Chapman, T. L., \& Brown, T. S. (2015). A strategy to increase the social interactions of 3-year-old children with disabilities in an inclusive classroom. Topics in Early Childhood Special Education, 35(1), 4-14.

Sucuoglu, B., Akalin, S., \& Sazak-Pinar, E. (2010). The effects of classroom management on the behaviors of students with disabilities in inclusive classrooms in Turkey. Journal of the International Association of Special Education, 11(1), 64-74.

Sucuoglu, N. B., Akalin, S., \& Pinar, E. S. (2014). Instructional variables of inclusive elementary classrooms in Turkey. International Journal of Special Education, $29(3), 40-57$.

Sukbunpant, S., Arthur-Kelly, M., \& Dempsey, I. (2013). Thai preschool teachers' views about inclusive education for young children with disabilities. International Journal of Inclusive Education, 17(10), 1106-1118.

Takala, M., Pirttimaa, R., \& Törmänen, M. (2009). Inclusive special education: The role of special education teachers in Finland. British Journal of Special Education, 36(3), 162-173.

Thaver, T., \& Lim, L. (2014). Attitudes of pre-service mainstream teachers in Singapore towards people with disabilities and inclusive education. International Journal of Inclusive Education, 18(10), 1038-1052.

Tremblay, P. (2013). Comparative outcomes of two instructional models for students with learning disabilities: Inclusion with co-teaching and solo-taught special education. Journal of Research in Special Educational Needs, 13(4), 251-258. 
Unianu, E. M. (2012). Attitudes towards inclusive education-A qualitative metaanalysis of recent studies. Scientific Research \& Education in the Air ForceAFASES, 1.

Valencia, R. R. (2015). Students of color and the achievement gap: Systemic challenges, systemic transformations. New York, NY: Routledge.

Vlachou, A., Didaskalou, E., \& Kontofryou, M. (2015). Roles, duties and challenges of special/support teachers at secondary education: Implications for promoting inclusive practices. European Journal of Special Needs Education, 30(4), 551564.

Vorapanya, S., \& Dunlap, D. (2014). Inclusive education in Thailand: Practices and challenges. International Journal of Inclusive Education, 18(10), 1014-1028.

Wang, M. C., \& Reynolds, M. C. (1997). Progressive inclusion: Meeting new challenges in special education. Retrieved from http://files.eric.ed.gov/fulltext/ED420134 .pdf

Wang, P., \& Woolf, S. B. (2016). Trends and issues in bilingual special education teacher preparation: A literature review. Journal of Multilingual Education Research, 6(1), 4 .

Weber, A. S., \& City, E. (2012). Inclusive education in the Gulf cooperation council. Journal of Educational and Instructional Studies in the World, 2(2), 8597.

Will, M. C. (1986). Educating children with learning problems: A shared responsibility. Exceptional Children, 52(5), 411-415. 
Wong, M. E., Poon, K. K., Kaur, S., \& Ng, Z. J. (2015). Parental perspectives and challenges in inclusive education in Singapore. Asia Pacific Journal of Education, 35(1), 85-97.

Yell, M. L. (2016). The law and special education. New York, NY: Teachers College Press.

Zigmond, N., Kloo, A., \& Volonino, V. (2009). What, where, and how? Special education in the climate of full inclusion. Exceptionality, 17(4), 189-204. 
APPENDIX A

SURVEY PROTOCOL

\section{TEXAS A\&M UNIVERSITY HUMAN SUBJECTS PROTECTION PROGRAM SURVEY PROTOCOL}

\section{Survey Protocol on Inclusion Introduction, Explanation}

Hello, my name is Ali Alansari and I am a doctoral student at Texas A\&M University, College Station, Texas, USA. I am conducting a study under the supervision of Dr. Beverly Irby, Professor at Texas A\&M University. The intent of the project is to identify challenges of the implementation of inclusion approaches that face private primary school Administrators in Kuwait ‘(b) to identify how inclusion practices are implemented by administrators, teachers, and counselors in private Kuwaiti primary schools rand (c) to identify the differences in the implementation practices of inclusion between two private primary schools in Kuwait. This project will help to provide insights into challenges that school face as well as successful practices in the establishment of the inclusion approach in this country and have deep understanding of the conditions in which implementation has been developing will be helpful to administrators and teachers to establishing better strategies to include students with disabilities in their schools. I am interested in your opinions, in other words, what you think about each topic related to inclusion of students with learning disabilities in your classroom. Everything you say in this survey will be kept private, and no names will be used in the report. It is important to us that you give us your honest opinion. The results 
of the survey will be used for a researcher to review and summarize your thoughts in a report. The results will be kept confidential.

The survey is to be completed during the school day during your break time for about an hour, or you can answer the questions at home within two days. Please write clearly and share your opinions. There are no right or wrong answers.

If you are willing to have a follow up interview for clarifying your answers, please check the item that indicates your agreement. I will then be in touch with you for the follow up interview.

\section{The Questions of the Qualitative Survey Background questions}

1. Please provide some information about yourself-for example, experience, certificate, and interest?

\section{Experience questions}

1. How many years have you worked with students with learning disabilities?

2. What the best experience that you have as a teacher or a principal or a counselor who work with students with learning disabilities?

3. What was the negative experience that you met as a teacher or a principal or a counselor who work with these students?

\section{Expectations questions}

1. What immediate consequences were you expecting from having inclusion students?

2. Do you consider that an inclusive school helps students to develop their skills, knowledge, and abilities and why? 
3. Do you consider that the inclusive school contributes to students' academic success and why?

\section{Opinion questions that related to the inclusive approach}

1. What are the challenges of implementing inclusion approaches in your school?

2. What are the practices of implementing inclusion inside the classrooms?

3. What are the practices of implementing inclusion out-door the classrooms?

4. What practices would you like to define, to say that the inclusion was effective or not? If yes, what would you say was the impact?

5. Do you consider the inclusive school has enough resource to enhance students with learning disabilities' levels? Provide one example please.

6. Do you consider that your school has good curricula to enhance students' performance and why?

7. How has the inclusive school affected of the students' grades and behavior maintained over time?

8. Do you think there is an inclusive environment in your school and why?

9. What kind of activities does your school offer to students with learning disabilities? And do you think, the activities are enough to students?

10. What strategies do school members use to treat their students equitably?

11. How do school officials assess students with learning disabilities?

12. What can the principal do to encourage collaboration between teachers and workers? 
13. What kind of courses that is provided to teachers or school workers to be prepared for inclusion approach?

14. Is there anything I did not ask that should have been asked?

15. Check yes if you are willing to be contacted for a follow up interview. Yes No Thank you for sharing your thoughts with us today. If you are willing to participate in the follow up interview please write:

Your name:

Email:

IRB NUMBER: IRB2017-0090D IRB APPROVAL DATE: 03/03/2017 IRB

EXPIRATION DATE: 03/01/2018

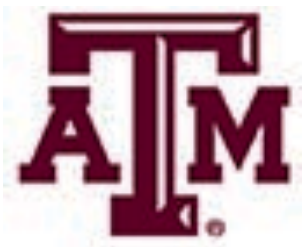




\section{APPENDIX B}

\section{THE INFORMATION SHEET}

\section{Project Title: INCLUSION OF STUDENTS WITH SPECIAL NEEDS IN PRIVATE}

SCHOOLS IN KUWAIT: CHALLENGES THAT FACE SCHOOL

\section{ADMINISTRATORS}

I am Ali Alansari, a PhD. Student in the Education Administration and Human Resource Department at Texas A\&M University. I am conducting under the supervision of Dr. Beverly Irby this study. I am inviting you to participate in our study. The purpose of this case study is (a) to identify challenges of the implementation of inclusion approaches that face private primary school Administrators in Kuwait ‘(b) to identify how inclusion practices are implemented in private Kuwaiti primary schools and (c) to identify the differences in the implementation practices of inclusion between two private primary schools in Kuwait. The information in this form is provided to help you decide whether or not to take part. If you decide you do not want to participate, there will be no penalty to you, and you will not lose any benefits you normally would have. Also, you are being asked to be in this study because you are a teacher or a principal or a counselor who work with students with learning disabilities in an inclusive private school in Kuwait. Your participation is completely voluntary. You may withdraw from this study at anytime without penalty. 


\section{How Many People Will Be Asked To Be In This Study?}

The overall participants will reach 20 in two of private schools in Kuwait that have students with learning disabilities included in the classroom with their normal peers in fourth grade.

\section{What Are the Alternatives to being in this study?}

The only alternative to being in the study is not to participate.

\section{What Will I Be Asked To Do In This Study?}

I would like to invite you to participate in Questions for the qualitative survey that will be given to the participants in Qualtric who agree to be a part of the study and will be completed within two days. The survey will be used to gather your opinions and perceptions of the implementation of inclusion. The survey should take about 45 minutes to an hour complete, however, you can take it at home and write your answer within 2 days. (2) Interviews where a researcher will ask you questions about what are the challenges of implementing inclusion approaches that face private primary school administrators in Kuwait and In what ways are inclusion practices implemented in private schools in Kuwait via the Go-to-meeting interview. Both programs are owned by a College of Education and Human Development account under the Center for Research and Develop in Dual Language and Literacy Acquisition. And both programs are secure for the participants.

The interview will be conducted through a secured platform, Go-to-Meeting, which is owned by a College of Education and Human Development account under the Center for Research and Development in Dual Language and Literacy Acquisition (The 
researchers for this project have a personal Go-to-Meeting account with usernames and passwords); there will be two sessions of Go-to-Meeting. One to access consent and record that consent, and the second one for the interviews which will be recorded by the Go-to-Meeting account holder in the system and will be transcribed, then the recording will be deleted and no names will be attached to the transcriptions.). All information obtained in this study will be kept strictly confidential. Information about you will be kept confidential to the extent permitted or required by law. People who have access to your information include the Principal Investigator and research study personnel.

Representatives of regulatory agencies such as the Office of Human Research Protection (OHRP) and entities such as the Texas A\&M University Human Research Protection Program may access your records to make sure the study is being run correctly and that information is collected properly. There will be no hard copy information for this study; only recorded consent forms, recorded interviews (the recorded interviews will be deleted once transcripts are completed), and the electronic copies of the transcripts. Only the Principal Investigator (Beverly Irby) and the Researcher (Ali Alansari) will have an access to the data. The recorded consents and transcribed electronic documents will be secured by password. The results of this study will be reported as a group, and no individual participants will be identified.

\section{Are There Any Risks To Me?}

The things that you will be doing are no greater than risks than you would come across in everyday life. There is the chance that expressing your opinions will put you in social discomfort. But you do not have to answer any questions you do not want to. Also, the 
answers you provide will be kept confidential. Any reports or publications based on this research will use only group data and will not identify you or any individual as being affiliated with this project.

\section{What if I Change My Mind About Participating?}

This research is voluntary and you have the choice whether or not to be in this research study. You may decide to not begin or to stop participating at any time. If you choose not to be in this study or to stop being in the study, there will be no effect on your student status, course grade, medical care, employment, evaluation, and/or relationship with your school.

\section{Are There Any Benefits To Me?}

The direct benefit to you by being in this study is that you had the opportunity to hear and learn about challenges of the implementation of inclusion approaches that face private primary school Administrators in Kuwait, practices that are used to implement inclusion in private Kuwaiti primary schools.

\section{Will There Be Any Costs To Me?}

Aside from your time, there are no costs for taking part in the study.

\section{Will I Be Paid To Be In This Study?}

You will not be paid for being in this study.

\section{Will Information From This Study Be Kept Private?}

The records of this study will be kept private. The researchers will provide a formal report and will make a presentation of the aggregate results of the research to the School administrators. However, no identifiers linking you to this study will be included in any 
sort of report that might be published. Research records will be stored securely and only approved research study personnel will have access to the records.

\section{Who may I Contact for More Information?}

You may contact Dr. Beverly J. Irby, to tell her about a concern or complaint about this research +9368705536 or beverly.irby@tamu.edu and contact me “Ali Alansari” if you are willing to take a part of this research or in you want to ask questions for qualification +19797391266 or ali_alansari@tamu.edu. For questions about your rights as a research participant; or if you have questions, complaints, or concerns about the research, you may call the Texas A\&M University Human Subjects Protection Program office at (+979) 458-4067 or irb@tamu.edu.

By completing the survey(s), you are giving permission for the investigator to use your information for research purposes.

You are not giving up any legal rights by consenting to be in this study. Please make sure all your questions have been answered. Any new information about this research study will be provided to you as it becomes available. Completion and return of the data collection instruments implies that you have read the information in this form and consent to take part in the research. Please keep this form for your records or future reference

Thank you. Dr. Beverly J. Irby IRB NUMBER: IRB2017-0090D IRB APPROVAL DATE: 03/03/2017 IRB EXPIRATION DATE: 03/01/2018

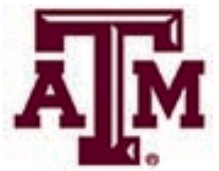

